US Army Corps

of Engineers ${ }_{\circledast}$

Engineer Research and

Development Center

\title{
Determination of Residual Low-Order Detonation Particle Characteristics from IMX-104 Mortar Rounds
}

Matthew F. Bigl, Samuel A. Beal, and Charles A. Ramsey

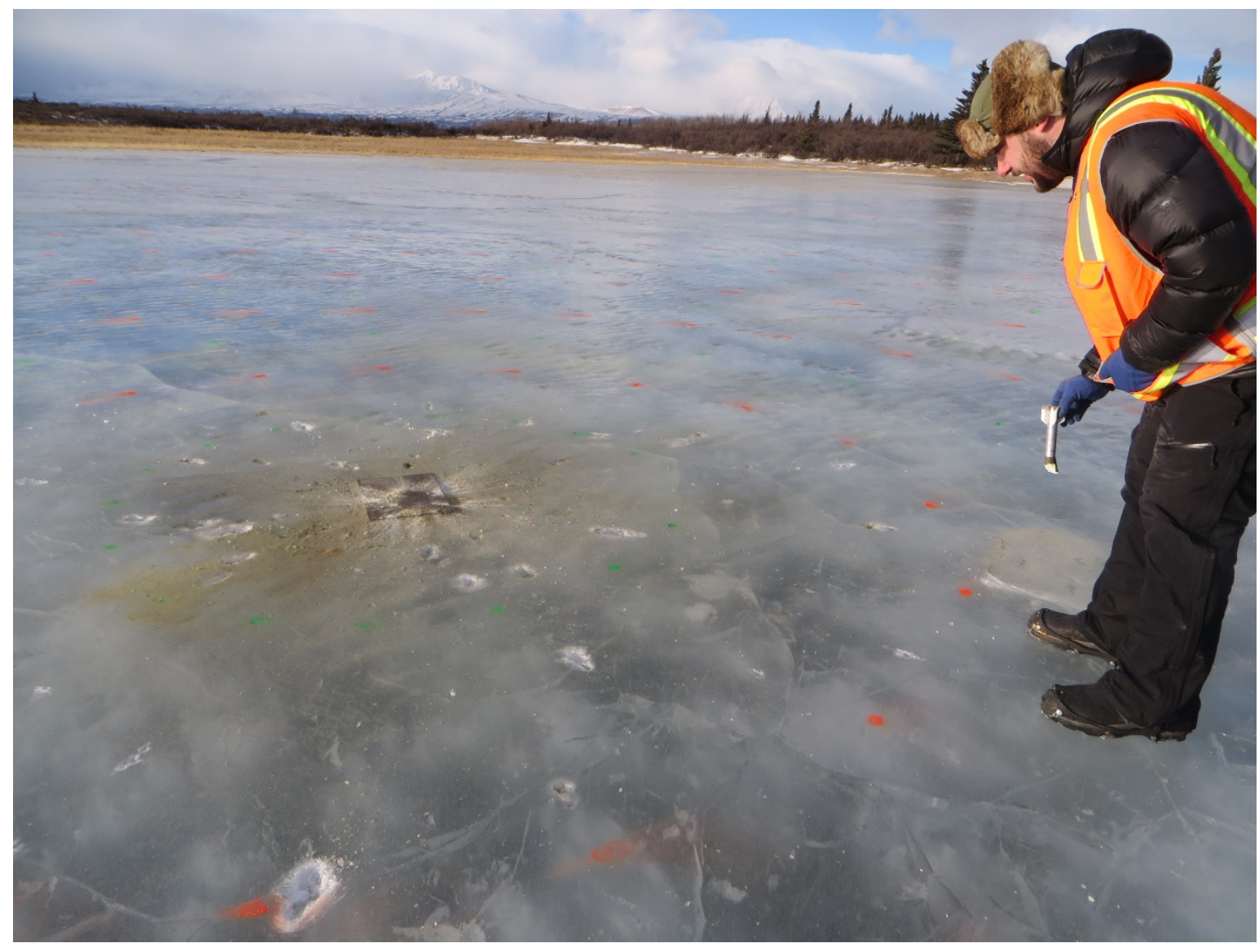


The U.S. Army Engineer Research and Development Center (ERDC) solves the nation's toughest engineering and environmental challenges. ERDC develops innovative solutions in civil and military engineering, geospatial sciences, water resources, and environmental sciences for the Army, the Department of Defense, civilian agencies, and our nation's public good. Find out more at www.erdc.usace.army.mil.

To search for other technical reports published by ERDC, visit the ERDC online library at https://erdclibrary.on.worldcat.org/discovery. 


\section{Determination of Residual Low-Order Detonation Particle Characteristics from IMX-104 Mortar Rounds}

Matthew F. Bigl and Samuel A. Beal

U.S. Army Engineer Research and Development Center (ERDC)

Cold Regions Research and Engineering Laboratory (CRREL)

72 Lyme Road

Hanover, NH 03755-1290

Charles A. Ramsey

Envirostat, Inc.

PO Box 339

Vail, AZ 85641

Final Report

Approved for public release; distribution is unlimited.

Prepared for Strategic Environmental Research and Development Program

Environmental Security Technology Certification Program

Environmental Restoration Program Area

4800 Mark Center Drive, Suite 17D08

Alexandria, VA 22350-3605

Under Environmental Restoration Program project number ER18-5105, "Determination of Residual Low-Order Detonation Particle Characteristics," through MIPRs W74RDV80715663, W74RDV80715688, W74RDV90156248, and W74RDV90497295 


\section{Abstract}

The environmental fate and transport of energetic compounds on military training ranges are largely controlled by the particle characteristics of loworder detonations. This study demonstrated a method of command detonation, field sampling, laboratory processing, and analysis techniques for characterizing low-order detonation particles from $60 \mathrm{~mm}$ and $81 \mathrm{~mm}$ mortar rounds containing the insensitive munition formulation IMX-104. Particles deposited from three rounds of each caliber were comprehensively sampled and characterized for particle size, energetic purity, and morphology. The $60 \mathrm{~mm}$ rounds were command-detonated low order consistently (seven low-order detonations of seven tested rounds), with consumption efficiencies of $62 \%-80 \%(n=3)$. The $81 \mathrm{~mm}$ rounds detonated low order inconsistently (three low-order detonations of ten tested rounds), possibly because the rounds were sourced from manufacturing test runs. These rounds had lower consumption efficiencies of $39 \%-64 \%$ $(n=3)$. Particle-size distributions showed significant variability between munition calibers, between rounds of the same caliber, and with distance from the detonation point. The study reviewed command-detonation configurations, particle transfer losses during sampling and particle-size analysis, and variations in the energetic purity of recovered particles. Overall, this study demonstrated the successful characterization of IMX-104 loworder detonation particles from command detonation to analysis. 


\section{Contents}

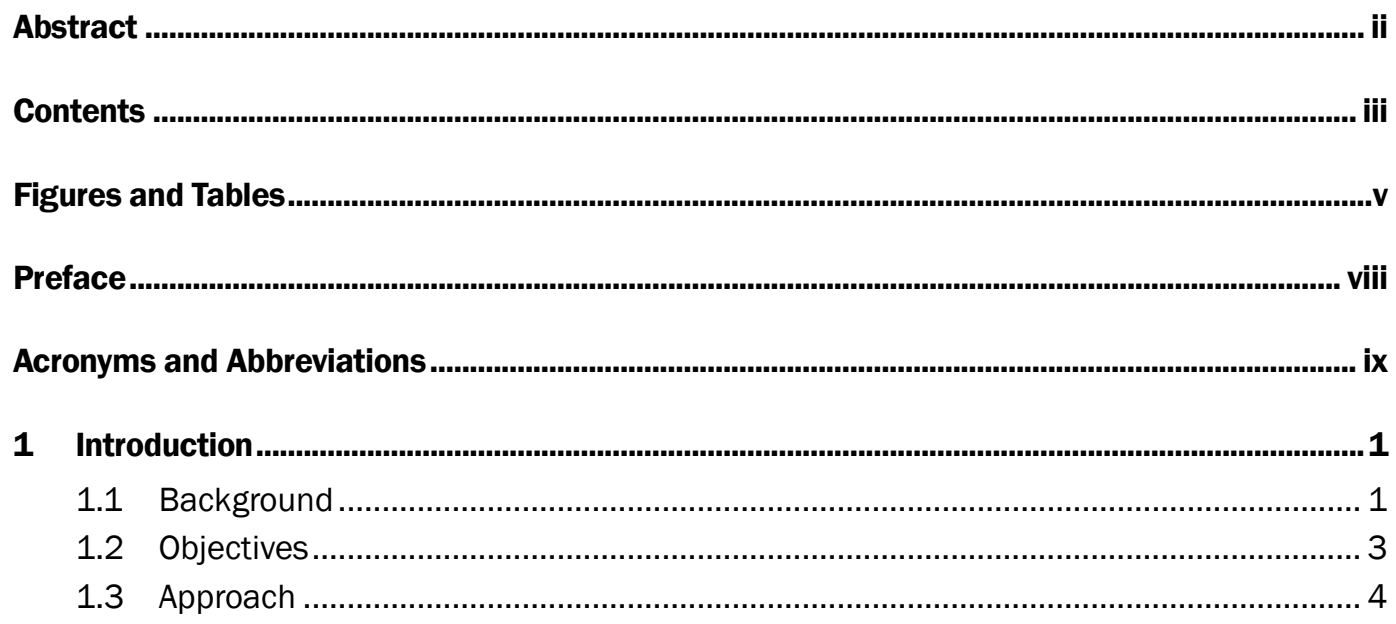

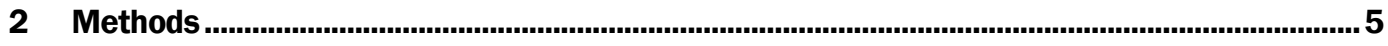

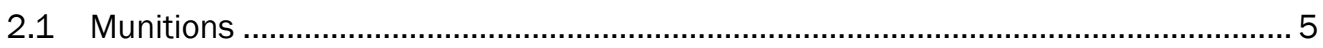

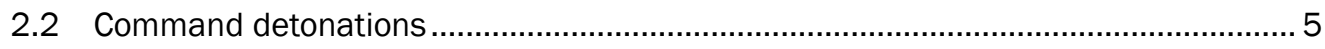

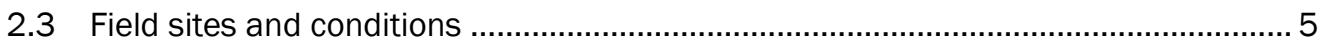

2.3.1 Eagle River Flats Impact Area................................................................................. 5

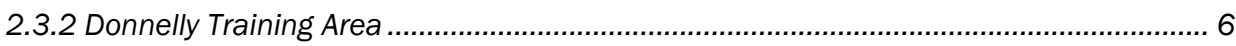

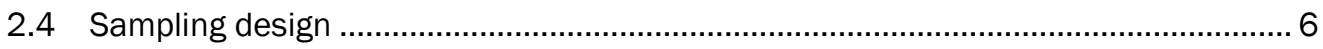

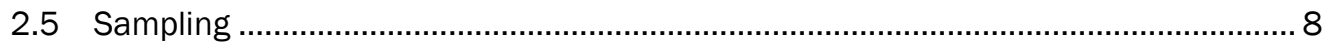

2.6 Quality assurance / quality control ..................................................................... 9

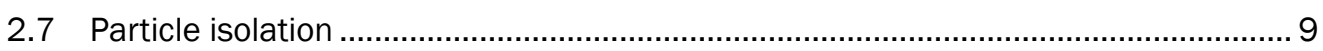

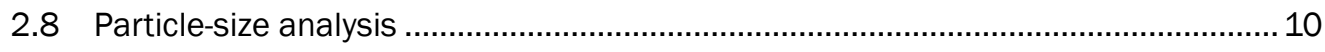

2.9 Particle sample extraction.............................................................................. 10

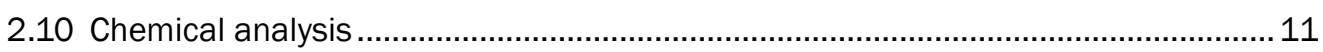

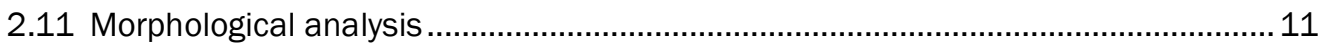

3 Results and Discussion ................................................................................................................12

3.1 Command-detonation optimization .................................................................. 12

3.2 Quality assurance / quality control ................................................................ 14

3.3 Sample extraction optimization ......................................................................... 15

3.460 mm IMX-104 ...................................................................................... 16

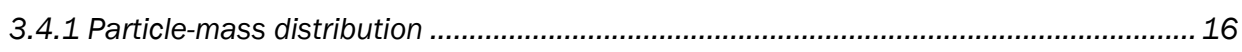

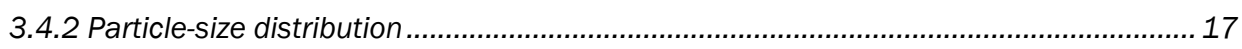

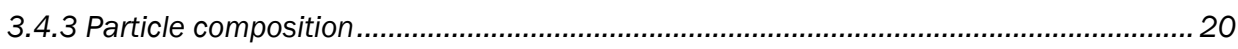

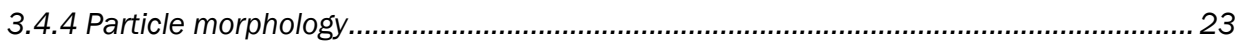

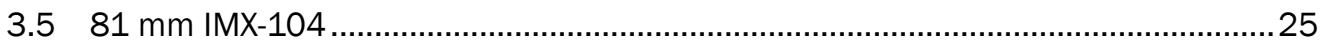

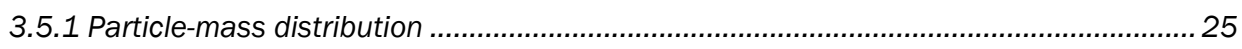

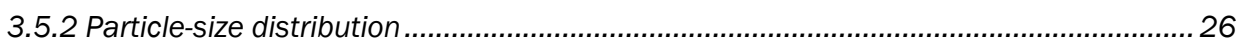

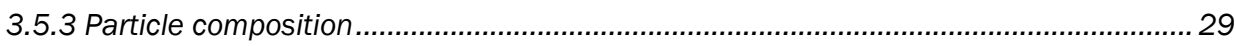

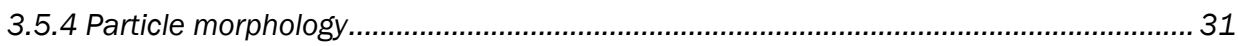




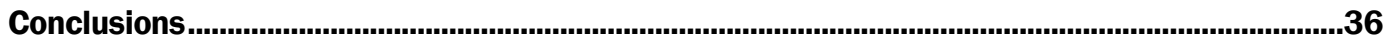

References ....................................................................................................................................38

Appendix A: Quality Control Data ...................................................................................................41

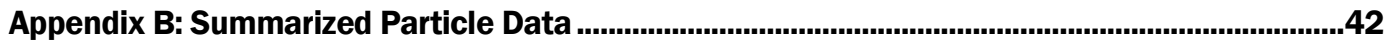

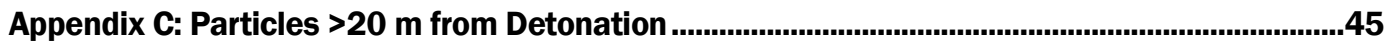

Appendix D: PSD Plots from Individual Detonations and Annuli.......................................................46

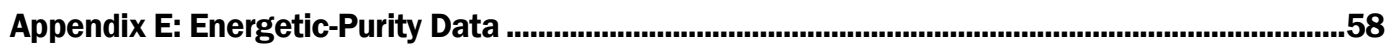

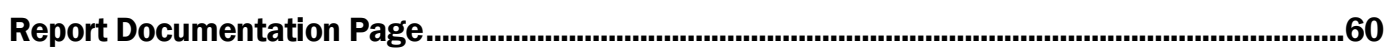




\section{Figures and Tables}

\section{Figures}

1 Aerial image of the cleared testing site on Eagle River Flats after tests ............................ 6

$2 \quad$ Fort Worth Lake testing site at Donnelly Training Area ........................................................

3 Conceptual sampling design with annuli marked by dashed lines up to 20 $\mathrm{m}$ from the point of detonation ..................................................................................... 7

$4 \quad$ Sweeping particles from a $1 \mathrm{~m}$ annulus with a push broom ..............................................

$5 \quad$ Collecting swept particle piles with a drywall knife and a paint brush ............................... 8

6 Low-order detonation residues from a $60 \mathrm{~mm}$ IMX-104 mortar round at DTA ................12

$7 \quad$ Low-order-detonation residues from an $81 \mathrm{~mm}$ IMX-104 round (19FRA LO2) ................14

8 High-order-detonation residues from an $81 \mathrm{~mm}$ IMX-104 round......................................14

9 Formulation-normalized compound concentrations following 18-hour extractions of discrete subsamples of 15FRA LO2 3-4 m at differing residue/solvent ratios and solvent types

10 Particle-size distributions from $60 \mathrm{~mm}$ IMX-104 detonations at Donnelly Training Area. Select annuli needed to be combined to have the mass necessary to process by LD-PSA.

11 Formulation-normalized compound concentrations in whole-sample extractions from $60 \mathrm{~mm}$ IMX-104 detonations. Concentrations are from both the material recovered in the vacuum container of the LD-PSA postanalysis (Sample) and material from shaking the vacuum filter (Fines)

12 Total energetic compound purity of recovered particles from $60 \mathrm{~mm}$ IMX104 rounds as a function of distance. Energetic composition is the massweighted average of sample and fines composition..........................................................22

13 SEM image from 19DTA L01 0-1 m ...........................................................................23

14 SEM image from 19DTA L01 4-5 m ..........................................................................24

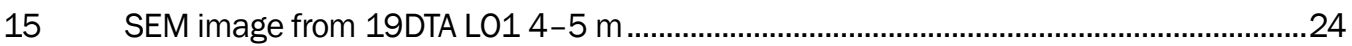

16 SEM image from 19DTA LO3 15-20 m ……....................................................................25

17 PSDs from $81 \mathrm{~mm}$ IMX-104 LO detonations. Select annuli needed to be combined to have the mass necessary to process by LD-PSA

18 Formulation-normalized compound concentrations in whole-sample extractions from $81 \mathrm{~mm}$ IMX-104 detonations. Concentrations from both the material recovered in the vacuum container of the LD-PSA postanalysis (Sample) and material from shaking the vacuum filter (Fines) are shown.

19 Total energetic compound purity of recovered particles from $81 \mathrm{~mm}$ IMX104 rounds as a function of distance. Energetic composition is the massweighted average of sample and fines composition

20 SEM image from 19FRA L01 0-1 m.............................................................................32

21 SEM image from 19FRA LO1 6-7 m......................................................................32

22 SEM image from 19FRA L01 10-15 m......................................................................33

23 A $\mu$ CT image of $>2$ mm particles from 19FRA L01 …...................................................34

$24 \quad$ A $\mu C T$ image of $>2$ mm particle from 19FRA L01 …..........................................................35 
D-1 PSDs from $60 \mathrm{~mm}$ IMX-104 LO detonations. Select annuli needed to be combined to have the mass necessary to process by LD-PSA.

D-2 PSDs from $81 \mathrm{~mm} \mathrm{IMX-104} \mathrm{LO} \mathrm{detonations.} \mathrm{Select} \mathrm{annuli} \mathrm{needed} \mathrm{to} \mathrm{be}$ combined to have the mass necessary to process by LD-PSA

\section{Tables}

1 Classification of detonation order based on energetic mass recovered

from M. R. Walsh et al. (2017) .........................................................................................

2 Visual test results and C4 masses used in the CFS for $60 \mathrm{~mm}$ rounds..........................13

$3 \quad$ Visual test results and $\mathrm{C} 4$ masses used in the CFS for $81 \mathrm{~mm}$ rounds ..........................13

$4 \quad$ Energetic masses from postsampling sweep quality control samples..............................15

5 The $2 \mathrm{~mm}$ sieve masses and mass proportions for 19DTA $60 \mathrm{~mm}$ samples ..................17

6 Particle-size metrics for the 19DTA L01 <2 mm fraction averaged for multiple analyses by LD-PSA

7 Particle-size metrics for the 19DTA L02 $<2 \mathrm{~mm}$ fraction averaged for multiple analyses by LD-PSA.

8 Particle-size metrics for the 19DTA LO3 $<2 \mathrm{~mm}$ fraction averaged for multiple analyses by LD-PSA.

9 Energetic-purity-corrected $2 \mathrm{~mm}$ sieve masses and mass proportions for 19DTA $60 \mathrm{~mm}$ samples

10 The $2 \mathrm{~mm}$ sieve masses and mass proportions for 19FRA $81 \mathrm{~mm}$ samples

11 Particle-size metrics for the 19FRA LO1 $<2 \mathrm{~mm}$ fraction averaged for multiple analyses by LD-PSA

12 Particle-size metrics for the 19FRA LO2 $<2 \mathrm{~mm}$ fraction averaged for multiple analyses by LD-PSA .

13 Particle-size metrics for the 19FRA LO3 $<2 \mathrm{~mm}$ fraction averaged for multiple analyses by LD-PSA

14 Energetic-purity-corrected $2 \mathrm{~mm}$ sieve masses and mass proportions for 19FRA $81 \mathrm{~mm}$ samples

A-1 SPE matrix spike (MS), matrix spike duplicate (MSD), and laboratory control samples (LCS) each spiked at $4 \mathrm{\mu g} / \mathrm{L}$ with HMX, RDX, and DNAN

B-1 Energetic-purity-corrected $2 \mathrm{~mm}$ sieve masses, mass proportions, and $<2$ $\mathrm{mm}$ particle sizes for $60 \mathrm{~mm}$ IMX-104 test 19DTA L01

B-2 Energetic-purity-corrected $2 \mathrm{~mm}$ sieve masses, mass proportions, and $<2$ $\mathrm{mm}$ particle sizes for $60 \mathrm{~mm}$ IMX-104 test 19DTA LO2

B-3 Energetic-purity-corrected $2 \mathrm{~mm}$ sieve masses, mass proportions, and $<2$ $\mathrm{mm}$ particle sizes for $60 \mathrm{~mm}$ IMX-104 test 19DTA LO3

B-4 Energetic-purity-corrected $2 \mathrm{~mm}$ sieve masses, mass proportions, and $<2$ $\mathrm{mm}$ particle sizes for $81 \mathrm{~mm}$ IMX-104 test 19FRA L01

B-5 Energetic-purity-corrected $2 \mathrm{~mm}$ sieve masses, mass proportions, and $<2$ $\mathrm{mm}$ particle sizes for $81 \mathrm{~mm}$ IMX-104 test 19FRA L02.

B-6 Energetic-purity-corrected $2 \mathrm{~mm}$ sieve masses, mass proportions, and $<2$ $\mathrm{mm}$ particle sizes for $81 \mathrm{~mm}$ IMX-104 test 19FRA LO3.

C-1 Particles identified $>20 \mathrm{~m}$ from the detonation site for 19DTA samples..........................45

C-2 Particles identified $>20 \mathrm{~m}$ from the detonation site for 19FRA samples .........................45 
E-1 Formulation-normalized energetic purity of whole-sample dissolved samples from the LD-PSA chamber, fines from shaking the LD-PSA filter, and total weighted masses of both the sample and fines ................................................58

E-2 Linear regressions statistics of the pooled total weighted purity (y) by median distance $(\mathrm{x})$ 


\section{Preface}

This research was sponsored by the Strategic Environmental Research and Development Program (SERDP) Environmental Security and Technology Certification Program (ESTCP) under Environmental Restoration Program project number ER18-5105, "Determination of Residual Low-Order Detonation Particle Characteristics." Funding was provided by MIPRs W74RDV80715663, W74RDV80715688, W74RDV90156248, and W74RDV90497295. Dr. Herb Nelson was Executive Director for SERDPESTCP, and Dr. Andrea Leeson was Deputy Director and Project Monitor.

This report was prepared by the Engineering Resources Branch (ERB) and the Biogeochemical Sciences Branch (BSB) of the Research and Engineering Division, U.S. Army Engineer Research and Development Center, Cold Regions Research and Engineering Laboratory (ERDC-CRREL). Researchers from ERDC-CRREL collaborated with Envirostat, Inc, of Vail, Arizona. At the time of publication, Dr. Caitlin A. Callaghan was Chief, ERB; Mr. Nathan Lamie was Chief, BSB; and Dr. George Calfas was Division Chief. The Deputy Director of ERDC-CRREL was Mr. David B. Ringelberg, and the Director was Dr. Joseph L. Corriveau.

The authors acknowledge Mr. Michael R. Walsh, Dr. Susan Taylor, Ms. Katrina Burch, Mr. Brandon Booker, and Ms. Lauren Farnsworth of ERDC-CRREL for experimentation support and Mr. Arthur Gelvin, Mr. William Burch, Mr. Christopher Felt, and Ms. Ann Staples of ERDCCRREL and Mr. Nathan Hoffman of the USACE Environmental and Munitions Center of Expertise for field support. The authors would also like to thank MSG Maximo Cabrera, SFC Kewan Lemmon, SFC James Little, SSG Aaron Healy, and Mr. Gerald Schrek Jr. of the Combat Capabilities Development Command Armaments Center's Explosive Ordnance Disposal Technology Directorate, the 716th Explosive Ordnance Disposal Company, and the Range Control offices of Richardson and Donnelly Training Areas for coordination and field support. Manuscript review was coordinated with Joint Program Executive Office Armaments and Ammunition. Ms. Stacey Doherty and Ms. Ashley Mossell, ERDC-CRREL, provided manuscript technical review comments.

COL Teresa A. Schlosser was Commander of ERDC, and Dr. David W. Pittman was the ERDC Director. 


\section{Acronyms and Abbreviations}

\begin{tabular}{|c|c|}
\hline BIP & Blow-In-Place Detonation \\
\hline BSB & Biogeochemical Sciences Branch \\
\hline $\mathrm{C}_{4}$ & Composition 4 \\
\hline CFS & CRREL Fuze Simulator \\
\hline Comp B & $\begin{array}{l}\text { Composition B (a munition formulation containing TNT } \\
\text { and RDX) }\end{array}$ \\
\hline CRREL & Cold Regions Research and Engineering Laboratory \\
\hline D10 & $\begin{array}{l}\text { Diameter at which } 10 \% \text { of the distribution has smaller } \\
\text { particle size }\end{array}$ \\
\hline D50 & $\begin{array}{l}\text { Diameter at which } 50 \% \text { of the distribution has smaller } \\
\text { particle size }\end{array}$ \\
\hline D90 & $\begin{array}{l}\text { Diameter at which } 90 \% \text { of the distribution has smaller } \\
\text { particle size }\end{array}$ \\
\hline DF & Degrees of Freedom \\
\hline DNAN & 2,4,-Dinitroanisole \\
\hline DTA & Donnelly Training Area \\
\hline EDS & Energy Dispersive X-Ray Spectroscopy \\
\hline EPA & United States Environmental Protection Agency \\
\hline ERB & Engineering Resources Branch \\
\hline ERDC & U.S. Army Engineer Research and Development Center \\
\hline $\mathrm{ERF}$ & Eagle River Flats \\
\hline ESTCP & Environmental Security Technology Certification Program \\
\hline HMX & 1,3,5,7-Tetranitro-1,3,5,7-Tetrazoctane \\
\hline HPLC & High-Performance Liquid Chromatography \\
\hline
\end{tabular}


IHE

IMX-101

IMX-104

JBER

LCS

LD-PSA

LO

MS

MSD

NTO

PAX-21

PSD

RDX

SD

SEM

SERDP

SPE

TNT

$\mathrm{v} / \mathrm{v}$

$\mu \mathrm{CT}$
Insensitive High Explosive

Insensitive Munitions Explosive 101 (a formulation containing DNAN, NTO, and nitroguanidine)

Insensitive Munitions Explosive 104 (a formulation containing DNAN, NTO, and RDX)

Joint Base Elmendorf-Richardson

Laboratory Control Sample

Laser Diffraction Particle-Size Analysis

Low Order

Matrix Spike

Matrix Spike Duplicate

3-Nitro-1,2,4-Triazol-5-One

Picatinny Arsenal Explosive 21 (an insensitive munition formulation containing ammonium perchlorate, RDX, DNAN, and N-methyl-4-nitroaniline)

Particle-Size Distribution

1,3,5-Trinitro-1,3,5-Triazinane

Standard Deviation

Scanning Electron Microscope

Strategic Environmental Research and

Development Program

Solid Phase Extraction

2,4,6-Trinitrotoluene

Volume/Volume

Microcomputed Tomography 


\section{Introduction}

\subsection{Background}

Energetic compounds released from munitions during military training can present environmental risks and threaten the sustainment of training ranges. Of particular concern are impacts to ecosystem health and the mobilization of compounds into groundwater, both of which have resulted in range restrictions in the past (Clausen et al. 2004; Racine et al. 1992; M. E. Walsh et al. 1996). When munitions detonate as designed, these high-order detonations release generally small quantities (less than $10 \mathrm{mg}^{*}$ ) of energetic compounds for conventional explosives (Hewitt et al. 2005; M. R. Walsh et al. 2011) and relatively minor quantities (1-4 g) for some new insensitive munitions (M. R. Walsh et al. 2013, 2014; M. R. Walsh, Bigl, et al. 2018). Occasional malfunctioning of a munition can result in a dud (an intact round) or in a low-order (LO) detonation that scatters a significant portion of its energetic filler (M. E. Walsh 2008; M. R. Walsh et al. 2017). While duds are thought to remain intact for decades (Chendorain and Stewart 2005), LO detonations scatter energetic particles over a localized area, typically less than $500 \mathrm{~m}^{2}$ (Taylor et al. 2004; M. E. Walsh et al. 2008; M. R. Walsh et al. 2013, 2014), which can then become immediately environmentally available and mobile.

Prior studies have characterized postdetonation particles using a variety of techniques. Steel witness plates surrounding a point of detonation at varying distances have been used to determine particle mass, and to some extent size, from high-order detonations of conventional explosives (AbdulKarim, Blackman, Gill, and Karu 2016; Abdul-Karim, Blackman, Gill, Morgan, et al. 2016; Borusiewicz et al. 2013). Abdul-Karim, Blackman, Gill, and Karu (2016) found preliminary evidence for particle mass to relate to the inverse square of the distance from detonation, and they also found that mass decreases with increasing distance. Borusiewicz et al. (2013) found no consistent trend in mass deposition with distance from detonation. Taylor et al. (2004) and (2006) used pans and tarps, respectively, to collect discrete quantities from blow-in-place (BIP) detonations of mortar

* For a full list of the spelled-out forms of the units of measure used in this document, please refer to U.S. Government Publishing Office Style Manual, 31st ed. (Washington, DC: U.S Government Publishing Office, 2016), 248-252, https://www.govinfo.gov/content/pkg/GPO-STYLEMANUAL-2016/pdf/GPO- 
and howitzer rounds. BIP detonations are initiated with blocks of Composition 4 (C4) explosive and are commonly used in ordnance clearance. Taylor et al. $(2004,2006)$ described these detonations as LO and produced particles with widely ranging particle sizes from less than $0.053 \mathrm{~mm}$ to single large chunks up to $200 \mathrm{~mm}$. Pennington et al. (2008) used shaped charges to initiate described LO detonations of mortar and artillery rounds. Particles were collected from a $30 \mathrm{~m}$ by $30 \mathrm{~m}$ tarpaulin by sweeping with horsehair brushes. Shaped charge mass and standoff distance were found to be controlling factors on detonation energy, and recovered masses ranged from $17 \%$ to $54 \%$ of the original filler mass. Particle size was determined by sieves stack from 0.25 to $12.5 \mathrm{~mm}$.

In an effort to avoid cross contamination from previously deposited material, Jenkins et al. (2002) used fresh snow as a sampling surface to collect particles from BIP detonations of $60 \mathrm{~mm}$ and $81 \mathrm{~m}$ Composition B (Comp B) rounds, which Jenkins et al. (2002) found distributed particles up to $26 \mathrm{~m}$ from the detonation with no overall trends between mass deposition and distance. Taylor, Dontsova, et al. (2015) also conducted tests on snow but using the Cold Regions Research and Engineering Laboratory (CRREL) fuze simulator (CFS) to initiate a LO detonation on command (henceforth command detonation; M. R. Walsh et al. 2011) of munitions filled with Insensitive Munition Explosives 101 (IMX-101) and Picatinny Arsenal Explosive 21 (PAX-21). Taylor, Dontsova, et al. (2015) picked the particles manually from the snow surface, counted them, and weighed them. They found particle masses from $0.01 \mathrm{~g}$ to $10 \mathrm{~g}$ for a $155 \mathrm{~mm}$ IMX-101 round, $81 \mathrm{~mm}$ IMX-104 rounds, and $60 \mathrm{~mm}$ rounds filled with Picatinny Arsenal Explosive 21 (PAX-21). M. R. Walsh et al. (2013) also collected particles from $60 \mathrm{~mm}$ PAX-21 rounds detonated on ice with the CFS, but they collected only those particles greater than $1 \mathrm{~mm}$. These studies found that collecting particles on clean ice allowed maximum particle recovery while avoiding previous detonation material and detritus.

In 2015, under Strategic Environmental Research and Development Program (SERDP), project ER-2219 developed a new methodology for collecting LO particles by using brooms (M. R. Walsh, Thiboutot, and Gullet 2017). All postdetonation material was sampled from within sampling rings on clean ice surrounding $81 \mathrm{~mm}$ IMX-104 rounds initiated with the CFS. Of seven rounds tested, three were described as $\mathrm{LO}$ with $69 \%$ to $94 \%$ energetic consumption, two as partial detonations (approximately $20 \%$ consumption), and two initiated duds (approximately $1 \%$ consumption). 
Using estimates of mass from these tests on snow and ice, M. R. Walsh et al. (2017) proposed a classification for detonation order based on recovered energetic mass and observations of the munition state (Table 1). These descriptors were based on over 20 years of field experimentation and testing through SERDP-sponsored research projects on residue characterization performed by CRREL and others (ER-1155 [Pennington et al. 2006], ER-1481 [M. R. Walsh et al. 2011], and ER-2219 [M. R. Walsh et al. 2017]). For the purposes of this study, the phrase $L O$ detonation will be used to describe a LO functioning round as defined by the consumption rates and munition states defined in Table 1.

Table 1. Classification of detonation order based on energetic mass recovered from M. R. Walsh et al. (2017).

\begin{tabular}{|c|c|l|}
\hline $\begin{array}{c}\text { Detonation } \\
\text { Type }\end{array}$ & $\begin{array}{c}\text { Filler Mass } \\
\text { Consumed (\%) }\end{array}$ & \multicolumn{1}{c|}{ Munition State } \\
\hline High Order & $\geq 99.99$ & $\begin{array}{l}\text { Total fragmentation of projectile body. Very fine } \\
\text { residues (soot). }\end{array}$ \\
\hline Low Order & $75-99.98$ & $\begin{array}{l}\text { Incomplete body fragmentation. Energetics particles } \\
\text { on the ground and adhered to larger metal fragments. }\end{array}$ \\
\hline Partial & $25-75$ & $\begin{array}{l}\text { Little if any fragmentation of the body. Large chunks of } \\
\text { explosive filler (>cm size). }\end{array}$ \\
\hline Initiated Dud & $<25$ & $\begin{array}{l}\text { Fuze initiated. Mostly intact round. Adjacent loose } \\
\text { chunks of explosive filler possible. }\end{array}$ \\
\hline $\begin{array}{c}\text { Noninitiated } \\
\text { Dud }\end{array}$ & 0 & $\begin{array}{l}\text { Round intact, including fuze. No ejection of } \\
\text { explosive filler. }\end{array}$ \\
\hline
\end{tabular}

Despite these prior studies, a complete characterization of LO particles produced by insensitive munitions has not yet been conducted, in part due to lack of a demonstrated method. Particle size and morphology determine how quickly energetic compounds will dissolve and enter the vadose zone (Taylor, Park, et al. 2015), while the spatial distribution and total mass of energetic material dictate site source loading and the capacity for soil retention. Demonstration of a method to constrain these particle characteristics could produce data that significantly improves the accuracy of models used to determine contaminant fate and transport.

\subsection{Objectives}

The goal of this study was to demonstrate a method of purposefully initiating LO detonations and characterizing resulting particles, specifically using insensitive high-explosive (IHE) mortar rounds containing IMX-104. 
The specific demonstration objectives were

1. to successfully command detonate $60 \mathrm{~mm}$ and $81 \mathrm{~mm} \mathrm{IMX-104}$ mortar rounds LO;

2. to sample all of the resulting LO particles on clean ice in spatially resolved increments; and

3. to characterize LO particle samples for their size, composition, and morphology.

\subsection{Approach}

This study demonstrated a method of characterizing LO particles using two different caliber mortar rounds containing the IHE formulation IMX104. Three rounds of each size were successfully command-detonated LO on clean ice, and the particles were sampled in spatially resolved annuli up to the expected limit of maximum dispersion. The particles were isolated and then characterized using laser diffraction particle-size analysis (LDPSA), scanning electron microscopy (SEM), microcomputed tomography $(\mu \mathrm{CT})$, and high-performance liquid chromatography (HPLC). Reproducibility, quality control, and process observations were used to assess method performance and broader applications. 


\section{Methods}

\subsection{Munitions}

Munitions for testing were sourced through the Army Total Ammunition Management Information System and handled by the 716th Explosive Ordnance Disposal Company. The tested munitions were BA44 M720A2 $60 \mathrm{~mm}$ mortar rounds containing IMX-104 and CA61 M821A3 $81 \mathrm{~mm}$ mortar rounds containing IMX-104. The $81 \mathrm{~mm}$ rounds consisted of mortar bodies with no tail assembly or fuze. These rounds were excess manufacturing test rounds obtained during SERDP ER-2219 by Defence Research and Development Canada-Valcartier from Combat Capabilities Development Command Armaments Center (formerly Armaments, Research, Development, and Engineering Center), Picatinny Arsenal, New Jersey.

\subsection{Command detonations}

Low-order detonations were performed by replacing the issued fuze or fuze well plug with the CFS containing a field-variable amount of $\mathrm{C}_{4}$ and initiating by an electric blasting cap (M. R. Walsh et al. 2011). Remote detonators were used with electrically initiated blasting caps with less than 5 $\mathrm{m}$ of wire. Confirmation tests were conducted to determine the optimal mass of $\mathrm{C}_{4}$ in the CFS to trigger a LO detonation. Prior to detonation, the supplemental charges and all propellant charges were removed (except for Charge $\mathrm{o}$ in the tail assemblies, if present). For stability the $81 \mathrm{~mm}$ mortar bodies were secured to a $5 \times 5 \mathrm{~cm}$ aluminum base plate by using the tail assembly threads.

\subsection{Field sites and conditions}

Tests were conducted at two different field sites in Alaska during March 2019.

\subsubsection{Eagle River Flats Impact Area}

Confirmation tests of the $60 \mathrm{~mm}$ rounds, and all sampled $81 \mathrm{~mm}$ LO tests, were performed on the Eagle River Flats (ERF) Impact Area of Joint Base Elmendorf-Richardson (JBER) in Anchorage, Alaska, on 9 March 2019 (Figure 1). Prior to tests, snow was removed from $60 \times 100 \mathrm{~m}$ and $60 \times$ $60 \mathrm{~m}$ test areas of the frozen tidal estuary. However, the surface was determined too rough for reliable particle collection. Therefore, a towed water trailer was used to repeatedly flood the test area and create a smooth ice 
surface on 7 March 2019. Temperatures during sampled tests on 9 March were $-1^{\circ} \mathrm{C}$ to $2^{\circ} \mathrm{C}$, but light winds $(<2 \mathrm{~m} / \mathrm{s})$ kept the testing surface frozen. Higher temperatures at this testing site prompted moving subsequent tests to the second field site.

Figure 1. Aerial image of the cleared testing site on Eagle River Flats after tests.

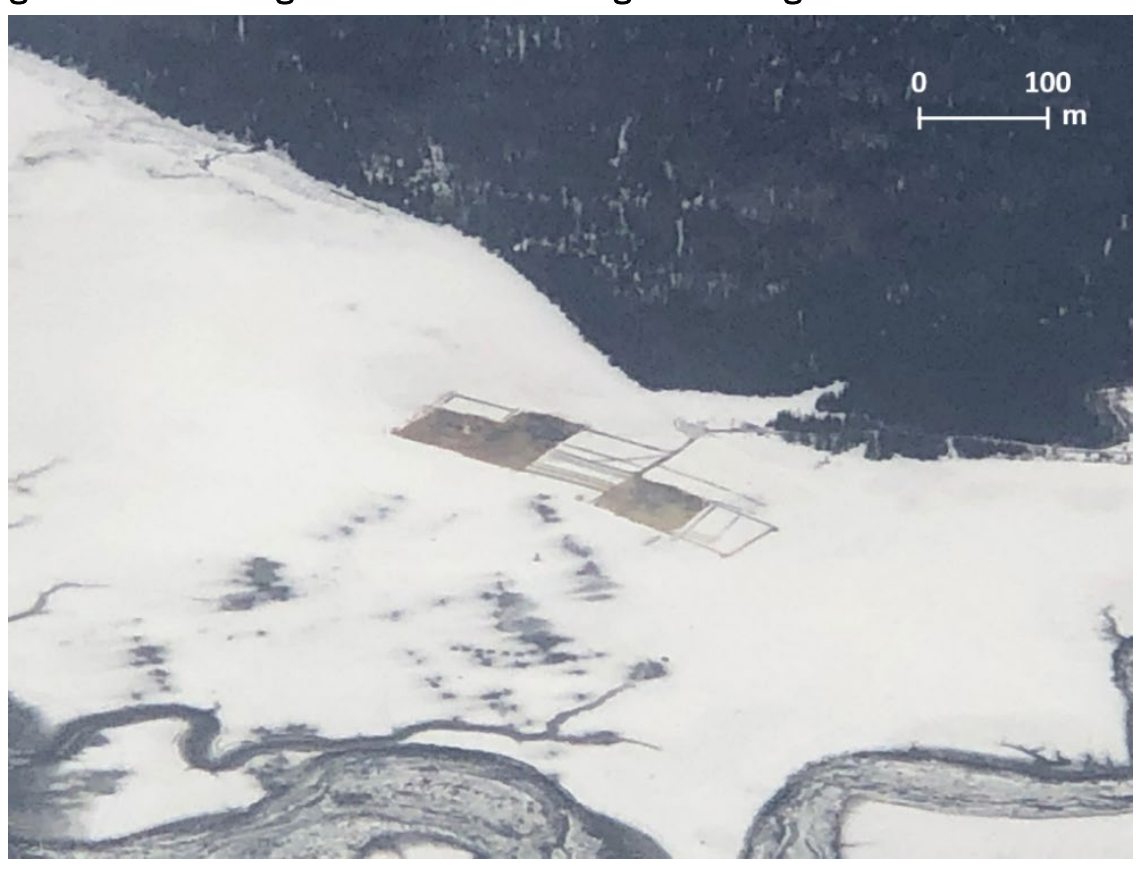

\subsubsection{Donnelly Training Area}

All sampled tests of $60 \mathrm{~mm}$ mortar rounds were performed on Fort Worth Lake at Donnelly Training Area (DTA) on Fort Greely in Delta Junction, Alaska, on 13 March 2019 (Figure 2). This small (3 ha) pond was cleared of snow on 12 March 2019 with a plow truck and shovels. On 13 March, overnight wind had removed nearly all remaining snow and revealed a smooth glare-ice surface. Temperatures on the test day were approximately $-2^{\circ} \mathrm{C}$ with light wind ( 1 to $2 \mathrm{~m} / \mathrm{s}$ ). High winds ( 8 to $15 \mathrm{~m} / \mathrm{s}$ ) on 14 March prevented further testing.

\subsection{Sampling design}

Each tested round was placed on a $30 \times 30 \mathrm{~cm}$ steel plate, marking the center of the sampling area. Sampling annuli centered on the munition were marked with spray paint at $1 \mathrm{~m}$ intervals from $\mathrm{o}$ to $10 \mathrm{~m}$ and $5 \mathrm{~m}$ intervals from 10 to $20 \mathrm{~m}$ from the center (Figure 3). 
Figure 2. Fort Worth Lake testing site at Donnelly Training Area.

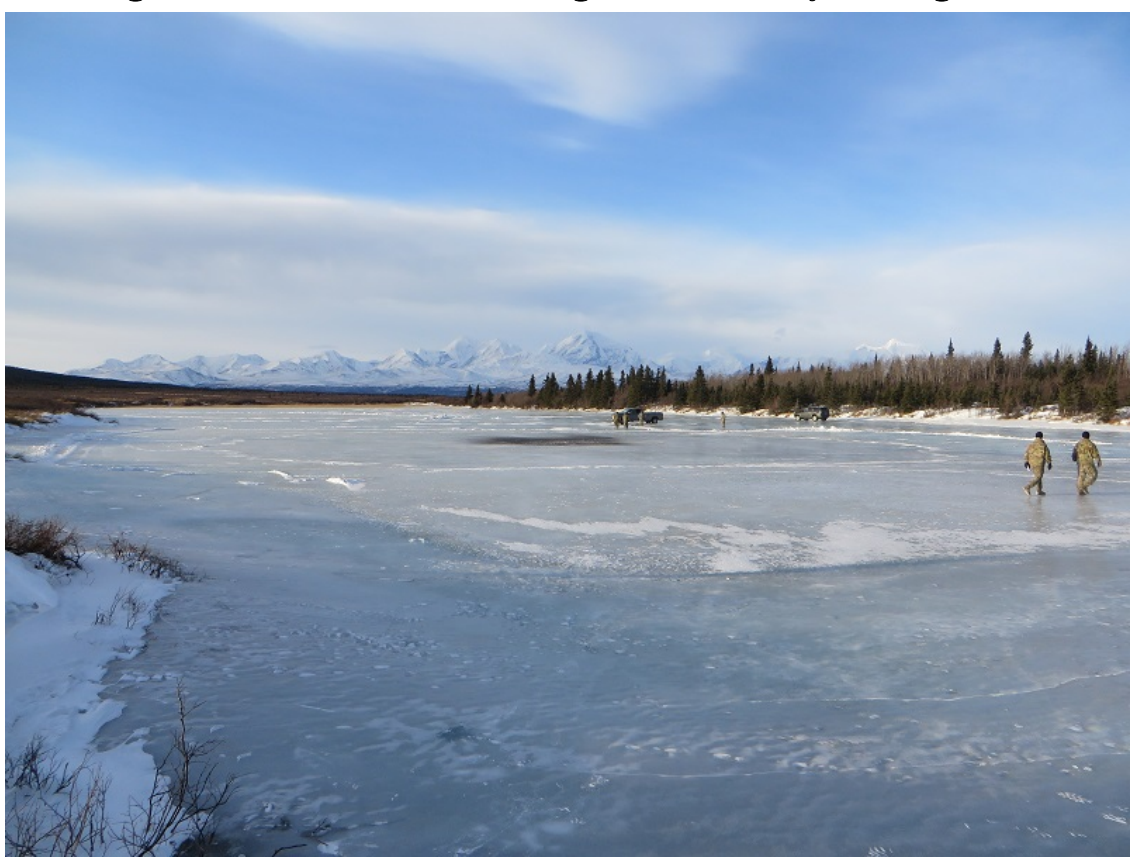

Figure 3. Conceptual sampling design with annuli marked by dashed lines up to $20 \mathrm{~m}$ from the point of detonation.

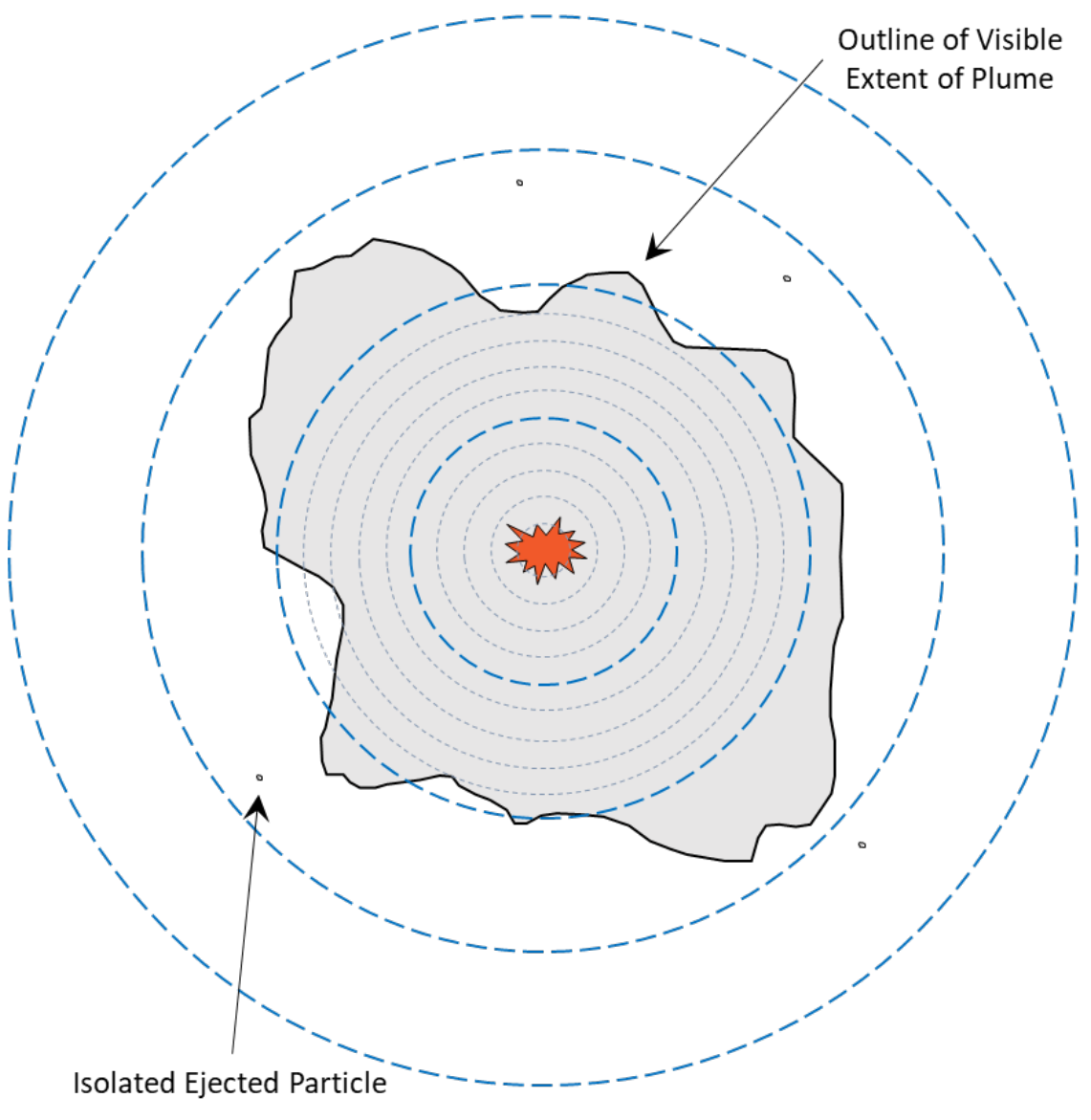




\subsection{Sampling}

Each annulus was swept carefully with push brooms to collect particles into a pile without abrading the particles with the ice surface (Figure 4). A metal screwdriver was run repeatedly through the broom bristles to dislodge any particles retained in the bristles. Paint brushes and stainlesssteel drywall knives were used to transfer particles from the ice to large Whirl-Pak bags (Figure 5). Each Whirl-Pak bag was placed in its own zipclosed plastic bag. Push brooms for the outer 10-15 $\mathrm{m}$ and 15-20 m annuli were kept separate from inner brooms to minimize cross-contamination. Push brooms were cleaned by running the broom over clean snow between samples and with Micro-90 solution between sampling days.

Figure 4. Sweeping particles from a $1 \mathrm{~m}$ annulus with a push broom.

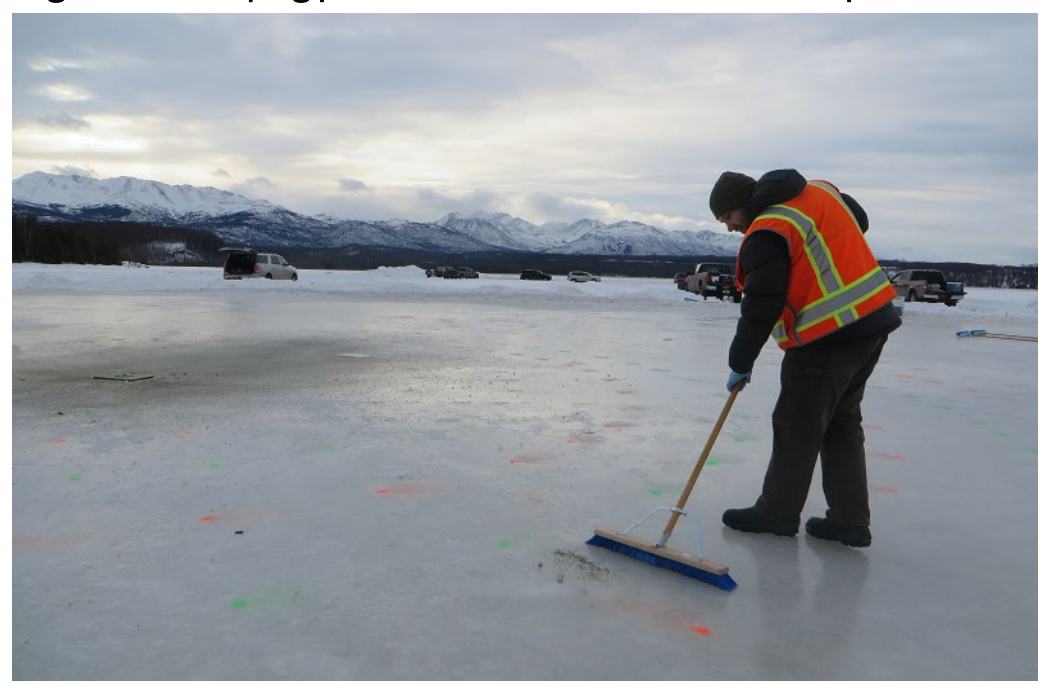

Figure 5. Collecting swept particle piles with a drywall knife and a paint brush.

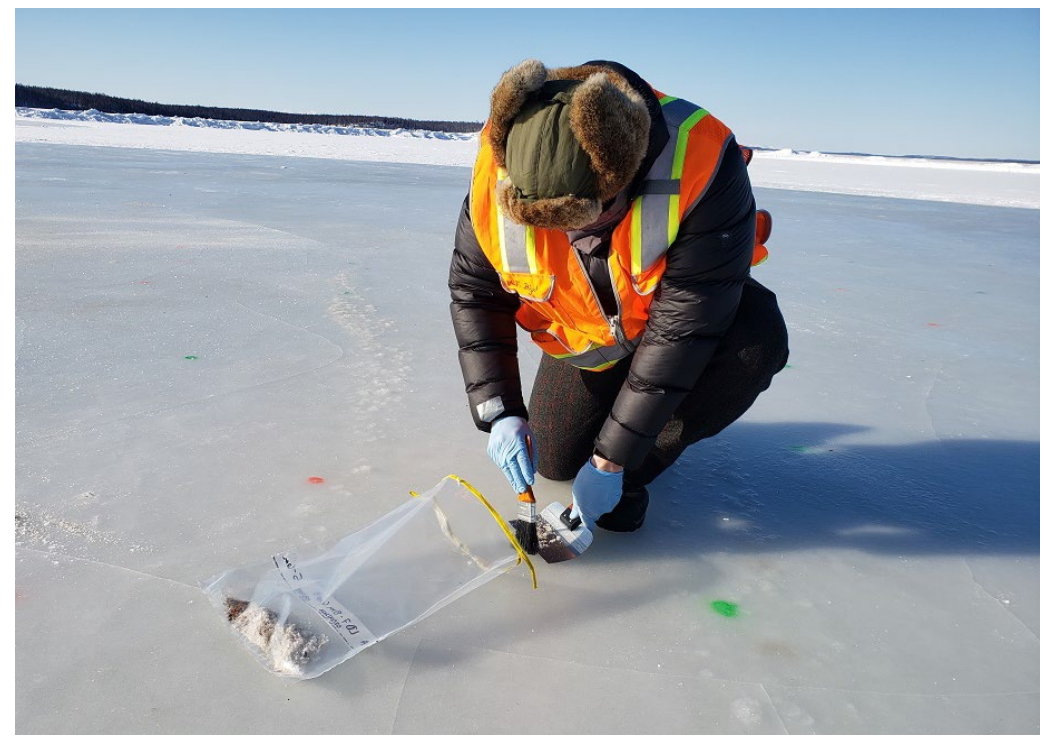




\subsection{Quality assurance / quality control}

Multi-increment samples were collected from background snow to ensure the absence of preexisting insensitive munition material. Each sample was composed of approximately 100 increments, with each increment collected using a $10 \times 10 \times 1 \mathrm{~cm}$ Teflon-coated steel scoop. Four snow samples were collected at the ERF site prior to detonations, and two samples were collected at Donnelly Training Area from plowed snow prior to detonations. Each background sample was melted in the laboratory on JBER and processed following M. E. Walsh (2016), including filtration through a glassfiber filter and solid-phase extraction (SPE) of $500 \mathrm{~mL}$ of filtrate with a Waters PoraPak RDX cartridge, and then shipped to CRREL in Hanover, New Hampshire, for analysis.

Following select samples, the entire sampling area was reswept into one sample and designated the postsample check to quantify the mass of energetic material missed after sweeping,. As a secondary check, the entire sampling area was reswept again with a dedicated push broom into one sample and designated the postsample check verification. These quality control samples were collected from two sampled LO detonation sites at DTA. They were melted and filtered through glass-fiber filters at the laboratory on JBER, then shipped to CRREL for analysis.

Pre- and postfiltration blanks, SPE blanks, matrix spikes, and laboratory control samples were also processed and analyzed at CRREL (Appendix A).

\subsection{Particle isolation}

Bagged samples from each annulus were transferred to preweighed $8 \mathrm{oz}$ wide-mouth glass jars in a cold room at approximately $-20^{\circ} \mathrm{C}$. An unbleached coffee filter was placed on the opening of each jar and affixed by a plastic ring cap. Sample jars were placed inside $600 \mathrm{~mL}$ freeze-drying glass bulbs and connected to a VirTis Freezemobile 12XL at a set temperature of $-75^{\circ} \mathrm{C}$ for $30-120$ hours.

Jars were weighed on a precision balance after freeze-drying to determine the total residue mass.

Freeze-dried samples were dry sieved at $2 \mathrm{~mm}$, with oblong particles $>2 \mathrm{~mm}$ in any dimension removed manually with tweezers to avoid obstruction of the LD-PSA system. Visibly nonenergetic materials (i.e., metal 
fragments and vegetation) were manually removed with tweezers and discarded. The energetic mass $>2 \mathrm{~mm}$ was stored in a separate vial and weighed on a precision balance.

\subsection{Particle-size analysis}

Following particle isolation and sieving, the samples were analyzed for particle size using a Horiba LA-96o laser diffraction particle-size analyzer. A Nilfisk 118EXP vacuum was used with this system to allow recovery of sample material. To mimic factory settings of the Nilfisk GM 80 typically used on the Horiba LA-960, the suction was adjusted with the use of a variable-speed controller. The Horiba LA-960 was run on automatic feeder settings with the forced air pressure set to $0.32 \mathrm{MPa}$, a refractive index of 1.845 0.1i, and sample data acquisition times of 50,000 (Bigl et al. 2020). Most samples greater than approximately $3 \mathrm{~g}$ required multiple analyses for all of the sample material to pass through the analyzer during a measurement cycle. Samples were recovered from the stainless-steel collection chamber using static-free brushes. After sample recovery, the filter of the Nilfisk 118EXP was shaken out into the stainless-steel collection chamber, and this fine material was recovered into a separate glass jar by using static-free brushes. To avoid cross contamination between samples, the instrument was cleaned after each sample by running Ottawa sand through the analyzer.

Almost all (64 of 66) of the samples had multiple output data files, each associated with an analysis, that required averaging. The volumetric percent for each analysis bin (0.011 $\mu \mathrm{m}$ to $5 \mathrm{~mm})$ and the instrument-calculated D10, D50 (median), and D9o values were averaged for each sample. These values represent the particle size at which 10,50, and 90 volume percent of the distribution fall under, respectively.

\subsection{Particle sample extraction}

Whole-sample extraction was required to avoid subsampling bias of specific particle sizes. Whole samples of the particle fractions that were $<2 \mathrm{~mm}$ were extracted for chemical analysis with $1: 1 \mathrm{v} / \mathrm{v}$ (volume/volume) acetonitrile/water (M. E. Walsh 2016). Extracts were manually shaken and then placed on a shaker table for 18 hours at $170 \mathrm{rpm}$. Extracts were syringe filtered at $0.45 \mu \mathrm{m}$ (Millex FH), diluted $1000 \times$ with $1: 1 \mathrm{v} / \mathrm{v}$ acetonitrile/water, and prepared for analysis. A direct aliquot of the filtered and diluted extract was used for analysis of 3-Nitro-1,2,4-Triazol-5-One (NTO). For analysis of 
2,4,-Dinitroanisole (DNAN); 1,3,5-Trinitro-1,3,5-Triazinane (RDX); 1,3,5,7Tetranitro-1,3,5,7-Tetrazoctane (HMX), and DNAN degradation products, $1.00 \mathrm{~mL}$ of filtered and diluted extract was mixed with $1.00 \mathrm{~mL}$ of Milli-Q water for an optimum acetonitrile/water ratio of 1:3 v/v.

\subsection{Chemical analysis}

Chemical analysis was conducted using HPLC following methods established in M. E. Walsh (2016). For NTO, a Hypercarb column (150 × $4.6 \mathrm{~mm}, 5 \mu \mathrm{m}$ ) was used on an Agilent 1260 Infinity II HPLC eluted with $3: 1 \mathrm{v} / \mathrm{v}$ acetonitrile/water and $0.1 \%$ trifluoroacetic acid at $1.5 \mathrm{~mL} / \mathrm{min}$ and $28^{\circ} \mathrm{C}$. NTO eluted at 1.73 minutes at $321 \mathrm{~nm}$. For DNAN, RDX, HMX, and DNAN degradation products, a Novapak column $(150 \times 3.9 \mathrm{~mm}, 4 \mu \mathrm{m})$ was used on an Agilent 1260 Infinity HPLC eluted with 15:85 v/v isopropa$\mathrm{nol} /$ water and $0.1 \%$ acetic acid at $1.2 \mathrm{~mL} / \mathrm{min}$ and $28^{\circ} \mathrm{C}$. The analytes had the following retention times and detection wavelengths: HMX (1.63 min and $230 \mathrm{~nm}$ ), 4-methoxy-3-nitroaniline (2.43 min and $230 \mathrm{~nm}$ ), RDX (3.02 min and $230 \mathrm{~nm}$ ), 4-methoxy-3-nitrophenol (3.60 min and $230 \mathrm{~nm}$ ), 2-methoxy-5-nitroaniline (4.03 $\mathrm{min}$ and $265 \mathrm{~nm}$ ), 2-methoxy-5nitrophenol and 2,4-dinitrophenol (4.5 min and $230 \mathrm{~nm}$ ), and 2,4-DNAN (7.22 min and $295 \mathrm{~nm}$ ). Concentrations were quantitated based on peak area and five-point calibrations, verified by independent calibration standards for HMX, RDX, and DNAN.

Discrete subsamples of select $<2 \mathrm{~mm}$ fractions were mounted on carbon adhesive tape, placed in a charge-reduction sample holder, and analyzed by SEM (Phenom ProX). Three samples from each size munition at different radial distances were analyzed. Qualitative elemental composition was measured by energy dispersive $\mathrm{x}$-ray spectroscopy (EDS) at $10 \mathrm{kV}$ in point mode.

\subsection{Morphological analysis}

Select $>2 \mathrm{~mm}$ samples were measured by $\mu \mathrm{CT}$ using a Bruker Skyscan. Detailed three-dimensional morphology was observed in the Bruker system software by rotating the sample reconstruction $360^{\circ}$. This imagining technique reveals the complete structure of the particle, including crystalline components, porosity, and shape. 


\section{Results and Discussion}

\subsection{Command-detonation optimization}

Prior tests with the M720A2 $60 \mathrm{~mm}$ mortar rounds used $12 \mathrm{~g}$ of $\mathrm{C}_{4}$ in the CFS to initiate high-order detonations (M. R. Walsh, Bigl, et al. 2018), but LO tests on these rounds had not been performed previously. The confirmation masses of $7 \mathrm{~g}$ and $6.8 \mathrm{~g}$ both produced, by visual inspection, $\mathrm{LO}$ detonations, characterized by yellow powder and a fully fragmented mortar body (Figure 6 and Table 2). Masses of $6.9 \mathrm{~g}$ consistently produced LO detonations (Table 2). In all $60 \mathrm{~mm}$ detonations, the tailfin was thrown intact more than $20 \mathrm{~m}$ from the detonation; but in one detonation (19DTA LO3) the tailfin and attached lower body of the round contained an in situ piece of energetic filler.

Figure 6. Low-order detonation residues from a $60 \mathrm{~mm}$ IMX-104 mortar round at DTA.

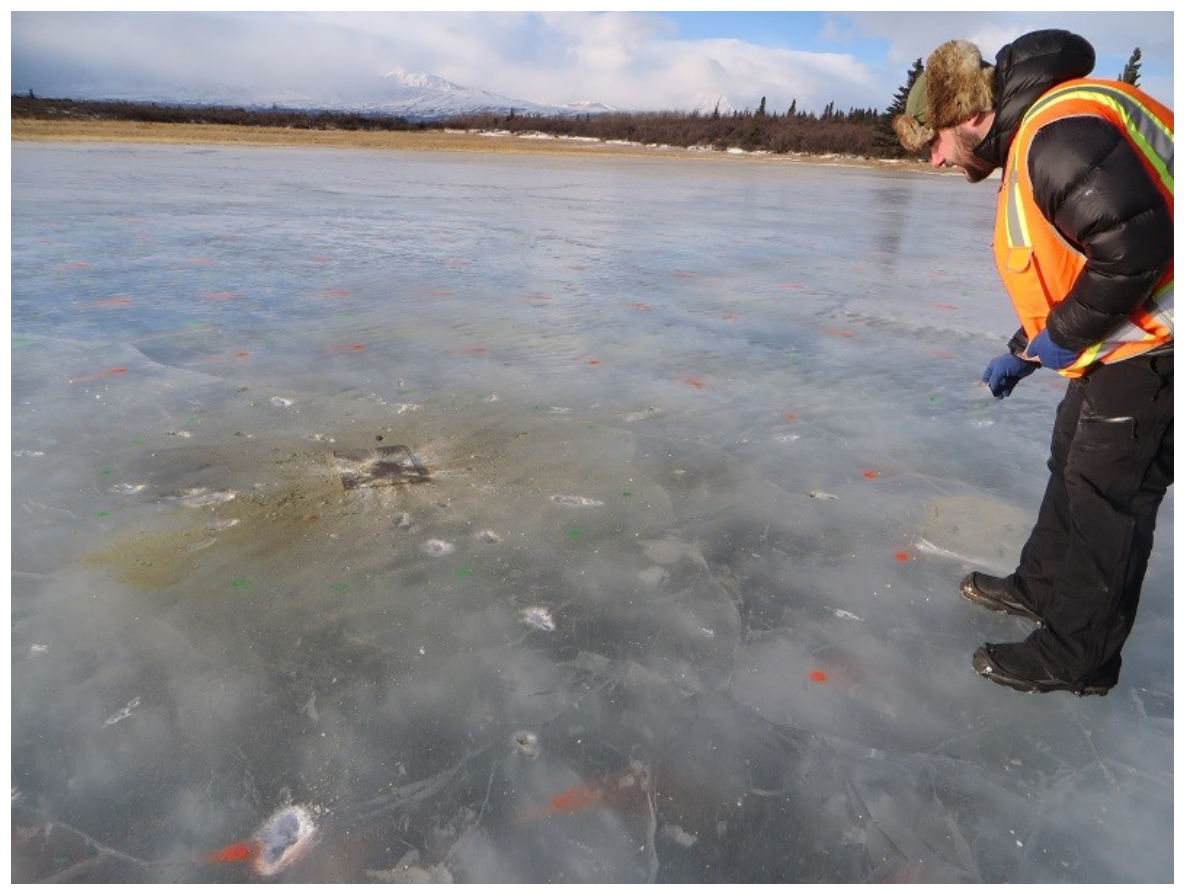


Table 2. Visual test results and C4 masses used in the CFS for $60 \mathrm{~mm}$ rounds.

\begin{tabular}{|l|l|c|c|c|c|}
\hline Round \# & Site & C4 $(\mathbf{g})$ & Visual Result & Observations & Designation \\
\hline 1 & ERF Confirmation & 7 & Low Order & Yellow powder & - \\
\hline 2 & ERF Confirmation & 6.8 & Low Order & Yellow powder & - \\
\hline 3 & DTA South Site A & 6.91 & Low Order & Yellow powder & 19DTA-LO1 \\
\hline 4 & DTA South Site A & 6.9 & Low Order & Yellow powder & 19DTA-LO2 \\
\hline 5 & DTA South Site C & 6.9 & Low Order & $\begin{array}{c}\text { Yellow powder, large } \\
\text { particle in tailfin }\end{array}$ & 19DTA-LO3 \\
\hline 6 & DTA South Site A & 6.9 & Low Order & Yellow Powder, High Wind & - \\
\hline 7 & DTA South Site C & 6.9 & Low Order & Yellow Powder, High Wind & - \\
\hline
\end{tabular}

Prior LO tests with the M821A3 81 mm IMX-104 rounds in 2015 used C4 masses between 7 and $9 \mathrm{~g}$, with mixed results from LO detonation to initiated dud. High-order detonations using these rounds used $12 \mathrm{~g}$ and $18 \mathrm{~g}$ $\mathrm{C}_{4}$ masses in the CFS (M. R. Walsh, Bigl, et al. 2018). These prior results informed the initial selection of $7.5 \mathrm{~g}$ of $\mathrm{C}_{4}$ for the 2019 tests and made confirmation tests unnecessary. The first round produced a LO detonation, but the second round with the same amount $(7.5 \mathrm{~g})$ of $\mathrm{C}_{4}$ was an initiated dud (Table 3). Subsequently, two rounds were initiated with $7.5 \mathrm{~g}$, with one LO (19FRA LO2; Figure 7) and the other a partial detonation characterized by approximately half of the round remaining intact. An increase of $0.1 \mathrm{~g}$ in $\mathrm{C}_{4}$ mass for two subsequent rounds resulted in a LO (19FRA LO3) but also a high-order detonation (Figure 8). These inconsistent results continued through the remaining tested rounds using even lower $\mathrm{C}_{4}$ masses. The inconsistency in the $81 \mathrm{~mm}$ rounds may be the result of their sourcing as excess manufacturing test rounds, whereas all $60 \mathrm{~mm}$ mortar rounds were from full production stock.

Table 3. Visual test results and C4 masses used in the CFS for $81 \mathrm{~mm}$ rounds.

\begin{tabular}{|l|l|c|c|c|c|}
\hline Round \# & Site & C4 $(\mathbf{g})$ & Visual Result & Observations & Designation \\
\hline 1 & ERF North Site & 7.5 & Low Order & Yellow powder & 19FRA-LO1 \\
\hline 2 & ERF South Site & 7.5 & Initiated Dud & Fuze blown out & - \\
\hline 3 & ERF North Site & 7.5 & Partial Detonation & Round ruptured & - \\
\hline 4 & ERF South Site & 7.5 & Low Order & Abundant yellow powder & 19FRA-LO2 \\
\hline 5 & ERF North Site & 7.6 & High Order & Black soot & - \\
\hline 6 & ERF South Site & 7.6 & Low Order & Yellow powder & 19FRA-LO3 \\
\hline 7 & DTA North Site & 7.47 & High Order & Black soot & - \\
\hline 8 & DTA South Site B & 7.31 & High Order & Black soot & - \\
\hline 9 & DTA South Site D & 7.0 & Partial Detonation & Round cracked in half & - \\
\hline 10 & DTA South Site D & 7.1 & Initiated Dud & Nose blown off & - \\
\hline
\end{tabular}


Figure 7. Low-order-detonation residues from an $81 \mathrm{~mm}$ IMX-104 round (19FRA LO2).

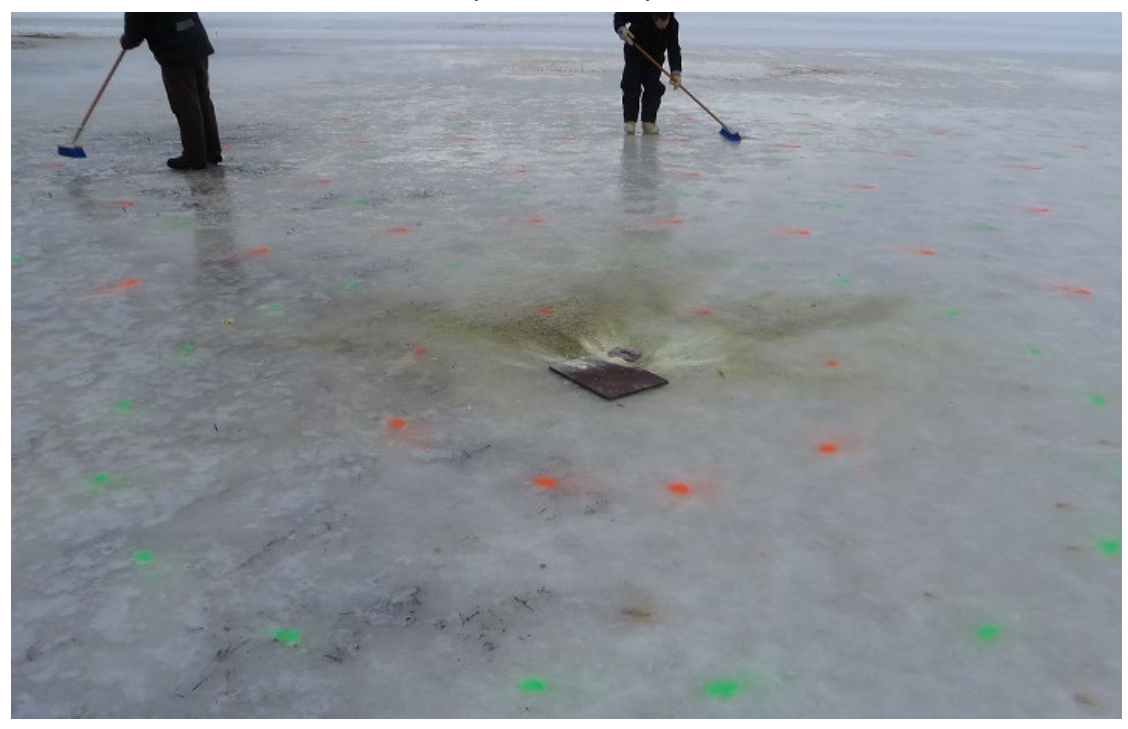

Figure 8. High-order-detonation residues from an $81 \mathrm{~mm}$ IMX-104 round.

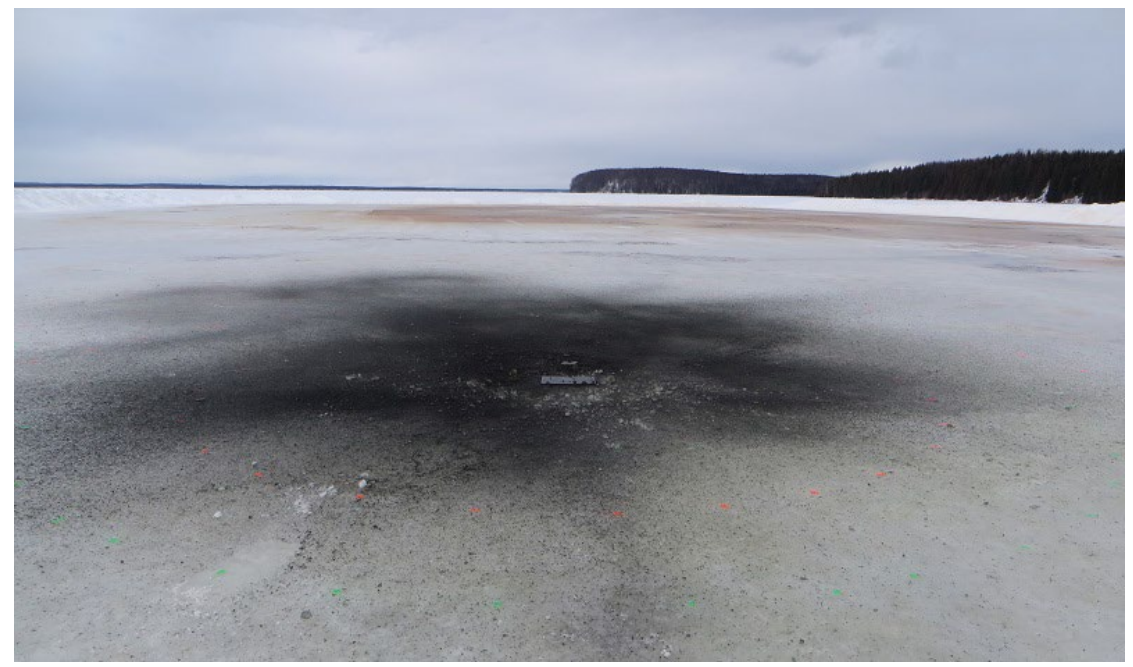

\subsection{Quality assurance / quality control}

Although complete recovery of the energetic material was desired, it was not feasible with the study design as particles could become temporarily trapped in irregularities and cracks in the ice surface. The postsample check provided an estimate of the amount of energetic mass missed while sampling. The postsample check, only collected at the DTA site after $60 \mathrm{~mm}$ samplings, contained approximately $8 \mathrm{~g}$ and $12 \mathrm{~g}$ of energetic mass for LO1 and LO3, respectively (Table 4). The postsample check verification after the postsample check of $\mathrm{LO}_{3}$ contained approximately $2.5 \mathrm{~g}$ of ener- 
getic mass, representing an approximately $80 \%$ decrease but still a significant unrecovered particle mass. The unrecovered particles quantified by these quality control samples are an order of magnitude lower than the sample masses (sections 3.4 and 3.5), which indicates that the reported sample masses serve as representative but lower-limit estimates of total distributed particle masses.

Table 4. Energetic masses from postsampling sweep quality control samples.

\begin{tabular}{|c|c|c|c|c|c|c|c|c|c|}
\hline \multirow[b]{2}{*}{ Sample } & \multicolumn{4}{|c|}{ Aqueous (mg) } & \multicolumn{4}{|c|}{ Solid (mg) } & \multirow{2}{*}{$\begin{array}{l}\text { Total } \\
(\mathrm{mg})\end{array}$} \\
\hline & HMX & RDX & DNAN & NTO & HMX & RDX & DNAN & NTO & \\
\hline $\begin{array}{c}\text { 19DTA LO1 } \\
\text { Postsample Check }\end{array}$ & 28.5 & 168 & 760 & 4870 & 67.1 & 377 & 1414 & 78.6 & 7760 \\
\hline $\begin{array}{c}\text { 19DTA LO3 } \\
\text { Postsample Check }\end{array}$ & 15.0 & 74.4 & 392 & 5770 & 188 & 1168 & 4219 & 311 & 12100 \\
\hline $\begin{array}{c}\text { 19DTA L03 Postsample } \\
\text { Check Verification }\end{array}$ & 3.3 & 22.3 & 101 & 373 & 47.2 & 495 & 1020 & 518 & 2580 \\
\hline
\end{tabular}

\subsection{Sample extraction optimization}

M. E. Walsh (2016) demonstrated the extraction procedure for IMX-104 residues for samples with relatively low concentrations of IMX-104 compounds. To ensure complete energetic dissolution of these high-concentration and high-mass residues, the current study used subsamples of an older IMX-104 LO detonation sample (15FRA LO2 3-4 m) to test the effects of differing residue/solvent ratios (Figure 9). While NTO tended to have complete recovery at all tested residue/solvent ratios (up to $100 \mathrm{~g} / \mathrm{L}$ ), the other compounds demonstrated a ratio-dependent solubility at and above approximately $12 \mathrm{~g}$ of residue per liter of $1: 1$ (v/v) acetonitrile/water. Overall, DNAN, HMX, and RDX recoveries were low, about $60 \%-$ $80 \%$, regardless of the residue/solvent ratio. To test whether the water was limiting solubility of these relatively hydrophobic compounds, a $100 \%$ acetonitrile extraction was conducted on subsamples, also at varying residue/solvent ratios. Concentrations of the hydrophobic compounds were equivalent at $7 \mathrm{~g} / \mathrm{L}$ with $1: 1$ acetonitrile/water to the acetonitrile extractions at all ratios, indicating the presence of water was not limiting dissolution at and below $7 \mathrm{~g} / \mathrm{L}$ with 1:1 acetonitrile. This finding indicates that the $7 \mathrm{~g} / \mathrm{L}$ with $1: 1$ acetonitrile/water completely dissolves the IMX-104 particles; and it suggests that the low recoveries of DNAN, RDX, and HMX are due to preferential consumption during LO detonation. In IMX-104, NTO is present as relatively large (about $300 \mu \mathrm{m}$ ) crystals added to molten 
DNAN, along with relatively smaller crystals of RDX (about $4 \mu \mathrm{m}$ ) (Dontsova et al. 2014). NTO is the predominant residual component in high-order detonations of IMX-104 (M. R. Walsh, Bigl, et al. 2018). The above investigation suggested a solution of $7 \mathrm{~g} / \mathrm{L}$ was appropriate for extraction of particles recovered for this study.

Figure 9. Formulation-normalized compound concentrations following 18-hour extractions of discrete subsamples of 15FRA LO2

3-4 $\mathrm{m}$ at differing residue/solvent ratios and solvent types.

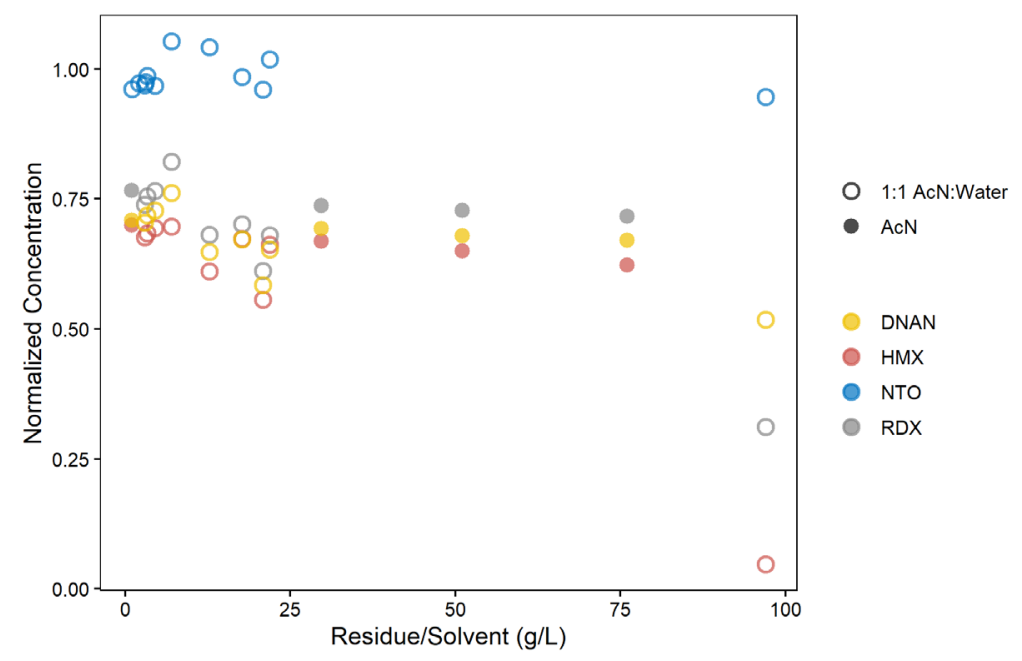

\section{$3.460 \mathrm{~mm} \mathrm{IMX-104}$}

\subsubsection{Particle-mass distribution}

Table 5 and Appendix B show the particle masses in each sampling annulus. With an initial predetonation energetic mass of $338 \mathrm{~g}$, the total particle masses represent estimated consumption efficiencies of $57 \%, 72 \%$, and $50 \%$ for $\mathrm{LO}_{1}, \mathrm{LO} 2$, and $\mathrm{LO}_{3}$, respectively. For all detonations, the $<2 \mathrm{~mm}$ fraction tends to dominate the total particle size for all sampled annuli. The large masses greater than $20 \mathrm{~m}$ for $\mathrm{LO}_{1}$ and $\mathrm{LO}_{3}$ are predominantly for single large particles contained in situ in the base of the round near the tailfin (Appendix C).

For both $\mathrm{LO}_{2}$ and $\mathrm{LO}_{3}$, more than $20 \%$ of the total mass deposited was within $1 \mathrm{~m}$ and approximately $47 \%$ of the total deposition within $5 \mathrm{~m}$ from the point of detonation. All three detonations also had the highest per-meter depositional percentages within $5 \mathrm{~m}$ from the point of detonation, even when accounting for large particles from the tailfins. Although a large amount of material was deposited within the first $5 \mathrm{~m}$ from the point of 
detonation, significant amounts were also transported to the furthest annuli measured. All three detonations had high masses (greater than $10 \mathrm{~g}$ ) recorded in the 10-15 and 15-20 m annuli. When these values are corrected from 5 radial meter values to 1 radial meter values to become comparable to the rest of the annuli $(\mathrm{o}-10 \mathrm{~m})$, there is an average deposition of 2.6-6.3 g per radial meter with the highest per meter deposition resulting from LO1. These outer annuli account for $37 \%, 37 \%$, and $19.5 \%$ of the total deposition for $\mathrm{LO} 1, \mathrm{LO} 2$, and $\mathrm{LO}_{3}$ respectively.

Table 5. The $2 \mathrm{~mm}$ sieve masses and mass proportions for 19DTA $60 \mathrm{~mm}$ samples.

\begin{tabular}{|c|c|c|c|c|c|c|c|c|c|}
\hline \multirow{2}{*}{$\begin{array}{c}\text { Distance } \\
(\mathbf{m})\end{array}$} & \multicolumn{3}{|c|}{ 19DTA LO1 } & \multicolumn{3}{c|}{ 19DTA LO2 } & \multicolumn{3}{|c|}{ 19DTA L03 } \\
\cline { 2 - 10 } & $\begin{array}{c}<\mathbf{m m} \\
(\%)\end{array}$ & $\begin{array}{c}\text { Total } \\
(\mathbf{g})\end{array}$ & $\begin{array}{c}<\mathbf{2} \mathbf{~ m m} \\
(\%)\end{array}$ & $\begin{array}{c}\mathbf{2} \mathbf{m m} \\
(\%)\end{array}$ & $\begin{array}{c}\text { Total } \\
(\mathbf{g})\end{array}$ & $\begin{array}{c}<2 \mathbf{m m} \\
(\%)\end{array}$ & $\begin{array}{c}\mathbf{2} \mathbf{m m} \\
(\%)\end{array}$ & $\begin{array}{c}\text { Total } \\
(\mathbf{g})\end{array}$ \\
\hline $0-1$ & 78.7 & 21.3 & 9.27 & 90.5 & 9.5 & 19.58 & 82.2 & 17.8 & 41.66 \\
\hline $1-2$ & 63.8 & 36.2 & 5.42 & 82.8 & 17.2 & 3.88 & 44.9 & 55.1 & 7.93 \\
\hline $2-3$ & 89.3 & 10.7 & 12.11 & 77.7 & 22.3 & 4.59 & 53.2 & 46.8 & 7.17 \\
\hline $3-4$ & 90.7 & 9.3 & 13.13 & 83.1 & 16.9 & 10.40 & 87.8 & 12.2 & 17.29 \\
\hline $4-5$ & 95.5 & 4.5 & 10.32 & 85.1 & 14.9 & 6.33 & 62.8 & 37.2 & 6.14 \\
\hline $5-6$ & 92.7 & 7.3 & 5.80 & 73.2 & 26.8 & 2.76 & 82.1 & 17.9 & 8.89 \\
\hline $6-7$ & 88.0 & 12.0 & 7.45 & 67.0 & 33.0 & 3.75 & 54.9 & 45.1 & 7.45 \\
\hline $7-8$ & 82.0 & 18.0 & 6.06 & 74.1 & 25.9 & 3.50 & 45.6 & 54.4 & 4.21 \\
\hline $8-9$ & 73.1 & 26.9 & 4.68 & 74.1 & 25.9 & 2.69 & 70.4 & 29.6 & 5.91 \\
\hline $9-10$ & 64.5 & 35.5 & 2.45 & 61.5 & 38.5 & 1.40 & 36.6 & 63.4 & 1.39 \\
\hline $10-15$ & 85.0 & 15.0 & 23.07 & 85.1 & 14.9 & 13.18 & 70.3 & 29.7 & 15.55 \\
\hline $15-20$ & 91.6 & 8.4 & 31.70 & 45.6 & 54.4 & 21.51 & 90.7 & 9.3 & 17.60 \\
\hline$>20$ & - & 100 & 15.04 & - & - & - & - & 100 & 28.31 \\
\hline Total & 77.7 & 22.3 & 146.50 & 74.3 & 25.7 & 93.55 & 62.3 & 37.7 & 169.50 \\
\hline
\end{tabular}

\subsubsection{Particle-size distribution}

Figure 10 shows the particle-size distribution (PSD) data for each detonation and sampling annulus. For all three detonations, there were pronounced fine particle peaks in the 10-15 and 15-20 m annuli. For LO2 and $\mathrm{LO}_{3}$, there were fine shoulder peaks of varying size for the $0-10 \mathrm{~m}$ annuli. LO1 had several strongly bimodal PSDs for the annuli 5-10 m, and the 8-10 $\mathrm{m}$ annuli for $\mathrm{LO}_{3}$ had a very broad distribution. The PSDs in Figure 10 and Appendix D showed LO1 and $\mathrm{LO}_{3}$ to have similar spatial trends, with relatively coarse particles close to the detonation site, and then became bimodal in the annuli closer to $10 \mathrm{~m}$ from the point of detonation. Beyond $10 \mathrm{~m}$, the PSDs then switched to singular peaks of relatively finer particles overall. The PSD plots for $\mathrm{LO} 2$ showed a different trend. The particles examined closer to the point of detonation tended to 
be bimodal with both fine and coarse peaks. Moving away from the point of detonation to $10 \mathrm{~m}$, the PSD shape went from bimodal to a single coarse peak and then singular fine peaks for the 10-15 and 15-20 $\mathrm{m}$ annuli.

Figure 10. Particle-size distributions from $60 \mathrm{~mm}$ IMX-104 detonations at Donnelly Training Area. Select annuli needed to be combined to have the mass necessary to process by LD-PSA.
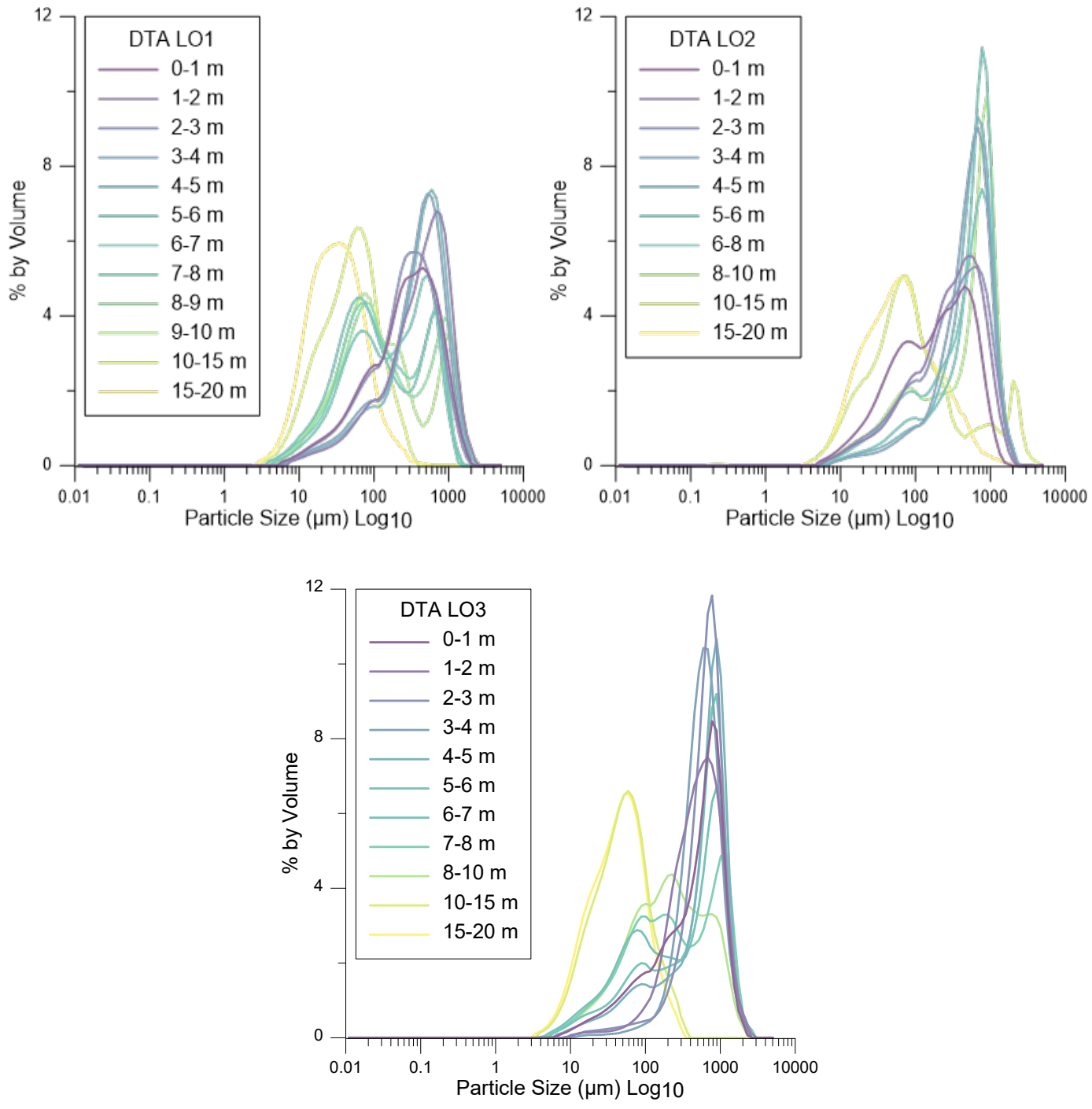

The particle-size measurements D10, D50, and D90 (i.e., diameters at which $10 \%, 50 \%$, and $90 \%$ of particle volumes are smaller) provide an alternate method of examining changes in PSD with distance (Tables 6-8). As Table 6 shows, the highest values are observed in the first $5 \mathrm{~m}$ from the point of detonation for LO1. This indicates that the material $<2 \mathrm{~mm}$ became finer the farther from the point of detonation. However, it is important to note that for D90, the standard deviation (SD) for several annuli past $5 \mathrm{~m}$ were the same order of magnitude as the average D9o value. 
Tables 7 and 8 do not show a similar reduction in particle size beyond the first $5 \mathrm{~m}$ from the point of detonation for $\mathrm{LO}_{2}$ and $\mathrm{LO}_{3}$. The $\mathrm{D}_{50}$ and D9o values for $\mathrm{LO}_{2}$ and $\mathrm{LO}_{3}$ stayed steady or increased slightly from the point of detonation to $10 \mathrm{~m}$. Beyond $10 \mathrm{~m}$, there was a reduction in particle sizes across D10, D50, and D90 for all three detonations. The only exception to this trend was the D10 measurement for $10-15 \mathrm{~m}$ for $\mathrm{LO} 2$.

Table 6. Particle-size metrics for the 19DTA L01 $<2 \mathrm{~mm}$ fraction averaged for multiple analyses by LD-PSA.

\begin{tabular}{|c|c|c|c|}
\hline $\begin{array}{c}\text { Distance } \\
(\mathrm{m})\end{array}$ & $\begin{array}{c}\mathrm{D} 10 \\
(\boldsymbol{\mu m})\end{array}$ & $\begin{array}{c}\text { D50 } \\
(\boldsymbol{\mu m})\end{array}$ & $\begin{array}{c}\text { D90 } \\
(\boldsymbol{\mu m})\end{array}$ \\
\hline $0-1$ & 43 & 260 & 780 \\
\hline $1-2$ & 72 & 420 & 990 \\
\hline $2-3$ & 46 & 260 & 730 \\
\hline $3-4$ & 57 & 370 & 850 \\
\hline $4-5$ & 70 & 410 & 900 \\
\hline $5-6$ & 28 & 160 & 630 \\
\hline $6-7$ & 21 & 100 & 600 \\
\hline $7-8$ & 24 & 110 & 680 \\
\hline $8-9$ & 28 & 180 & 800 \\
\hline $9-10$ & 25 & 190 & 690 \\
\hline $10-15$ & 13 & 46 & 130 \\
\hline $15-20$ & 10 & 30 & 88 \\
\hline
\end{tabular}

Table 7. Particle-size metrics for the 19DTA LO2 $<2 \mathrm{~mm}$ fraction averaged for multiple analyses by LD-PSA.

\begin{tabular}{|c|c|c|c|}
\hline $\begin{array}{c}\text { Distance } \\
(\mathrm{m})\end{array}$ & $\begin{array}{c}\mathrm{D} 10 \\
(\boldsymbol{\mu m})\end{array}$ & $\begin{array}{c}\text { D50 } \\
(\boldsymbol{\mu m})\end{array}$ & $\begin{array}{c}\text { D90 } \\
(\boldsymbol{\mu m})\end{array}$ \\
\hline $0-1$ & 30 & 180 & 610 \\
\hline $1-2$ & 47 & 290 & 820 \\
\hline $2-3$ & 42 & 310 & 910 \\
\hline $3-4$ & 130 & 490 & 960 \\
\hline $4-5$ & 100 & 530 & 1020 \\
\hline $5-6$ & 47 & 440 & 1010 \\
\hline $6-8$ & 95 & 560 & 1020 \\
\hline $8-10$ & 44 & 520 & 1020 \\
\hline $10-15$ & 49 & 260 & 680 \\
\hline $15-20$ & 16 & 68 & 280 \\
\hline
\end{tabular}


Table 8. Particle-size metrics for the 19DTA LO3 $<2 \mathrm{~mm}$ fraction averaged for multiple analyses by LD-PSA.

\begin{tabular}{|c|c|c|c|}
\hline $\begin{array}{c}\text { Distance } \\
(\mathrm{m})\end{array}$ & $\begin{array}{c}\mathrm{D} 10 \\
(\mu \mathrm{m})\end{array}$ & $\begin{array}{c}\text { D50 } \\
(\mu \mathrm{m})\end{array}$ & $\begin{array}{c}\text { D90 } \\
(\mu \mathrm{m})\end{array}$ \\
\hline $0-1$ & 93 & 470 & 970 \\
\hline $1-2$ & 160 & 480 & 1050 \\
\hline $2-3$ & 240 & 610 & 1090 \\
\hline $3-4$ & 250 & 530 & 980 \\
\hline $4-5$ & 87 & 620 & 1110 \\
\hline $5-6$ & 120 & 550 & 1080 \\
\hline $6-7$ & 32 & 360 & 1010 \\
\hline $7-8$ & 34 & 240 & 1110 \\
\hline $8-10$ & 41 & 260 & 870 \\
\hline $10-15$ & 13 & 46 & 130 \\
\hline $15-20$ & 12 & 41 & 110 \\
\hline
\end{tabular}

\subsubsection{Particle composition}

Though the size of the $>\mathbf{2} \mathrm{mm}$ fraction makes sorting samples for energetic versus nonenergetic particles relatively simple, nonenergetic particles cannot be easily removed from the $<2 \mathrm{~mm}$ fraction. Total extraction of select whole samples and analysis for the IMX-104 constituent compounds DNAN, RDX, HMX, and NTO provide quantitative measures of sample energetic purity. As sample losses were observed during LD-PSA, and with some material collected directly into the vacuum container and other finer material caught in the vacuum filter, the composition of both recovered fractions were of interest.

Figure 11 shows the composition of samples and the associated fine material as normalized to the composition of IMX-104. All the 19DTA samples contained less than $100 \%$ of each constituent compound, indicating the incorporation of nonenergetic material either from the site, the munition, or the detonation system. For all detonations, NTO was enriched in the samples close to the point of detonation relative to the other compounds present in the formulation. NTO is the predominant residual compound from high-order detonations (M. R. Walsh, Bigl, et al. 2018) and may similarly dominate LO residues. Overall, the fine material was enriched in HMX, $\mathrm{RDX}$, and DNAN relative to NTO. This trend may reflect the IMX-104 manufacturing process that uses DNAN as the molten matrix and relatively small crystals of RDX and HMX compared with NTO (Dontsova et al. 2014). 
The energetic purity of $<2 \mathrm{~mm}$ 19DTA samples ranged from $86 \%$ to as low as 11\% (Appendix E). Energetic purity tended to decrease with increasing distancing from the point of detonation (Figure 12). This relationship between distance and purity was used to correct particle-mass distributions. Linear regression of the pooled data from all three detonations was significant ( $p<0.0001)$ with a slope (purity/median distance) of -0.037 ( \pm 0.006$)$ and a y-intercept of $0.85( \pm 0.05)$.

Figure 11. Formulation-normalized compound concentrations in whole-sample extractions from $60 \mathrm{~mm}$ IMX-104 detonations. Concentrations are from both the material recovered in the vacuum container of the LD-PSA postanalysis (Sample) and material from shaking the

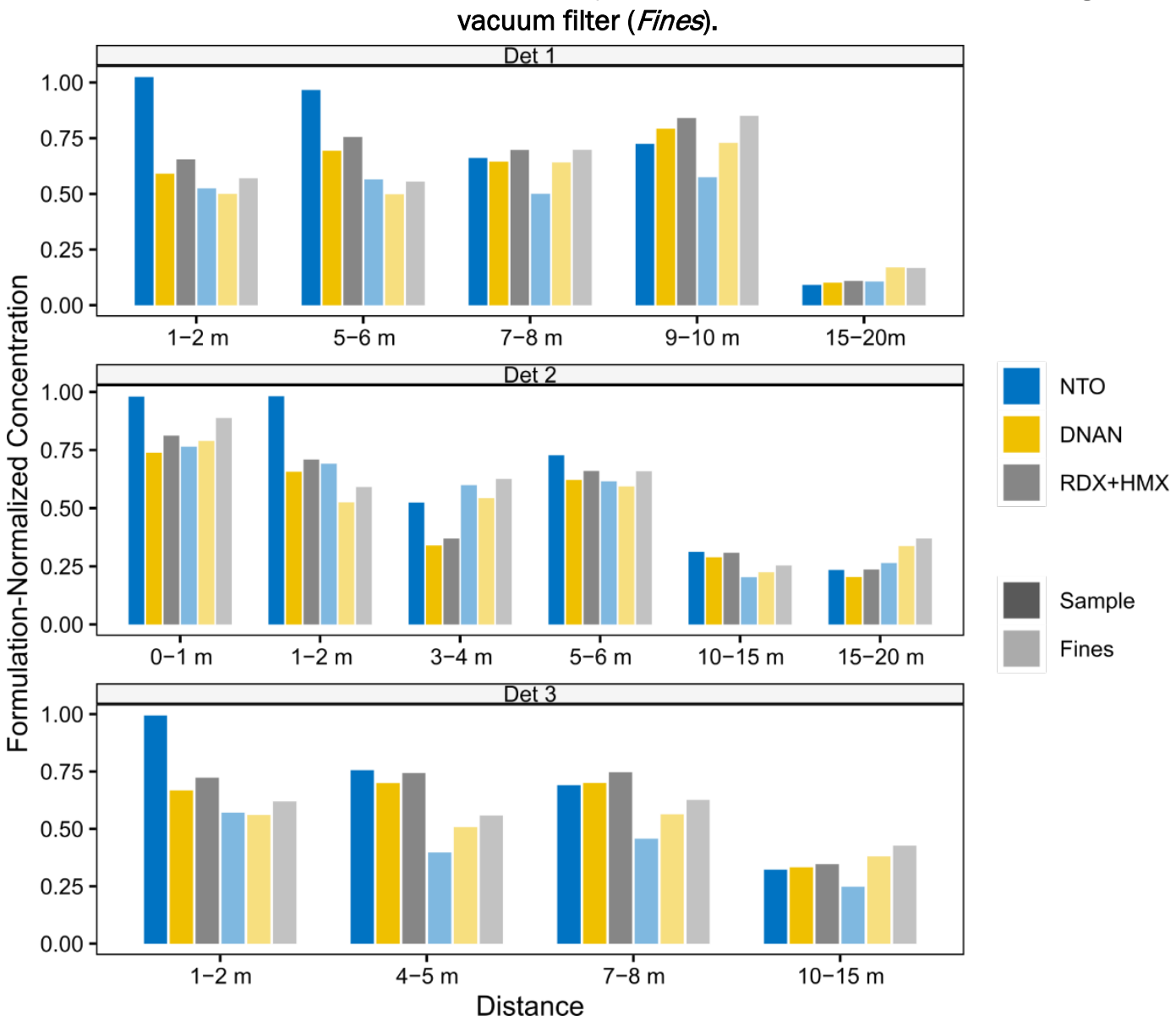


Figure 12. Total energetic compound purity of recovered particles from $60 \mathrm{~mm}$ IMX-104 rounds as a function of distance. Energetic composition is the mass-weighted average of sample and fines composition.

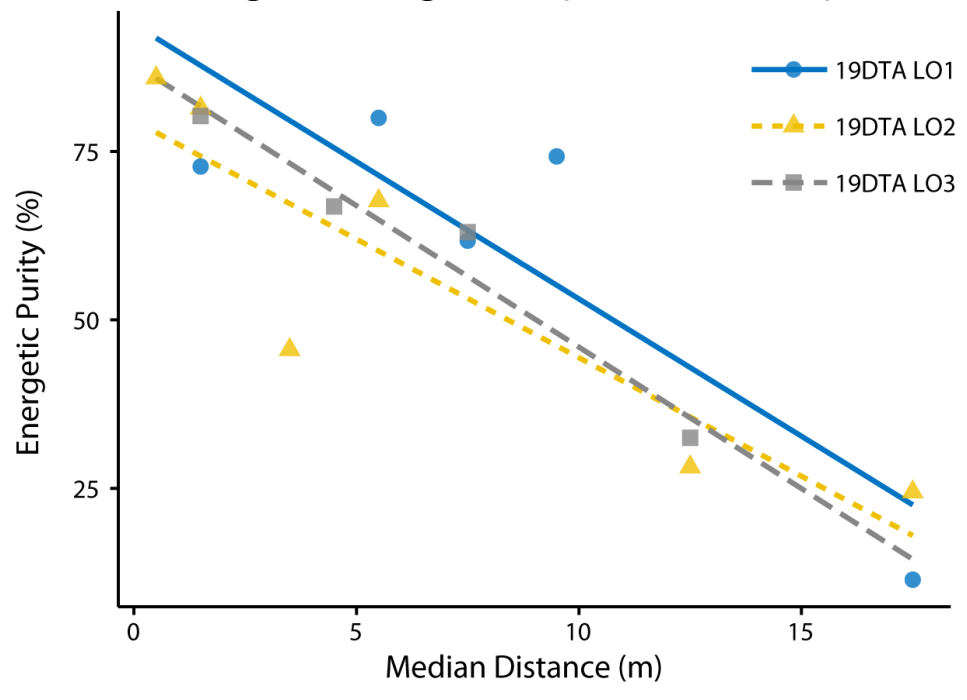

Table 9 shows the energetic-purity-corrected $<2 \mathrm{~mm}$ fractions in the corrected mass distributions. The $<2 \mathrm{~mm}$ fraction still dominates particularly close to the center of detonation, but the correction brings the $<2 \mathrm{~mm}$ masses in rough equivalency with $>2 \mathrm{~mm}$ masses overall. Estimated consumption efficiencies using these corrected figures are significantly higher at $73 \%, 80 \%$, and $62 \%$ for $\mathrm{LO}_{1}, \mathrm{LO}_{2}$, and $\mathrm{LO}_{3}$, respectively.

Table 9. Energetic-purity-corrected $2 \mathrm{~mm}$ sieve masses and mass proportions for 19DTA $60 \mathrm{~mm}$ samples.

\begin{tabular}{|c|c|c|c|c|c|c|c|c|c|}
\hline \multirow[b]{2}{*}{$\begin{array}{l}\text { Distance } \\
(\mathrm{m})\end{array}$} & \multicolumn{3}{|c|}{ 19DTA LO1 } & \multicolumn{3}{|c|}{ 19DTA LO2 } & \multicolumn{3}{|c|}{ 19DTA LO3 } \\
\hline & $\begin{array}{c}<2 \mathrm{~mm} \\
(\%)\end{array}$ & $\begin{array}{c}>2 \mathrm{~mm} \\
(\%)\end{array}$ & $\begin{array}{l}\text { Total } \\
\text { (g) }\end{array}$ & $\begin{array}{c}<2 \mathrm{~mm} \\
(\%)\end{array}$ & $\begin{array}{c}>2 \mathrm{~mm} \\
(\%)\end{array}$ & $\begin{array}{l}\text { Total } \\
\text { (g) }\end{array}$ & $\begin{array}{c}<2 \mathrm{~mm} \\
(\%)\end{array}$ & $\begin{array}{c}>2 \mathrm{~mm} \\
(\%)\end{array}$ & $\begin{array}{l}\text { Total } \\
\text { (g) }\end{array}$ \\
\hline $0-1$ & 75 & 25 & 8.0 & 89 & 11 & 17 & 79 & 21 & 36 \\
\hline $1-2$ & 58 & 42 & 4.7 & 79 & 21 & 3.2 & 39 & 61 & 7.2 \\
\hline $2-3$ & 86 & 14 & 9.5 & 73 & 27 & 3.7 & 46 & 54 & 6.2 \\
\hline $3-4$ & 87 & 13 & 9.8 & 78 & 22 & 8.0 & 84 & 16 & 13.0 \\
\hline $4-5$ & 94 & 6.4 & 7.2 & 80 & 20 & 4.6 & 54 & 46 & 4.9 \\
\hline $5-6$ & 89 & 11 & 3.9 & 64 & 36 & 2.0 & 75 & 25 & 6.3 \\
\hline $6-7$ & 82 & 18 & 4.9 & 55 & 45 & 2.8 & 43 & 57 & 5.9 \\
\hline $7-8$ & 72 & 28 & 3.9 & 62 & 38 & 2.4 & 32 & 68 & 3.4 \\
\hline $8-9$ & 59 & 41 & 3.1 & 60 & 40 & 1.8 & 56 & 44 & 4.0 \\
\hline $9-10$ & 48 & 52 & 1.7 & 44 & 56 & 1.0 & 22 & 78 & 1.1 \\
\hline $10-15$ & 69 & 31 & 11 & 69 & 31 & 6.3 & 48 & 52 & 8.9 \\
\hline $15-20$ & 69 & 31 & 8.6 & 14 & 86 & 14 & 66 & 34 & 5.0 \\
\hline$>20$ & - & 100 & 15.04 & - & - & - & - & 100 & 28.31 \\
\hline Total & 64 & 36 & 91.4 & 64 & 36 & 66 & 51 & 49 & 130 \\
\hline
\end{tabular}




\subsubsection{Particle morphology}

Figures 13 through 16 show SEM images of particles from 19DTA samples. Particles from the closest interval (Figure 13) show relatively large (approximately $100 \mu \mathrm{m}$ ) particles, some with flat-sided and angular surfaces and others with more irregular and rounded surfaces. Point EDS measurements of the flat particles commonly revealed elemental composition in the weight percent order of $\mathrm{N}>\mathrm{O}>\mathrm{C}$, ${ }^{*}$ which is characteristic of the composition of NTO. The irregular particles tended to have $\mathrm{C}>\mathrm{N}>\mathrm{O}$, which is characteristic of the composition of DNAN, although some irregular particles exhibited increased-N deviations that are potentially the result of intermingled RDX.

Figure 13. SEM image from 19DTA L01 0-1 $\mathrm{m}$.

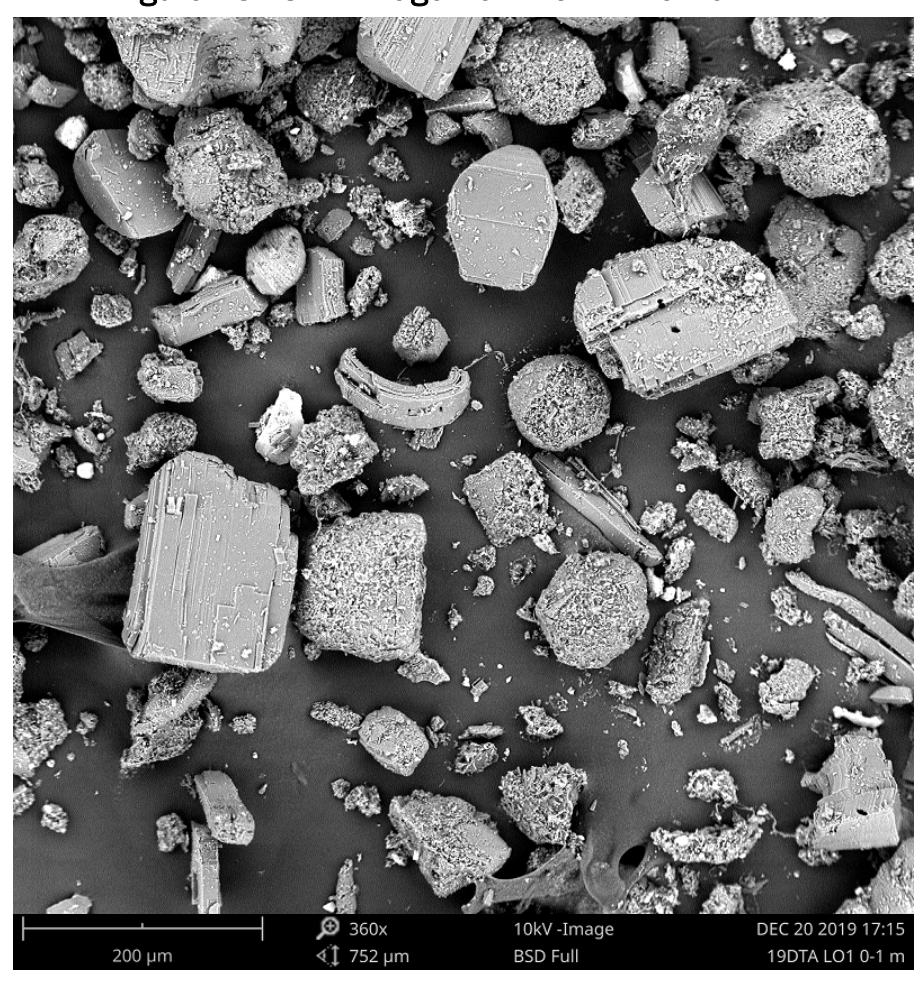

Figure 14 shows one flat-sided particle with visible linear erosions indicative of potential particle breakdown. Images from the 4-5 $\mathrm{m}$ (Figure 15) and 15-20 $\mathrm{m}$ (Figure 16) samples show the incorporation of brighter (more conductive) material that likely accounts for the low energetic purity of these samples. No nitrogenous particles were identified in the 15-

\footnotetext{
* For a full list of the spelled-out forms of the chemical elements used in this document, please refer to U.S. Government Publishing Office Style Manual, 31st ed. (Washington, DC: U.S Government Publishing Office, 2016), 265, https://www.govinfo.gov/content/pkg/GPO-STYLEMANUAL-2016/pdf/GPO-STYLEMANUAL2016.pdf.
} 
$20 \mathrm{~m}$ sample. EDS measurements of the 15-20 m particles reveal mostly $\mathrm{Ca}, \mathrm{C}, \mathrm{O}, \mathrm{Si}, \mathrm{Mg}$, and minor Fe.

Figure 14. SEM image from 19DTA LO1 4-5 m.

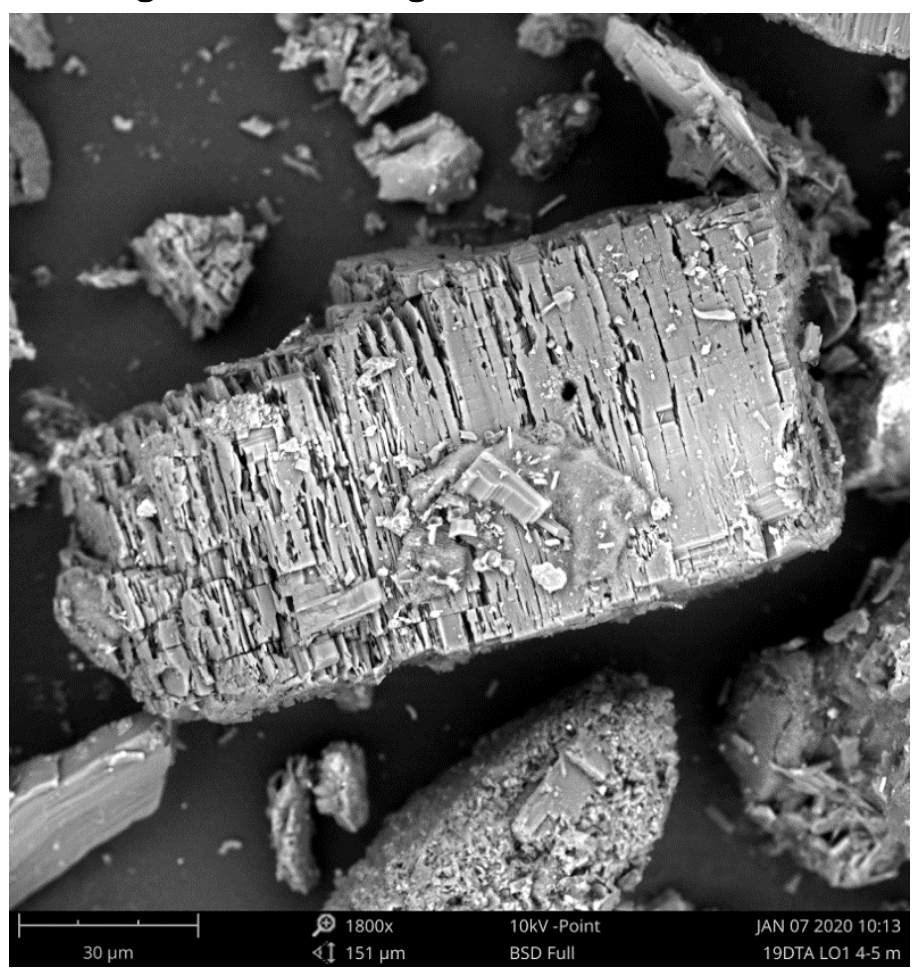

Figure 15. SEM image from 19DTA L01 4-5 m.

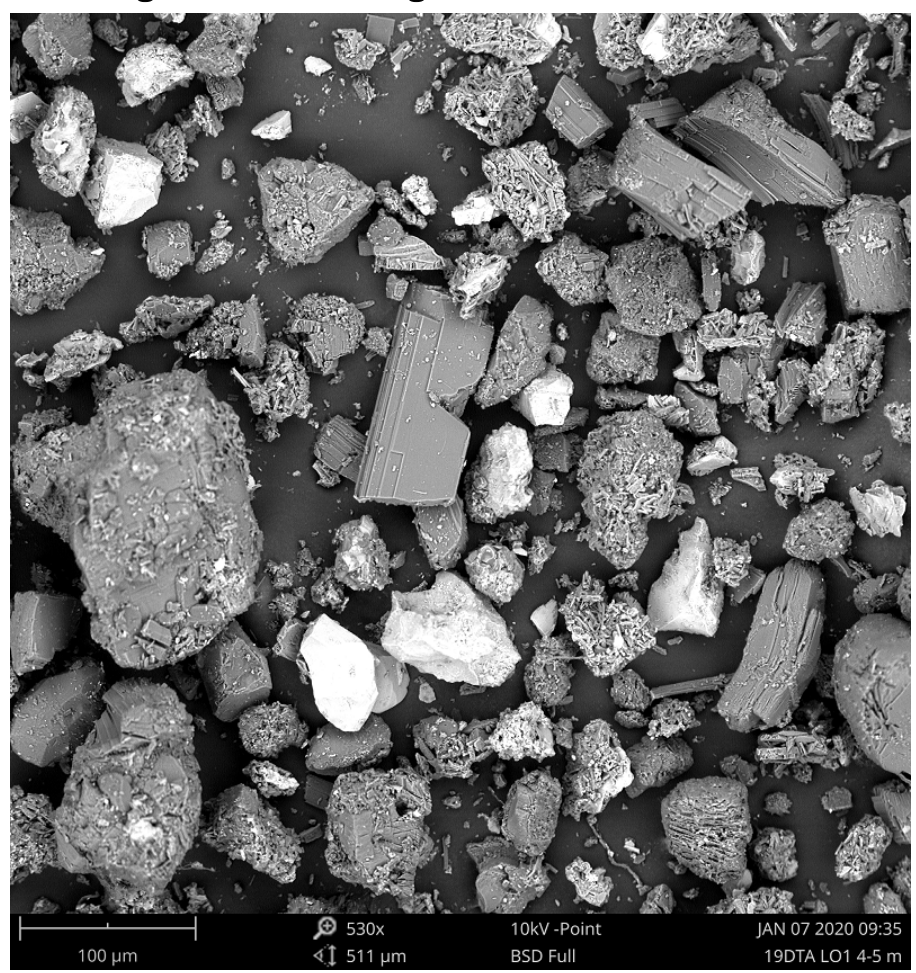


Figure 16. SEM image from 19DTA L03 15-20 m.

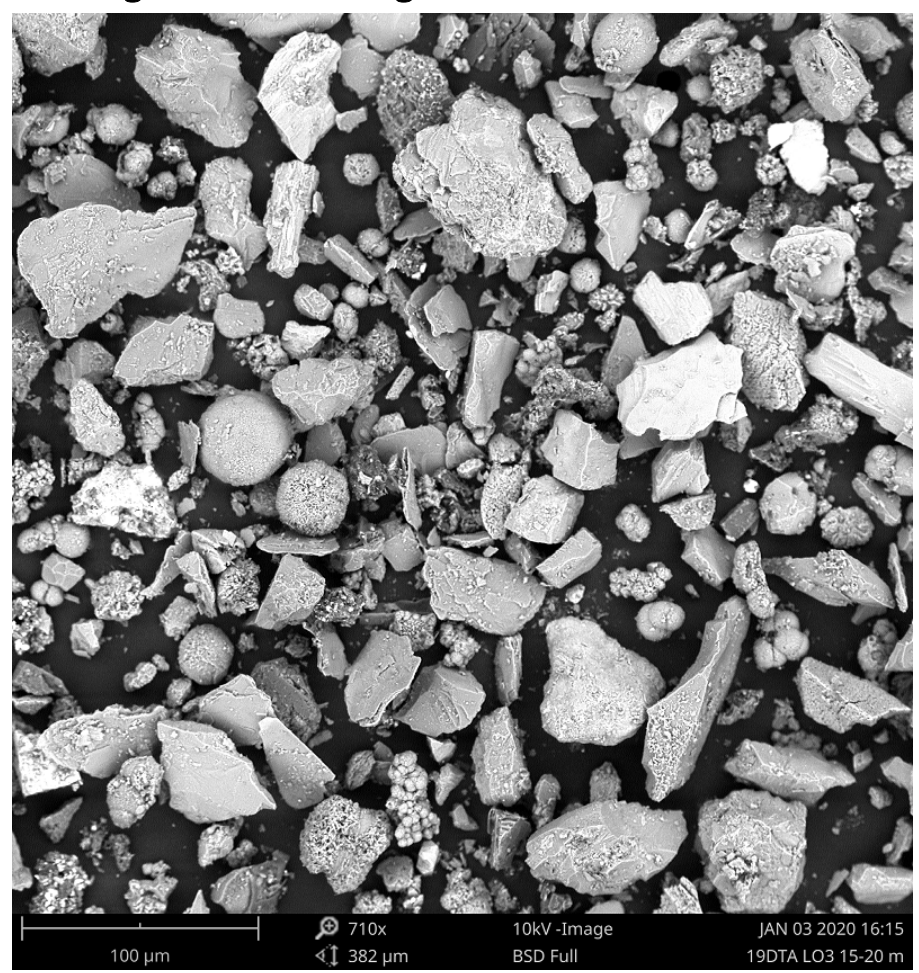

\section{$3.581 \mathrm{~mm}$ IMX-104}

\subsubsection{Particle-mass distribution}

Table 10 shows the particle masses in each sampling annulus. With an initial predetonation energetic mass of $807 \mathrm{~g}$, the total particle masses represent estimated consumption efficiencies of $61 \%, 37 \%$, and $49 \%$ for LO1, $\mathrm{LO}_{2}$, and $\mathrm{LO}_{3}$, respectively. The $<2 \mathrm{~mm}$ fraction represented the majority of particle mass for LO1, whereas the $>2 \mathrm{~mm}$ fraction dominated the mass for $\mathrm{LO}_{2}$ and $\mathrm{LO}_{3}$. For all detonations, though, the $\mathrm{o}-1 \mathrm{~m}$ annulus contained a majority of $<2 \mathrm{~mm}$ particles. This annulus represented an outsized proportion of the total mass for $\mathrm{LO}_{1}$ and $\mathrm{LO}_{2}$, but the mass for $\mathrm{LO}_{3}$ was distributed relatively evenly across all of the annuli. The mass proportion $<2 \mathrm{~mm}$ tended to decrease with increasing distance for $\mathrm{LO}_{2}$ and $\mathrm{LO}_{3}$ but remained relatively consistent for LO1. All three detonations had deposition of more than $10 \mathrm{~g}$ of material in the 10-15 and 15-20 m annuli. This is a similar trend to what was observed with the $60 \mathrm{~mm}$ mortar rounds. However, when these values are corrected from 5 radial meter values to 1 radial meter values to become comparable to the rest of the annuli $(0-10 \mathrm{~m})$ there is an average deposition of only $2.5-13.9 \mathrm{~g}$ per radial meter. Most of these annuli have radial meter deposition values less than $6 \mathrm{~g}$, only 19FRA LO2 10-15 $\mathrm{m}$ having a value of $13.9 \mathrm{~g}$. These annuli account 
for $10 \%, 16 \%$, and $10 \%$ of total deposition for $\mathrm{LO}_{1}, \mathrm{LO} 2$, and $\mathrm{LO} 3$, respectively. Even though these rounds had higher total deposition when compared to the $60 \mathrm{~mm}$ rounds, particles from the $81 \mathrm{~mm}$ were relatively more concentrated in the inner $10 \mathrm{~m}$ annuli.

Table 10. The $2 \mathrm{~mm}$ sieve masses and mass proportions for 19FRA $81 \mathrm{~mm}$ samples.

\begin{tabular}{|c|c|c|c|c|c|c|c|c|c|}
\hline \multirow[b]{2}{*}{$\begin{array}{l}\text { Distance } \\
(\mathrm{m})\end{array}$} & \multicolumn{3}{|c|}{ 19FRA L01 } & \multicolumn{3}{|c|}{ 19FRA LO2 } & \multicolumn{3}{|c|}{ 19FRA LO3 } \\
\hline & $\begin{array}{c}<2 \\
\mathrm{~mm} \\
(\%)\end{array}$ & $\begin{array}{c}>2 \\
\mathrm{~mm} \\
(\%)\end{array}$ & $\begin{array}{c}\text { Total } \\
\text { (g) }\end{array}$ & $\begin{array}{c}<2 \mathrm{~mm} \\
(\%)\end{array}$ & $\begin{array}{c}>2 \mathrm{~mm} \\
(\%)\end{array}$ & $\begin{array}{c}\text { Total } \\
\text { (g) }\end{array}$ & $\begin{array}{c}<2 \mathrm{~mm} \\
(\%)\end{array}$ & $\begin{array}{c}>2 \mathrm{~mm} \\
(\%)\end{array}$ & $\begin{array}{c}\text { Total } \\
\text { (g) }\end{array}$ \\
\hline $0-1$ & 77.5 & 22.5 & 132.96 & 53.5 & 46.5 & 150.91 & 72.1 & 27.9 & 31.09 \\
\hline $1-2$ & 65.8 & 34.2 & 28.45 & 28.7 & 71.3 & 40.70 & 34.3 & 65.7 & 39.31 \\
\hline $2-3$ & 61.3 & 38.7 & 25.76 & 20.0 & 80.0 & 56.37 & 33.3 & 66.7 & 42.05 \\
\hline $3-4$ & 79.5 & 20.5 & 27.86 & 39.2 & 60.8 & 28.62 & 35.3 & 64.7 & 38.82 \\
\hline $4-5$ & 71.5 & 28.5 & 18.20 & 25.9 & 74.1 & 24.63 & 22.2 & 77.8 & 42.57 \\
\hline $5-6$ & 68.0 & 32.0 & 13.79 & 28.3 & 71.7 & 26.33 & 17.6 & 82.4 & 52.16 \\
\hline $6-7$ & 71.8 & 28.2 & 15.86 & 20.2 & 79.8 & 33.07 & 17.8 & 82.2 & 25.91 \\
\hline $7-8$ & 64.1 & 35.9 & 9.32 & 17.5 & 82.5 & 22.89 & 7.8 & 92.2 & 24.77 \\
\hline $8-9$ & 68.5 & 31.5 & 6.67 & 16.4 & 83.6 & 18.33 & 5.4 & 94.6 & 57.73 \\
\hline $9-10$ & 54.2 & 45.8 & 7.54 & 3.3 & 96.7 & 22.52 & 11.3 & 88.7 & 10.02 \\
\hline $10-15$ & 61.6 & 38.4 & 19.30 & 4.6 & 95.4 & 69.50 & 8.0 & 92.0 & 26.60 \\
\hline $15-20$ & 31.5 & 68.5 & 12.54 & 2.2 & 97.8 & 13.63 & 2.1 & 97.9 & 15.27 \\
\hline$>20$ & - & 100 & 1.58 & - & 100 & 1.67 & - & 100 & 7.88 \\
\hline Total & 70.4 & 29.6 & 319.83 & 28.8 & 71.2 & 509.17 & 23.0 & 77.0 & 414.19 \\
\hline
\end{tabular}

\subsubsection{Particle-size distribution}

Figure 17 shows the PSD data for each detonation and sampling annulus for the $81 \mathrm{~mm} \mathrm{IMX-104}$ mortar rounds. The PSD plots for $\mathrm{LO}_{2}$ and $\mathrm{LO}_{3}$ have more overlap between all annuli and much-less-pronounced fine peaks when compared to LO1. The annuli closer to the point of detonation for LO1 have broader peaks and shift to a finer particle size when compared to those of the annuli farthest from the point of detonation. For all detonations, the magnitude of the coarse peaks for the annuli farther away from the point of detonation were larger than those closer to the point of detonation. This was nearly opposite of what was observed for the $60 \mathrm{~mm}$ mortar rounds. There is a tentative link between consumption efficiency and the uniformity of particle sizes across annuli, with relatively consistent sizes for the low-efficiency $\mathrm{LO}_{2}$ and $\mathrm{LO}_{3}$ and more variable sizes for the higher-efficiency LO1 (Appendix D). 
Figure 17. PSDs from $81 \mathrm{~mm} I M X-104$ LO detonations. Select annuli needed to be combined to have the mass necessary to process by LD-PSA.
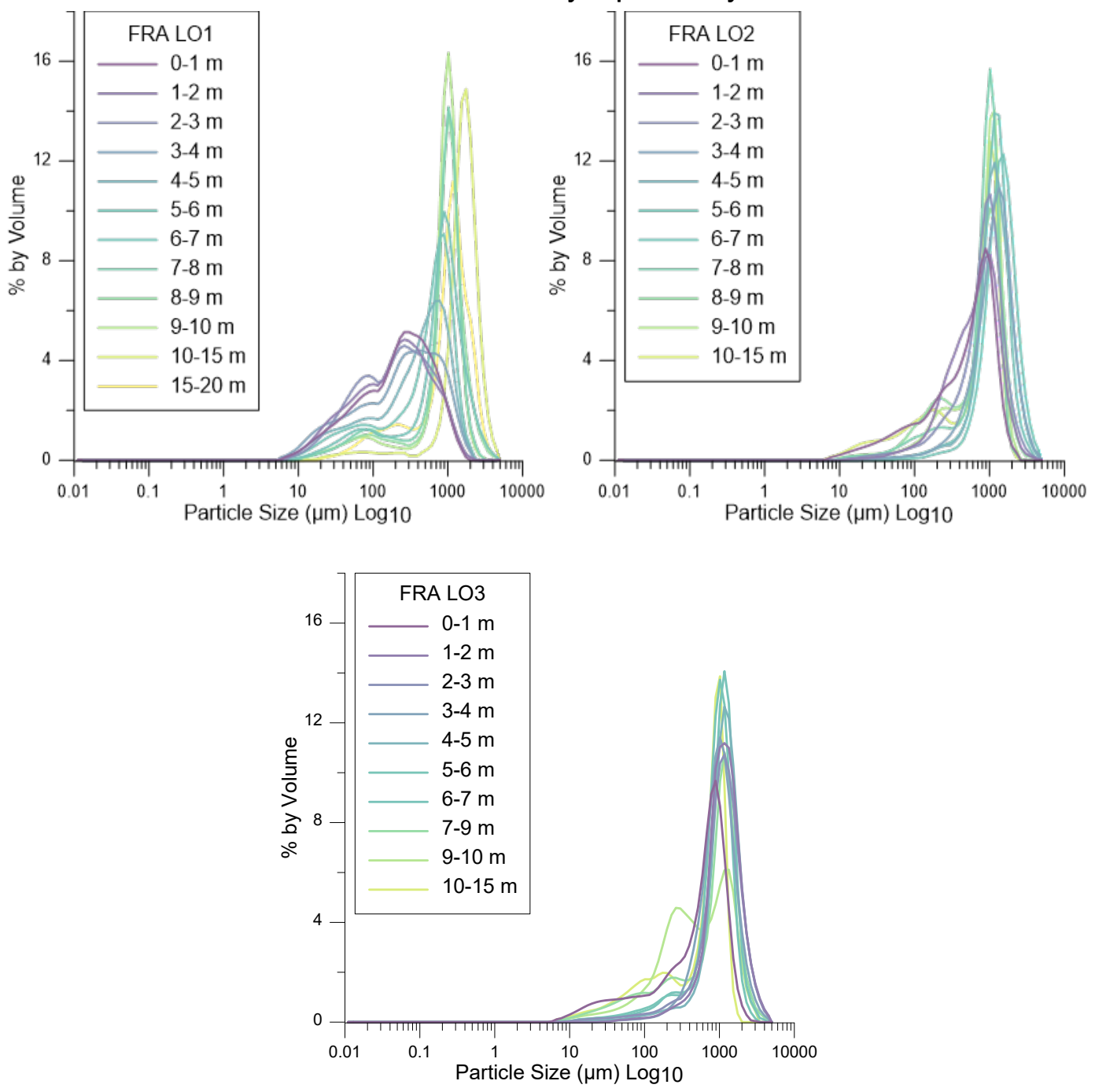

As Tables 11-13 show, the values of D10, D50, and D90 tended to increase from the point of detonation. This indicates that the $<2 \mathrm{~mm}$ material becomes coarser the farther from the point of detonation, mimicking the trend seen in the PSDs above. This was most pronounced in the values for LO1. The values for $\mathrm{LO}_{2}$ and $\mathrm{LO}_{3}$, although increasing, do not increase consistently from the point of detonation to $20 \mathrm{~m}$ and tended to peak between 5-10 m. Particle size appears to become coarser with distance and then shifts to a finer particle size beyond $10 \mathrm{~m}$. The only exception to this trend was the D50 measurement for 10-15 $\mathrm{m}$ for $\mathrm{LO} 2$. 
Table 11. Particle-size metrics for the 19FRA L01 $<2 \mathrm{~mm}$ fraction averaged for multiple analyses by LD-PSA.

\begin{tabular}{|c|c|c|c|}
\hline $\begin{array}{c}\text { Distance } \\
(\mathrm{m})\end{array}$ & $\begin{array}{c}\mathrm{D} 10 \\
(\boldsymbol{\mu m})\end{array}$ & $\begin{array}{c}\text { D50 } \\
(\boldsymbol{\mu m})\end{array}$ & $\begin{array}{c}\text { D90 } \\
(\boldsymbol{\mu m})\end{array}$ \\
\hline $0-1$ & 35 & 220 & 700 \\
\hline $1-2$ & 32 & 220 & 670 \\
\hline $2-3$ & 35 & 190 & 720 \\
\hline $3-4$ & 27 & 250 & 880 \\
\hline $4-5$ & 45 & 390 & 980 \\
\hline $5-6$ & 48 & 560 & 1090 \\
\hline $6-7$ & 170 & 800 & 1500 \\
\hline $7-8$ & 96 & 870 & 1350 \\
\hline $8-9$ & 230 & 960 & 1520 \\
\hline $9-10$ & 230 & 900 & 1290 \\
\hline $10-15$ & 740 & 1520 & 2400 \\
\hline $15-20$ & 310 & 1110 & 1670 \\
\hline
\end{tabular}

Table 12. Particle-size metrics for the 19FRA L02 $<2 \mathrm{~mm}$ fraction averaged for multiple analyses by LD-PSA.

\begin{tabular}{|c|c|c|c|}
\hline $\begin{array}{c}\text { Distance } \\
(\mathrm{m})\end{array}$ & $\begin{array}{c}\text { D10 } \\
(\boldsymbol{\mu m})\end{array}$ & $\begin{array}{c}\text { D50 } \\
(\boldsymbol{\mu m})\end{array}$ & $\begin{array}{c}\text { D90 } \\
(\boldsymbol{\mu m})\end{array}$ \\
\hline $0-1$ & 68 & 520 & 1110 \\
\hline $1-2$ & 200 & 660 & 1330 \\
\hline $2-3$ & 260 & 830 & 1450 \\
\hline $3-4$ & 440 & 1110 & 2000 \\
\hline $4-5$ & 580 & 1140 & 1820 \\
\hline $5-6$ & 690 & 1310 & 2250 \\
\hline $6-7$ & 560 & 1060 & 1650 \\
\hline $7-8$ & 170 & 850 & 1230 \\
\hline $8-9$ & 200 & 790 & 1360 \\
\hline $9-10$ & 170 & 870 & 1340 \\
\hline $10-15$ & 61 & 740 & 1230 \\
\hline $15-20$ & - & - & - \\
\hline
\end{tabular}


Table 13. Particle-size metrics for the 19FRA LO3 $<2 \mathrm{~mm}$ fraction averaged for multiple analyses by LD-PSA.

\begin{tabular}{|c|c|c|c|}
\hline $\begin{array}{c}\text { Distance } \\
(\mathrm{m})\end{array}$ & $\begin{array}{c}\text { D10 } \\
(\boldsymbol{\mu m})\end{array}$ & $\begin{array}{c}\text { D50 } \\
(\boldsymbol{\mu m})\end{array}$ & $\begin{array}{c}\text { D90 } \\
(\boldsymbol{\mu m})\end{array}$ \\
\hline $0-1$ & 91 & 5890 & 1130 \\
\hline $1-2$ & 480 & 1150 & 2050 \\
\hline $2-3$ & 380 & 1030 & 1790 \\
\hline $3-4$ & 470 & 960 & 1620 \\
\hline $4-5$ & 510 & 1120 & 1900 \\
\hline $5-6$ & 320 & 900 & 1350 \\
\hline $6-7$ & 370 & 1000 & 1550 \\
\hline $7-9$ & 230 & 850 & 1550 \\
\hline $9-10$ & 100 & 480 & 1480 \\
\hline $10-15$ & 64 & 690 & 1100 \\
\hline $15-20$ & - & - & - \\
\hline
\end{tabular}

\subsubsection{Particle composition}

Unlike the 19DTA $60 \mathrm{~mm}$ mortar rounds, the composition of the $<2 \mathrm{~mm}$ particles from 19FRA were relatively pure, between $83 \%$ and $100 \%$; and purity did not appear to vary with distance from the detonation (Figures 18 and 19). Similar to the $60 \mathrm{~mm}$ samples, the closest annuli were enriched in NTO relative to the other constituent compounds, indicating preferential deposition of these larger crystals near the detonation site. Also similar to $60 \mathrm{~mm}$ rounds, the fines recovered from the vacuum filter were depleted in NTO and enriched in DNAN, HMX, and RDX. Linear regression of pooled purity and distance was not significant $(p>0.1)$ for the $81 \mathrm{~mm}$ samples (Figure 19). To correct for the minor impurities in the $<2 \mathrm{~mm}$ fraction, the mean $(1 \mathrm{SD})$ purity of $89.0 \%( \pm 4.6$ percentage points, $n=14$ ) was used as a corrective factor for all 19FRA sample masses.

Table 14 lists the energetic-purity-corrected mass distribution for 19FRA samples. The simple correction reduces the $<2 \mathrm{~mm}$ fraction by $11 \%$, but the same trends remain. The corrected estimated consumption efficiencies are $64 \%, 39 \%$, and $50 \%$ for $\mathrm{LO}_{1}, \mathrm{LO}_{2}$, and $\mathrm{LO}_{3}$, respectively. 
Figure 18. Formulation-normalized compound concentrations in whole-sample extractions from $81 \mathrm{~mm}$ IMX-104 detonations. Concentrations from both the material recovered in the vacuum container of the LD-PSA postanalysis (Sample) and material from shaking the vacuum filter (Fines) are shown.

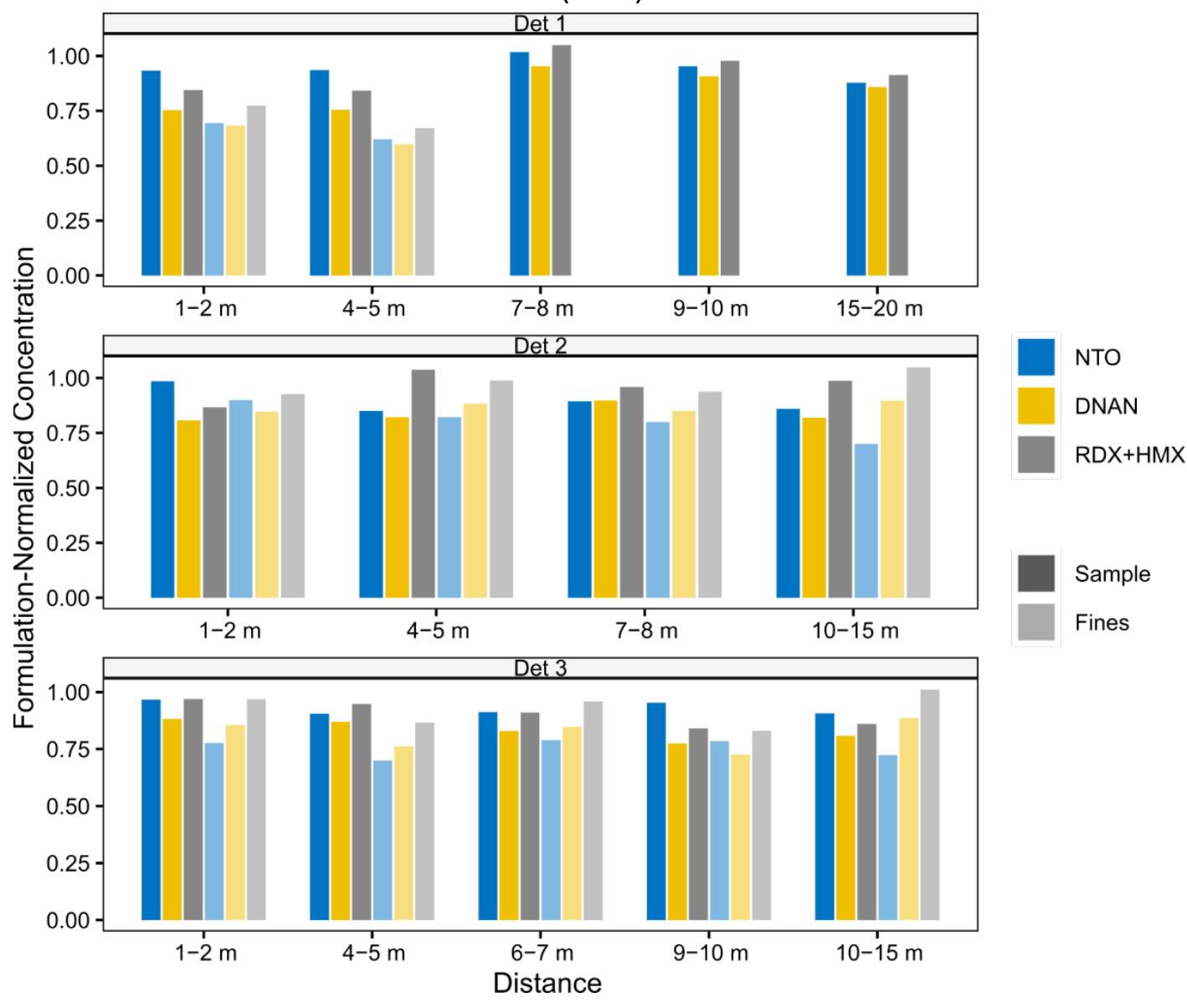

Figure 19. Total energetic compound purity of recovered particles from $81 \mathrm{~mm}$ IMX-104 rounds as a function of distance. Energetic composition is the mass-weighted average of sample and fines composition.

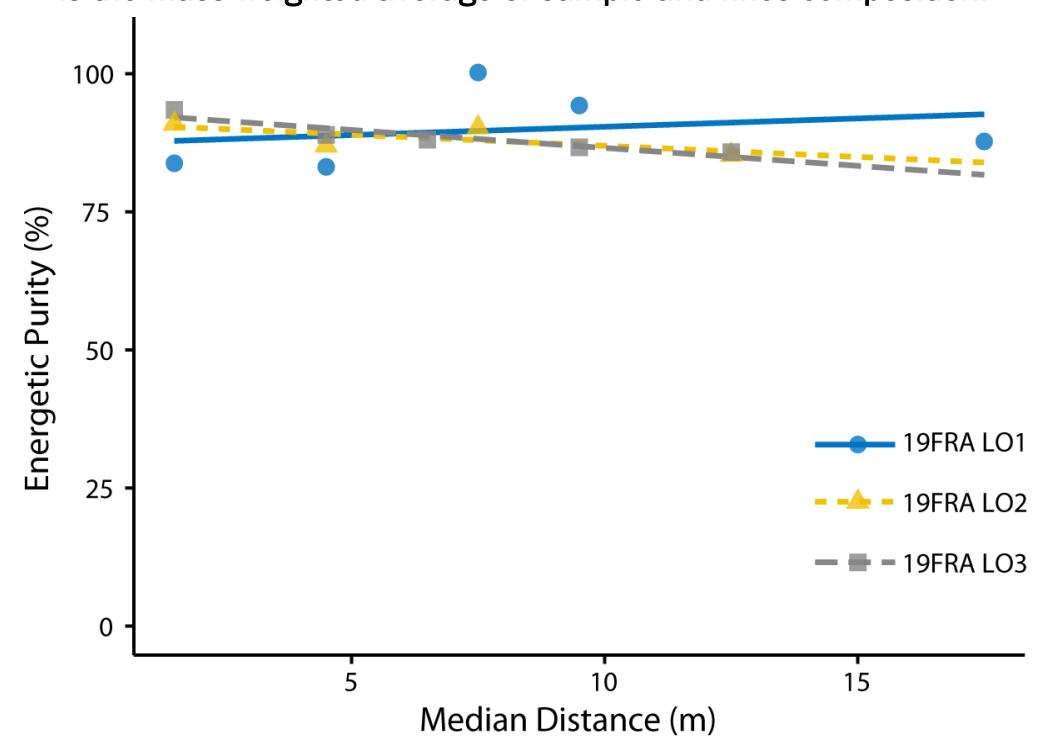


Table 14. Energetic-purity-corrected $2 \mathrm{~mm}$ sieve masses and mass proportions for 19FRA $81 \mathrm{~mm}$ samples.

\begin{tabular}{|c|c|c|c|c|c|c|c|c|c|}
\hline \multirow[b]{2}{*}{$\begin{array}{l}\text { Distance } \\
(\mathrm{m})\end{array}$} & \multicolumn{3}{|c|}{ 19FRA L01 } & \multicolumn{3}{|c|}{ 19FRA LO2 } & \multicolumn{3}{|c|}{ 19FRA LO3 } \\
\hline & $\begin{array}{c}<2 \mathrm{~mm} \\
(\%)\end{array}$ & $\begin{array}{c}>2 \mathrm{~mm} \\
(\%)\end{array}$ & $\begin{array}{c}\text { Total } \\
\text { (g) }\end{array}$ & $\begin{array}{c}<2 \mathrm{~mm} \\
(\%)\end{array}$ & $\begin{array}{c}>2 \mathrm{~mm} \\
(\%)\end{array}$ & $\begin{array}{l}\text { Total } \\
\text { (g) }\end{array}$ & $\begin{array}{c}<2 \mathrm{~mm} \\
(\%)\end{array}$ & $\begin{array}{c}>2 \mathrm{~mm} \\
(\%)\end{array}$ & $\begin{array}{c}\text { Total } \\
\text { (g) }\end{array}$ \\
\hline $0-1$ & 75 & 25 & 120 & 51 & 49 & 142 & 70 & 30 & 29 \\
\hline $1-2$ & 63 & 37 & 26 & 26 & 74 & 39 & 32 & 68 & 38 \\
\hline $2-3$ & 59 & 41 & 24 & 18 & 82 & 55 & 31 & 69 & 41 \\
\hline $3-4$ & 78 & 22 & 25 & 36 & 64 & 27 & 33 & 67 & 37 \\
\hline $4-5$ & 69 & 31 & 17 & 24 & 76 & 24 & 20 & 80 & 42 \\
\hline $5-6$ & 65 & 35 & 13 & 26 & 74 & 26 & 16 & 84 & 51 \\
\hline $6-7$ & 69 & 31 & 15 & 18 & 82 & 32 & 16 & 84 & 25 \\
\hline $7-8$ & 61 & 39 & 8.7 & 16 & 84 & 22 & 7.0 & 93 & 25 \\
\hline $8-9$ & 66 & 34 & 6.2 & 15 & 85 & 18 & 4.8 & 95 & 57 \\
\hline $9-10$ & 51 & 49 & 7.1 & 2.9 & 97 & 22 & 10 & 90 & 10 \\
\hline $10-15$ & 59 & 41 & 18 & 4.1 & 96 & 69 & 7.2 & 93 & 26 \\
\hline $15-20$ & 29 & 71 & 12 & 2.0 & 98 & 14 & 1.9 & 98 & 15 \\
\hline$>20$ & - & 100 & 1.58 & - & 100 & 1.67 & - & 7.88 & 7.88 \\
\hline Total & 68 & 32 & 295 & 26 & 74 & 493 & 21 & 79 & 404 \\
\hline
\end{tabular}

\subsubsection{Particle morphology}

Figures 20-22 present representative SEM images from 19FRA samples at three different sampling annuli. Similar to the 19DTA images, two distinct types of particles were present: flat-sided angular particles and irregular rounded particles. Point EDS measurements of the flat-sided particles typically contained $\mathrm{N}>\mathrm{O}>\mathrm{C}$, characteristic of NTO, whereas the irregular particles had $\mathrm{C}>\mathrm{N}>\mathrm{O}$, characteristic of a mixture of DNAN and RDX. The flat-sided particles varied in shape from blocky to columnar/prismatic. These spot analyses indicate that NTO crystals were liberated from the energetic matrix and their dissolution would not be limited by incorporation in the DNAN matrix at this particle size. The absence of nonenergetic material in all samples reflects the relative purity of residual particles from the $81 \mathrm{~mm}$ tests. 
Figure 20. SEM image from 19FRA L01 0-1 $\mathrm{m}$.

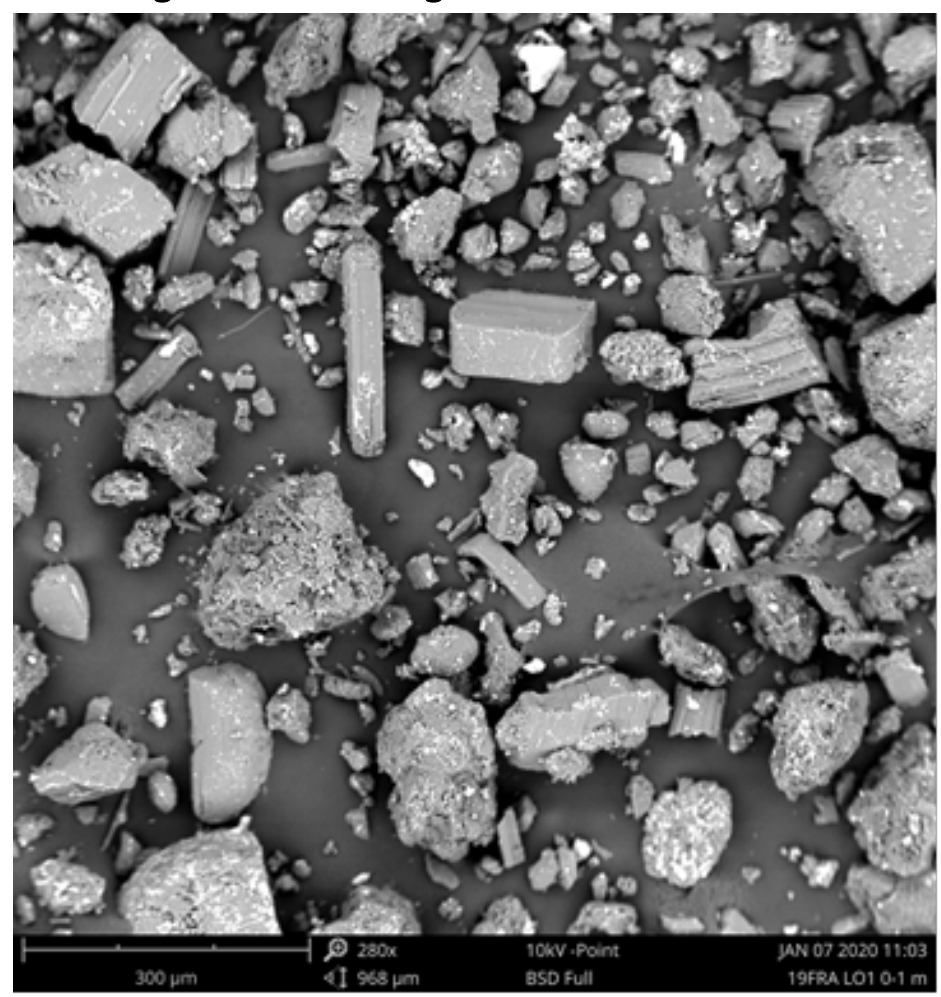

Figure 21. SEM image from 19FRA L01 6-7 m.

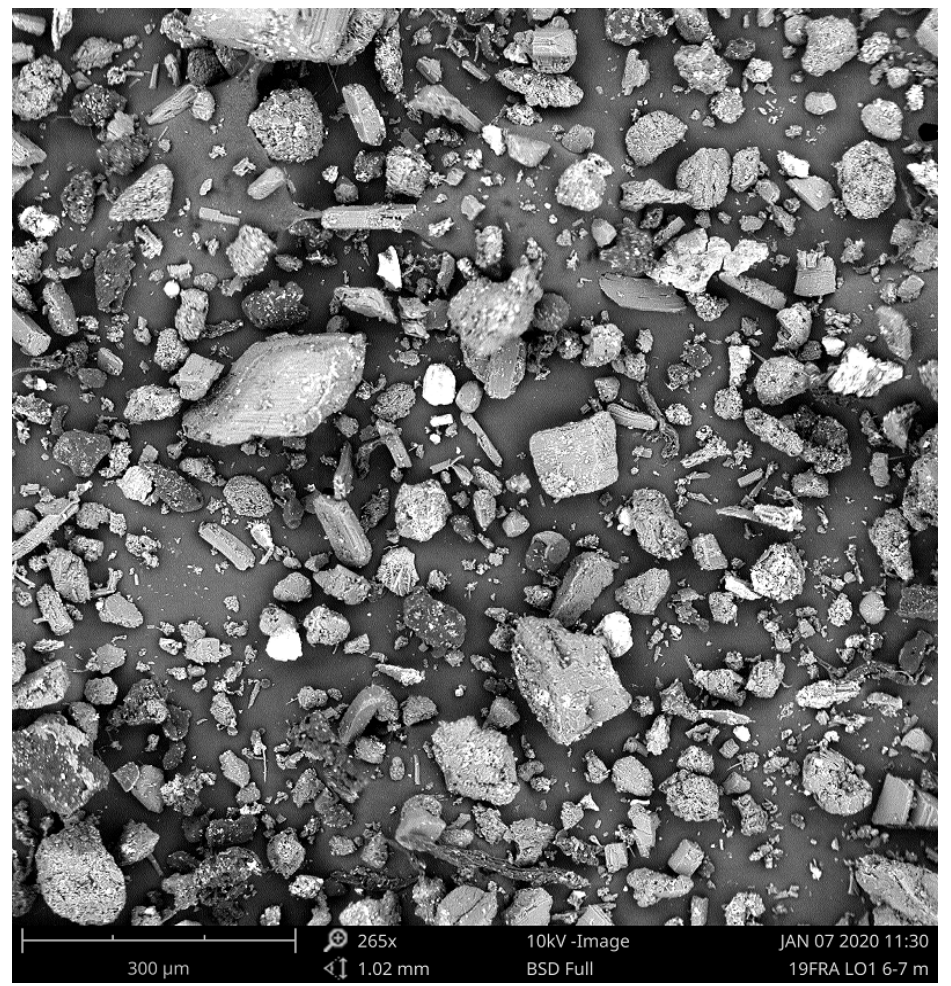


Figure 22. SEM image from 19FRA LO1 10-15 m.

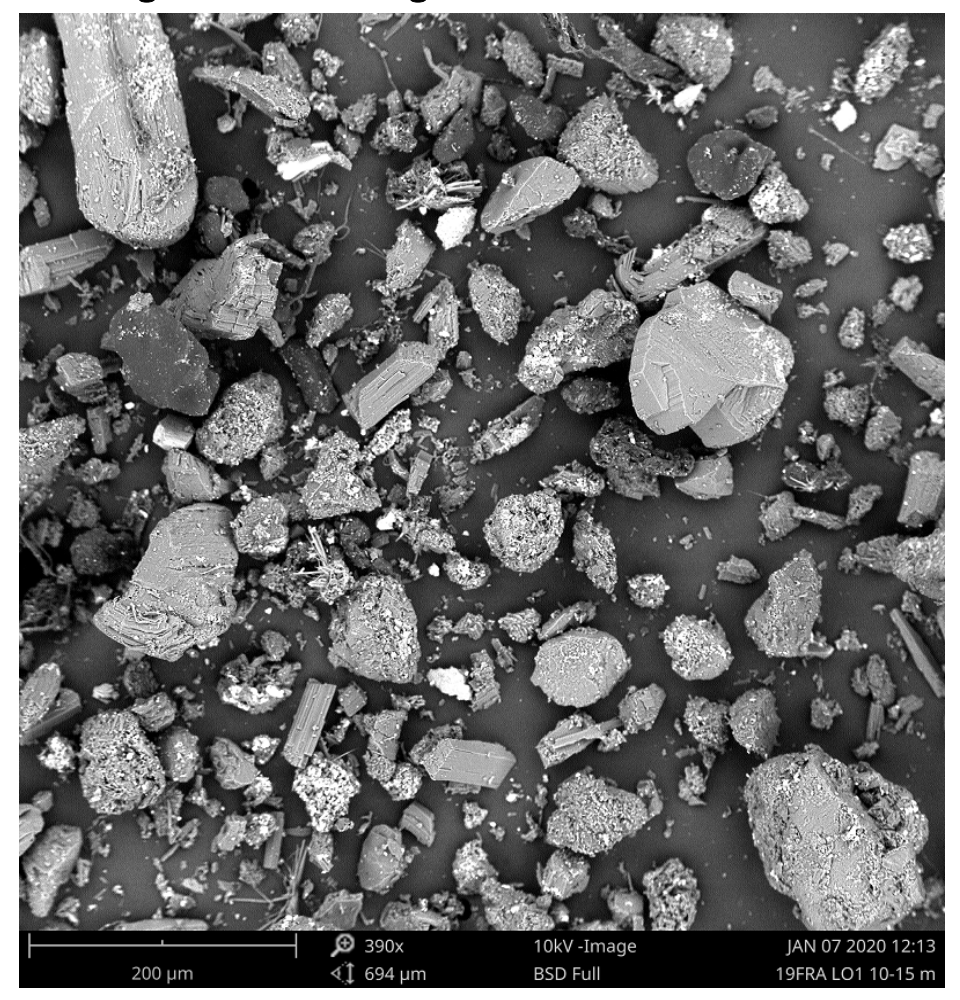

Figures 23 and 24 present $\mu \mathrm{CT}$ images taken of several $>2 \mathrm{~mm}$ particles from 19FRA LO1. Examining these images allowed better understanding of the internal structure of the particles. All the particles in Figures 23 and 24 show signs of internal fractures. The surfaces of all particles are rough and appear to be less stable with sections that show signs of breaking off entirely (Figure 24). The particle shown in Figure 24 has a fracture that runs to the center of the particle. This could potentially serve as a pathway for water to break down the particle more readily over time. The large lightcolored particles are likely NTO crystals (Taylor, Park, et al. 2015), and they appear to be fully intact with no dissolution having taken place during the field sampling and sample processing. This would support that during LO particle sampling and processing the particles were not exposed to much liquid water. The observed friability of the studied particles warrants further investigation into whether the sampling and processing methods affect particle structure. 
Figure 23. A $\mu C T$ image of $>2 \mathrm{~mm}$ particles from 19FRA LO1.

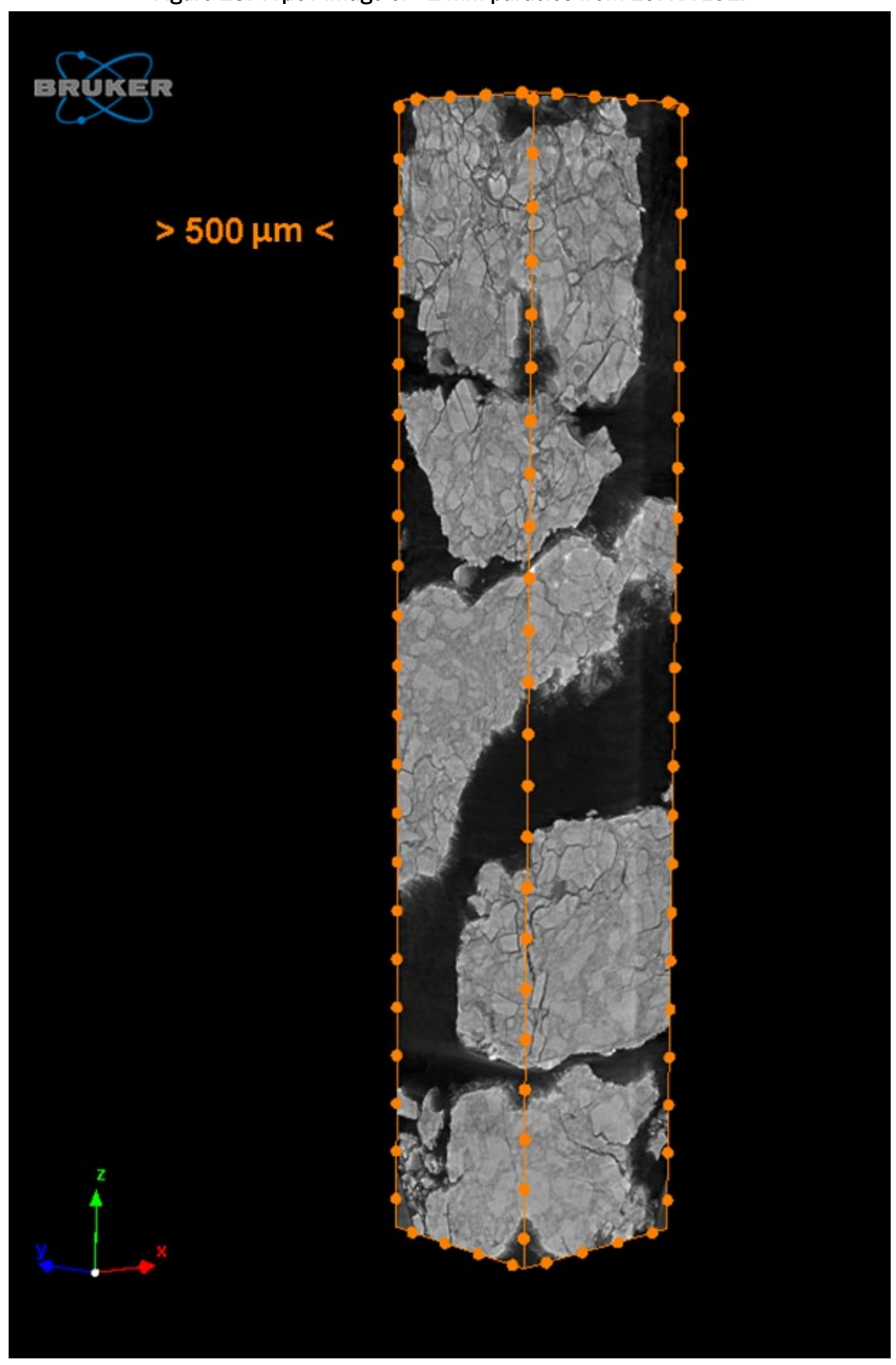


Figure 24. A $\mu C T$ image of $>2 \mathrm{~mm}$ particle from 19FRA L01.

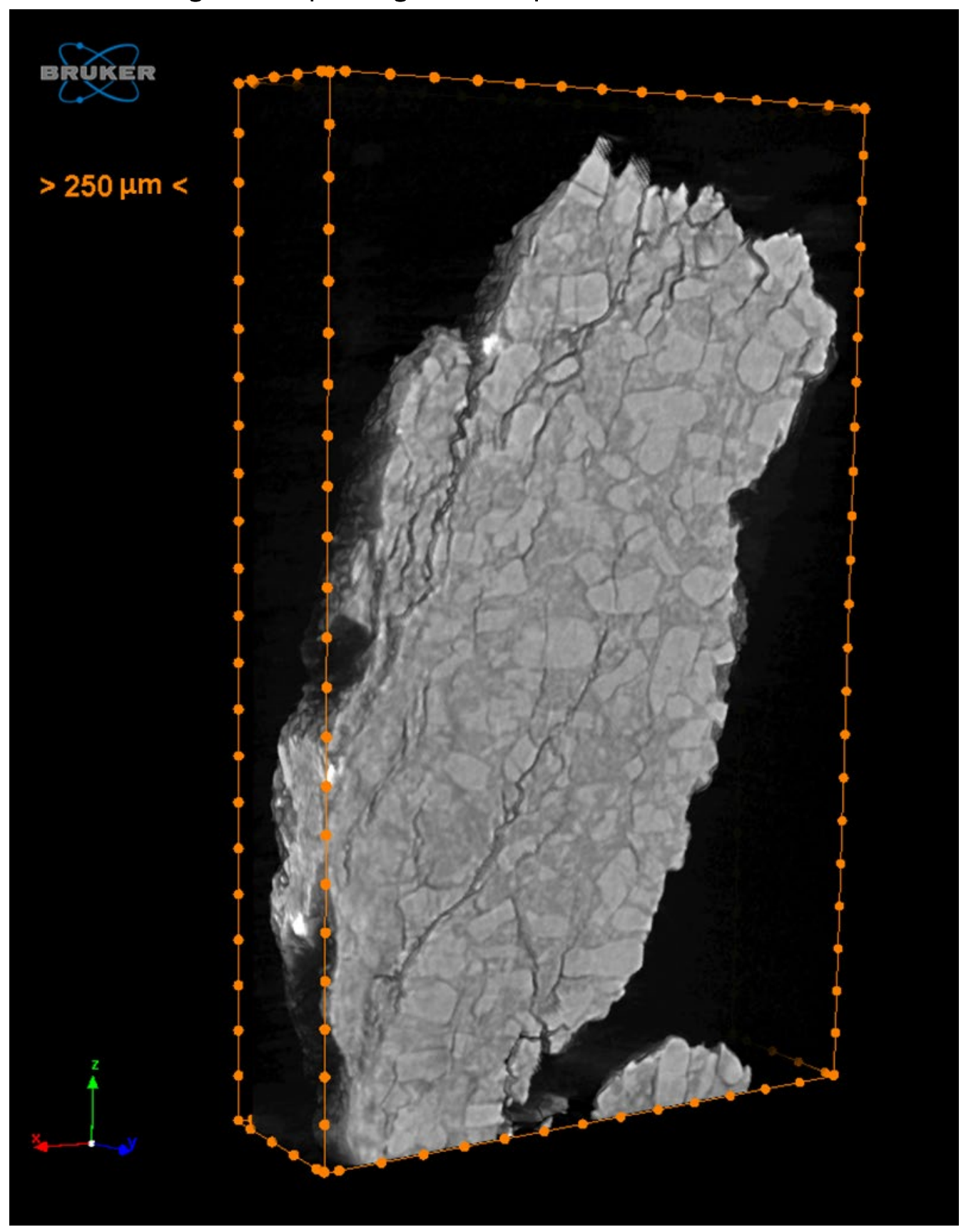




\section{Conclusions}

The successful execution of this demonstration provided novel fate-controlling particle characteristics for these two types of IMX-104 munitions. The observed variability, spatial extent, and particle distribution data can constrain LO detonation inputs for fate-transport models. In addition, through the execution of this demonstration for IMX-104 rounds, from command detonation through sample analysis, a number of observational comments and quantitative indicators of method performance emerged.

Command detonation was fully successful for the $60 \mathrm{~mm}$ rounds, while the $81 \mathrm{~mm}$ rounds proved difficult to consistently initiate LO. This may have been because of the manufacture level status of the rounds, but other factors may have also played a role. The mass of $\mathrm{C}_{4}$ is very controllable in the field by using a two or three decimal field balance covered from wind, but how the fuze simulator integrates with the round and the blasting cap with the fuze simulator can vary by Explosive Ordnance Disposal technician. Threading the fuze simulator all the way into the round, instead of flush with the top of round, puts the donor charge in closer contact with the filler and likely influences detonation order. Keeping this level of threading consistent could be crucial. Similarly, the depth of insertion of the blasting cap could be critical, and there is potential for the insertion to dislodge the $\mathrm{C}_{4}$ from the fuze simulator and put it in closer contact with the filler. Using tape underneath the $\mathrm{C}_{4}$ to secure it and using a $\mathrm{C}_{4}$ punch could minimize test-to-test variability.

During sampling, ice condition played a critical role in ease and likely effectiveness of particle collection. Bumps and cracks in the ice can prevent particles from being collected, leading the reported mass distributions to serve as minimum estimates. The postsample sweep samples and quality control provide quantitative estimates of the unrecovered particle mass during sampling. Further, loss of ultrafine particles (M. R. Walsh, Gullett, et al. 2018) and altered particle trajectory by wind are also possible, despite efforts to sample during no- or low-wind periods. Flooding the sample site repeatedly with water was effective at creating a relatively smooth ice surface, although imperfections were still present. Using a Zamboni to create a perfect ice surface could improve sampling accuracy, although the detonation itself causes some surface pitting from fragmentation. 
There was a shot-to-shot variability observed in the masses recovered and PSDs that were subsequently produced from those samples. This variability underlines the need to collect more replicate detonations when performing this type of testing. An increased replicate count could provide more precise bounds on the variability by allowing for more samples, additional analyses, and a better understanding of LO depositional patterns overall.

Particle transfer losses are inherent to this method throughout the process. The bristles of the sampling and collection brushes can retain particles. Alternative collection methods using a vacuum could be effective but would require attention to the maintenance of particle integrity. Losses also occur during transfer to freeze-drying jars and all subsequent container transfers. Mass losses following LD-PSA, and occasionally mass gains for small samples, were significant (typically 10\% to 25\%). Although these changes do not impact the mass distribution measurements (collected prior to LD-PSA), they do influence subsequent analyses (i.e., HPLC and SEM).

This study demonstrated that LD-PSA is a powerful tool to automate the analysis of the $<2 \mathrm{~mm}$ fraction and that there is considerable variability between munition types and individual detonations in full-range PSD. For formulations susceptible to rapid dissolution, such as IMX-104, the PSD in the $<2 \mathrm{~mm}$ fraction may carry less environmental significance than larger particle sizes. Larger particle classes could be quantified using sieves, image analysis, or wet LD-PSA using a compatible solvent. Still, removal of nonenergetic material is needed and can have a major impact on the results if not included. Purity analysis by HPLC is particularly important for small particles that are difficult to separate manually.

Building on these tests, it will be important to conduct similar LO detonation sampling on additional formulations, including but not limited to conventional fillers, such as Composition B. Applying this method to legacy materiel would provide particle characterization data for use in range management models, as conventional munitions continue to be expended in training and leave residues that persist over long timescales. 


\section{References}

Abdul-Karim, N., C. S. Blackman, P. P. Gill, and K. Karu. 2016. “The Spatial Distribution Patterns of Condensed Phase Post-Blast Explosive Residues Formed during Detonation." Journal of Hazardous Materials 316:204-213. https://doi.org/10.1016/i.jhazmat.2016.04.081

Abdul-Karim, N., C. S. Blackman, P. P. Gill, R. M. Morgan, L. Matjacic, R. Webb, and W. H. Ng. 2016. "Morphological Variations of Explosive Residue Particles and Implications for Understanding Detonation Mechanisms.” Analytical Chemistry 88 (7): 3899-3908. https://doi.org/10.1021/acs.analchem.6b00080.

Bigl, M. F., S. A. Beal, M. R. Walsh, C. A., Ramsey, and K. A. Burch. 2020. Sieve Stack and Laser Diffraction Particle Size Analysis of IMX-104 Low-Order Detonation Particles. ERDC/CRREL TR-20-3. Hanover, NH: U.S. Army Engineer Research and Development Center, Cold Regions Research and Engineering Laboratory. http://dx.doi.org/10.21079/11681/35515.

Borusiewicz, R., G. Zadora, and J. Zieba-Palus. 2013. "Chemical Analysis of Post Explosion Samples Obtained as a Result of Model Field Experiments." Talanta 116:630-636. https://doi.org/10.1016/i.talanta.2013.07.050.

Chendorain, M., and L. D. Stewart. 2005. "Corrosion of Unexploded Ordnance in Soil-Field Results.” Environmental Science and Technology 39 (8): 2442-2447. https://doi.org/10.1021/es049300x.

Clausen, J. L., J. Robb, D. Curry, and N. Korte. 2004. "A Case Study of Contaminants on Military Ranges: Camp Edwards, Massachusetts, USA.” Environmental Pollution 129 (1): 13-24. https://doi.org/10.1016/i.envpol.2003.10.002.

Dontsova, K., S. Taylor, R. Pesce-Rodriguez, M. Brusseau, J. Arthur, N. Mark, M. E. Walsh, J. Lever, and J. Šimůnek. 2014. Dissolution of NTO, DNAN, and Insensitive Munitions Formulations and Their Fates in Soils. ERDC/CRREL TR14-23. Hanover, NH: U.S. Army Engineer Research and Development Center, Cold Regions Research and Engineering Laboratory. https://hdl.handle.net/11681/5486.

Hewitt, A. D., T. F. Jenkins, M. E. Walsh, M. R. Walsh, and S. Taylor. 2005. "RDX and TNT Residues from Live-Fire and Blow-in-Place Detonations." Chemosphere 61 (6): 888-894. https://doi.org/10.1016/i.chemosphere.2005.04.058.

Jenkins, T. F., M. E. Walsh, P. H. Miyares, A. D. Hewitt, N. H. Collins, and T. A. Ranney. 2002. "Use of Snow-Covered Ranges to Estimate Explosives Residues from HighOrder Detonations of Army Munitions." Thermochimica Acta 384 (1-2): 173185. https://doi.org/10.1016/S0040-6031(01)00803-6.

Pennington, J. C., T. F. Jenkins, G. Ampleman, S. Thiboutot, J. M. Brannon, A. D. Hewitt, J. Lewis, S. Brochu, E. Diaz, M. R. Walsh, M. E. Walsh, S. Taylor, J. C. Lynch, J. L. Clausen, T. A. Ranney, C. A. Ramsey, C. A. Hayes, C. L. Grant, M. Charles, S. R. Bigl, S. L. Yost, and K. M. Dontsova. 2006. Distribution and Fate of Energetics on DoD Test and Training Ranges: Final Report. ERDC TR-06-13. Vicksburg, MS: U.S. Army Engineer Research and Development Center. http://hdl.handle.net/11681/8521. 
Pennington, J. C., B. Silverblatt, K. Poe, C. A. Hayes, and S. Yost. 2008. “Explosive Residues from Low-Order Detonations of Heavy Artillery and Mortar Rounds." Soil and Sediment Contamination 17 (5): 533-546. https://doi.org/10.1080/15320380802306669.

Racine, C. H., M. E. Walsh, B. D. Roebuck, C. M. Collins, D. J. Calkins, L. R. Reitsma, P. Buchli, and G. Goldfarb. 1992. "White Phosphorus Poisoning of Waterfowl in an Alaskan Salt Marsh.” Journal of Wildlife Diseases 28 (4): 669-673. https://doi.org/10.7589/0090-3558-28.4.669.

Taylor, S., K. Dontsova, M. E. Walsh, and M. R. Walsh. 2015. "Outdoor Dissolution of Detonation Residues of Three Insensitive Munitions (IM) Formulations." Chemosphere 134:250-256. https://doi.org/10.1016/i.chemosphere.2015.04.041.

Taylor, S., E. Campbell, L. Perovich, J. Lever, and J. Pennington. 2006. "Characteristics of Composition B Particles from Blow-in-Place Detonations." Chemosphere 65 (8): 1405-1413. https://doi.org/10.1016/i.chemosphere.2006.03.077.

Taylor, S., A. D. Hewitt, J. Lever, C. Hayes, L. Perovich, P. Thorne, and C. Daghlian. 2004. "TNT Particle Size Distributions from Detonated 155-mm Howitzer Rounds." Chemosphere 55 (3): 357-367. https://doi.org/10.1016/j.chemosphere.2003.11.031.

Taylor, S., E. Park, K. Bullion, and K. Dontsova. 2015. "Dissolution of Three Insensitive Munitions Formulations." Chemosphere 119:342-348. https://doi.org/10.1016/i.chemosphere.2014.06.050.

Walsh, M. E. 2016. "Analytical Methods for Detonation Residues of Insensitive Munitions." Journal of Energetic Materials 34:76-91. https://doi.org/10.1080/07370652.2014.999173.

Walsh, M. E., C. M. Collins, and C. H. Racine. 1996. "Persistence of White Phosphorus (P4) Particles in Salt Marsh Sediments." Environmental Toxicology and Chemistry 15 (6): 846-855. https://doi.org/10.1002/etc.5620150605.

Walsh, M. E., C. M. Collins, M. R. Walsh, C. A. Ramsey, S. Taylor, S. R. Bigl, R. N. Bailey, A. D. Hewitt, and M. Prieksat. 2008. Energetic Residues and Crater Geometries from the Firing of 12O-mm High-Explosive Mortar Projectiles into Eagle River Flats, June 2007. ERDC/CRREL TR-08-10. Hanover, NH: U.S. Army Engineer Research and Development Center, Cold Regions Research and Engineering Laboratory. https://apps.dtic.mil/sti/pdfs/ADA484240.pdf.

Walsh, M. R., M. F. Bigl, M. E. Walsh, E. T. Wrobel, D. L. Zaloga, S. A. Beal, and T. Temple. 2018. "Physical Simulation of Live-Fire Detonations Using CommandDetonation Fuzing." Propellants Explosives Pyrotechnics 43:602-608. https://doi.org/10.1002/prep.201700316.

Walsh, M. R., B. Gullett, M. E. Walsh, M. F. Bigl, and J. Aurell. 2018. "Improving PostDetonation Energetics Residues Estimations for the Life Cycle Environmental Assessment Process for Munitions." Chemosphere 194:622-627. https://doi.org/10.1016/i.chemosphere.2017.11.072. 
Walsh, M. R., T. Temple, M. F. Bigl, S. F. Tshabalala, N. Mai, and M. Ladyman. 2017. "Investigation of Energetic Particle Distribution from High-Order Detonations of Munitions." Propellants, Explosives, Pyrotechnics 42 (8):932-941. https://doi.org/10.1002/prep.201700089.

Walsh, M. R., S. Thiboutot, and B. Gullett. 2017. Characterization of Residues from the Detonation of Insensitive Munitions. SERDP Project ER-2219. Alexandria, VA: Strategic Environmental Research and Development Program. https://www.serdpestcp.org/content/download/47274/451031/file/ER-2219\%20Final\%20Report.pdf.

Walsh, M. R., S. Thiboutot, M. E. Walsh, G. Ampleman, R. Martel, I. Poulin, and S. Taylor. 2011. Characterization and Fate of Gun and Rocket Propellant Residues on Testing and Training Ranges: Final Report. ERDC/CRREL TR-11-13. Hanover, NH: U.S. Army Engineer Research and Development Center. http://hdl.handle.net/11681/5515.

Walsh, M. R., M. E. Walsh, C. A. Ramsey, S. Thiboutot, G. Ampleman, E. Diaz, and J. E. Zufelt. 2014. "Energetic Residues from the Detonation of IMX-104 Insensitive Munitions." Propellants, Explosives, Pyrotechnics 39 (2):243-250. https://doi.org/10.1002/prep.201300095.

Walsh, M. R., M. E. Walsh, S. Taylor, C. A. Ramsey, D. B. Ringelberg, J. E. Zufelt, S. Thiboutot, G. Ampleman, and E. Diaz. 2013. "Characterization of PAX-21 Insensitive Munition Detonation Residues.” Propellants, Explosives, Pyrotechnics 38 (3): 399-409. https://doi.org/10.1002/prep.201200150. 


\section{Appendix A: Quality Control Data}

Table A-1. Prefiltering glassware method blanks, postfiltering method blanks, and background sample concentrations in aqueous filtrate and after filter extraction.

\begin{tabular}{|l|c|c|c|c|c|c|c|c|}
\hline & \multicolumn{4}{|c|}{ Aqueous (mg) } & \multicolumn{4}{c|}{ Filter (mg) } \\
\cline { 2 - 9 } \multicolumn{1}{|c|}{ Sample } & NTO & HMX & RDX & DNAN & NTO & HMX & RDX & DNAN \\
\hline Pre-Filter Blank 1 & $<0.02$ & $<0.0004$ & $<0.0004$ & $<0.0004$ & $<0.0001$ & $<0.0004$ & $<0.0004$ & $<0.0004$ \\
\hline Pre-Filter Blank 2 & $<0.02$ & $<0.0004$ & $<0.0004$ & $<0.0004$ & $<0.0001$ & $<0.0004$ & $<0.0004$ & $<0.0004$ \\
\hline Post-Filter Blank 1 & $<0.02$ & $<0.0004$ & $<0.0004$ & $<0.0004$ & $<0.0001$ & $<0.0004$ & $<0.0004$ & $<0.0004$ \\
\hline Post-Filter Blank 2 & $<0.02$ & $<0.0004$ & $<0.0004$ & $<0.0004$ & $<0.0001$ & $<0.0004$ & $<0.0004$ & $<0.0004$ \\
\hline 19FRA BG \#1 & $<0.04$ & $<0.0008$ & $<0.0008$ & $<0.0008$ & $<0.0001$ & $<0.0004$ & $<0.0004$ & $<0.0004$ \\
\hline 19FRA BG \#2 & $<0.05$ & $<0.001$ & $<0.001$ & $<0.001$ & 0.0002 & $<0.0004$ & $<0.0004$ & $<0.0004$ \\
\hline 19FRA BG \#3 & $<0.05$ & $<0.001$ & $<0.001$ & $<0.001$ & $<0.0001$ & $<0.0004$ & $<0.0004$ & $<0.0004$ \\
\hline 19FRA BG \#4 & $<0.06$ & $<0.001$ & $<0.001$ & $<0.001$ & $<0.0002$ & $<0.0008$ & $<0.0008$ & $<0.0008$ \\
\hline 19DTA BG \#5 & $<0.02$ & $<0.0003$ & $<0.0003$ & $<0.0003$ & $<0.0001$ & $<0.0004$ & $<0.0004$ & $<0.0004$ \\
\hline 19DTA BG \#6 & $<0.04$ & 0.0015 & 0.0139 & 0.0108 & $<0.0002$ & $<0.0008$ & $<0.0008$ & 0.0027 \\
\hline
\end{tabular}

Table A-1. SPE matrix spike (MS), matrix spike duplicate (MSD), and laboratory control samples (LCS) each spiked at $4 \mu \mathrm{g} / \mathrm{L}$ with $\mathrm{HMX}$, RDX, and DNAN.

\begin{tabular}{|l|c|c|c|}
\hline \multirow{2}{*}{ Sample } & \multicolumn{3}{c|}{ Recovery (\%) } \\
\cline { 2 - 4 } & HMX & RDX & DNAN \\
\hline 19DTA Background 6 MS & $113 \%$ & $114 \%$ & $116 \%$ \\
\hline 19DTA Background 6 MSD & $112 \%$ & $114 \%$ & $115 \%$ \\
\hline LCS-1 & $113 \%$ & $114 \%$ & $117 \%$ \\
\hline LCS-2 & $113 \%$ & $114 \%$ & $116 \%$ \\
\hline LCS-3 & $112 \%$ & $114 \%$ & $115 \%$ \\
\hline
\end{tabular}




\section{Appendix B: Summarized Particle Data}

Table B-1. Energetic-purity-corrected $2 \mathrm{~mm}$ sieve masses, mass proportions, and $<2 \mathrm{~mm}$ particle sizes for $60 \mathrm{~mm}$ IMX-104 test 19DTA L01.

\begin{tabular}{|c|c|c|c|c|c|c|c|}
\hline \multirow[b]{2}{*}{$\begin{array}{l}\text { Distance } \\
(\mathrm{m})\end{array}$} & \multirow[b]{2}{*}{\begin{tabular}{|} 
Total Mass \\
(g)
\end{tabular}} & \multirow[b]{2}{*}{$\begin{array}{c}>2 \mathrm{~mm} \\
(\%)\end{array}$} & \multirow[b]{2}{*}{$\begin{array}{c}<2 \mathrm{~mm} \\
(\%)\end{array}$} & \multicolumn{3}{|c|}{$<2 \mathrm{~mm}$ Fraction } & \multirow[b]{2}{*}{$\begin{array}{l}\text { Total Deposition Rate } \\
\left(\mathrm{mg} / \mathrm{m}^{2}\right)\end{array}$} \\
\hline & & & & $\begin{array}{l}\text { D10 } \\
(\mu \mathrm{m})\end{array}$ & $\begin{array}{l}\text { D50 } \\
(\mu \mathrm{m})\end{array}$ & $\begin{array}{l}\mathrm{D} 90 \\
(\mu \mathrm{m})\end{array}$ & \\
\hline $0-1$ & 8.0 & 25 & 75 & 43 & 260 & 780 & 2600 \\
\hline $1-2$ & 4.7 & 42 & 58 & 72 & 420 & 990 & 500 \\
\hline $2-3$ & 9.5 & 14 & 86 & 46 & 260 & 730 & 600 \\
\hline $3-4$ & 9.8 & 13 & 87 & 57 & 370 & 850 & 450 \\
\hline $4-5$ & 7.2 & 6.4 & 94 & 70 & 410 & 900 & 260 \\
\hline $5-6$ & 3.9 & 11 & 89 & 28 & 160 & 630 & 110 \\
\hline $6-7$ & 4.9 & 18 & 82 & 21 & 100 & 600 & 120 \\
\hline $7-8$ & 3.9 & 28 & 72 & 24 & 110 & 680 & 84 \\
\hline $8-9$ & 3.1 & 41 & 59 & 28 & 180 & 800 & 58 \\
\hline $9-10$ & 1.7 & 52 & 48 & 25 & 190 & 690 & 28 \\
\hline $10-15$ & 11 & 31 & 69 & 13 & 46 & 130 & 28 \\
\hline $15-20$ & 8.6 & 31 & 69 & 10 & 30 & 88 & 16 \\
\hline$>20$ & 15.04 & 100 & - & - & - & - & - \\
\hline Total & 91.4 & 36 & 64 & - & - & - & - \\
\hline
\end{tabular}

Table B-2. Energetic-purity-corrected $2 \mathrm{~mm}$ sieve masses, mass proportions, and $<2 \mathrm{~mm}$ particle sizes for $60 \mathrm{~mm}$ IMX-104 test 19DTA L02.

\begin{tabular}{|c|c|c|c|c|c|c|c|}
\hline \multirow[b]{2}{*}{$\begin{array}{l}\text { Distance } \\
(\mathrm{m})\end{array}$} & \multirow[b]{2}{*}{$\begin{array}{c}\text { Total Mass } \\
(\mathrm{g})\end{array}$} & \multirow[b]{2}{*}{$\begin{array}{c}>2 \mathrm{~mm} \\
(\%)\end{array}$} & \multirow[b]{2}{*}{$\begin{array}{c}<2 \mathrm{~mm} \\
(\%)\end{array}$} & \multicolumn{3}{|c|}{$<2 \mathrm{~mm}$ Fraction } & \multirow[b]{2}{*}{$\begin{array}{l}\text { Total Deposition Rate } \\
\qquad\left(\mathrm{mg} / \mathrm{m}^{2}\right)\end{array}$} \\
\hline & & & & $\begin{array}{l}\mathrm{D} 10 \\
(\mu \mathrm{m})\end{array}$ & $\begin{array}{l}\text { D50 } \\
(\mu \mathrm{m})\end{array}$ & $\begin{array}{l}\mathrm{D} 90 \\
(\mu \mathrm{m})\end{array}$ & \\
\hline $0-1$ & 17 & 11 & 89 & 30 & 180 & 610 & 5300 \\
\hline $1-2$ & 3.2 & 21 & 79 & 47 & 290 & 820 & 340 \\
\hline $2-3$ & 3.7 & 27 & 73 & 42 & 310 & 910 & 240 \\
\hline $3-4$ & 8.0 & 22 & 78 & 130 & 490 & 960 & 360 \\
\hline $4-5$ & 4.6 & 20 & 80 & 100 & 530 & 1020 & 160 \\
\hline $5-6$ & 2.0 & 36 & 64 & 47 & 440 & 1010 & 59 \\
\hline $6-7$ & 2.8 & 45 & 55 & \multirow{2}{*}{95} & \multirow{2}{*}{560} & \multirow{2}{*}{1020} & 68 \\
\hline $7-8$ & 2.4 & 38 & 62 & & & & 51 \\
\hline $8-9$ & 1.8 & 40 & 60 & \multirow{2}{*}{44} & \multirow{2}{*}{520} & \multirow{2}{*}{1020} & 33 \\
\hline $9-10$ & 1.0 & 56 & 44 & & & & 16 \\
\hline $10-15$ & 6.3 & 31 & 69 & 49 & 260 & 680 & 16 \\
\hline $15-20$ & 14 & 86 & 14 & 16 & 68 & 280 & 25 \\
\hline$>20$ & - & - & - & - & - & - & - \\
\hline Total & 66 & 36 & 64 & - & - & - & - \\
\hline
\end{tabular}


Table B-3. Energetic-purity-corrected $2 \mathrm{~mm}$ sieve masses, mass proportions, and $<2 \mathrm{~mm}$ particle sizes for $60 \mathrm{~mm}$ IMX-104 test 19DTA L03.

\begin{tabular}{|c|c|c|c|c|c|c|c|}
\hline \multirow[b]{2}{*}{$\begin{array}{c}\text { Distance } \\
(\mathrm{m})\end{array}$} & \multirow[b]{2}{*}{$\begin{array}{l}\text { Total Mass } \\
\text { (g) }\end{array}$} & \multirow[b]{2}{*}{$\begin{array}{c}>2 \mathrm{~mm} \\
(\%)\end{array}$} & \multirow[b]{2}{*}{$\begin{array}{c}<2 \mathrm{~mm} \\
(\%)\end{array}$} & \multicolumn{3}{|c|}{$<2 \mathrm{~mm}$ Fraction } & \multirow[b]{2}{*}{$\begin{array}{l}\text { Total Deposition Rate } \\
\left(\mathrm{mg} / \mathrm{m}^{2}\right)\end{array}$} \\
\hline & & & & $\begin{array}{l}\text { D10 } \\
(\mu \mathrm{m})\end{array}$ & $\begin{array}{l}\text { D50 } \\
(\mu \mathrm{m})\end{array}$ & $\begin{array}{l}\mathrm{D} 90 \\
(\mu \mathrm{m})\end{array}$ & \\
\hline $0-1$ & 36 & 21 & 79 & 93 & 470 & 970 & 11000 \\
\hline $1-2$ & 7.2 & 61 & 39 & 160 & 480 & 1050 & 760 \\
\hline $2-3$ & 6.2 & 54 & 46 & 240 & 610 & 1090 & 400 \\
\hline $3-4$ & 13.0 & 16 & 84 & 250 & 530 & 980 & 590 \\
\hline $4-5$ & 4.9 & 46 & 54 & 87 & 620 & 1110 & 170 \\
\hline $5-6$ & 6.3 & 25 & 75 & 120 & 550 & 1080 & 180 \\
\hline $6-7$ & 5.9 & 57 & 43 & 32 & 360 & 1010 & 140 \\
\hline $7-8$ & 3.4 & 68 & 32 & 34 & 240 & 1110 & 72 \\
\hline $8-9$ & 4.0 & 44 & 56 & \multirow{2}{*}{41} & \multirow{2}{*}{260} & \multirow{2}{*}{870} & 75 \\
\hline $9-10$ & 1.1 & 78 & 22 & & & & 19 \\
\hline $10-15$ & 8.9 & 52 & 48 & 13 & 46 & 130 & 23 \\
\hline $15-20$ & 5.0 & 34 & 66 & 12 & 41 & 110 & 9 \\
\hline$>20$ & 28.31 & 100 & - & - & - & - & - \\
\hline Total & 130 & 49 & 51 & - & - & - & - \\
\hline
\end{tabular}

Table B-4. Energetic-purity-corrected $2 \mathrm{~mm}$ sieve masses, mass proportions, and $<2 \mathrm{~mm}$ particle sizes for $81 \mathrm{~mm}$ IMX-104 test 19FRA L01.

\begin{tabular}{|c|c|c|c|c|c|c|c|}
\hline \multirow[b]{2}{*}{$\begin{array}{l}\text { Distance } \\
\quad(\mathrm{m})\end{array}$} & \multirow[b]{2}{*}{$\begin{array}{l}\text { Total Mass } \\
\text { (g) }\end{array}$} & \multirow[b]{2}{*}{$\begin{array}{c}>2 \mathrm{~mm} \\
(\%)\end{array}$} & \multirow[b]{2}{*}{$\begin{array}{c}<2 \mathrm{~mm} \\
(\%)\end{array}$} & \multicolumn{3}{|c|}{$<2 \mathrm{~mm}$ Fraction } & \multirow[b]{2}{*}{$\begin{array}{l}\text { Total Deposition Rate } \\
\qquad\left(\mathrm{mg} / \mathrm{m}^{2}\right)\end{array}$} \\
\hline & & & & $\begin{array}{l}\text { D10 } \\
(\mu \mathrm{m})\end{array}$ & $\begin{array}{l}\text { D50 } \\
(\mu \mathrm{m})\end{array}$ & $\begin{array}{l}\mathrm{D} 90 \\
(\mu \mathrm{m})\end{array}$ & \\
\hline $0-1$ & 120 & 25 & 75 & 35 & 220 & 700 & 39000 \\
\hline $1-2$ & 26 & 37 & 63 & 32 & 220 & 670 & 2800 \\
\hline $2-3$ & 24 & 41 & 59 & 35 & 190 & 720 & 1500 \\
\hline $3-4$ & 25 & 22 & 78 & 27 & 250 & 880 & 1200 \\
\hline $4-5$ & 17 & 31 & 69 & 45 & 390 & 980 & 590 \\
\hline $5-6$ & 13 & 35 & 65 & 48 & 560 & 1090 & 370 \\
\hline $6-7$ & 15 & 31 & 69 & 170 & 800 & 1500 & 360 \\
\hline $7-8$ & 8.7 & 39 & 61 & 96 & 870 & 1350 & 180 \\
\hline $8-9$ & 6.2 & 34 & 66 & 230 & 960 & 1520 & 120 \\
\hline $9-10$ & 7.1 & 49 & 51 & 230 & 900 & 1290 & 120 \\
\hline $10-15$ & 18 & 41 & 59 & 740 & 1520 & 2400 & 46 \\
\hline $15-20$ & 12 & 71 & 29 & 310 & 1110 & 1670 & 22 \\
\hline$>20$ & 1.58 & 100 & - & - & - & - & - \\
\hline Total & 295 & 32 & 68 & - & - & - & - \\
\hline
\end{tabular}


Table B-5. Energetic-purity-corrected $2 \mathrm{~mm}$ sieve masses, mass proportions, and $<2 \mathrm{~mm}$ particle sizes for $81 \mathrm{~mm}$ IMX-104 test 19FRA LO2.

\begin{tabular}{|c|c|c|c|c|c|c|c|}
\hline \multirow[b]{2}{*}{$\begin{array}{l}\text { Distance } \\
(\mathrm{m})\end{array}$} & \multirow[b]{2}{*}{$\begin{array}{l}\text { Total Mass } \\
\text { (g) }\end{array}$} & \multirow[b]{2}{*}{$\begin{array}{c}>2 \mathrm{~mm} \\
(\%)\end{array}$} & \multirow[b]{2}{*}{$\begin{array}{c}<2 \mathrm{~mm} \\
(\%)\end{array}$} & \multicolumn{3}{|c|}{$<2 \mathrm{~mm}$ Fraction } & \multirow[b]{2}{*}{$\begin{array}{l}\text { Total Deposition Rate } \\
\qquad\left(\mathrm{mg} / \mathrm{m}^{2}\right)\end{array}$} \\
\hline & & & & $\begin{array}{l}\text { D10 } \\
(\mu \mathrm{m})\end{array}$ & $\begin{array}{l}\text { D50 } \\
(\mu \mathrm{m})\end{array}$ & $\begin{array}{l}\text { D90 } \\
(\mu \mathrm{m})\end{array}$ & \\
\hline $0-1$ & 142 & 49 & 51 & 68 & 520 & 1110 & 45000 \\
\hline $1-2$ & 39 & 74 & 26 & 200 & 660 & 1330 & 4200 \\
\hline $2-3$ & 55 & 82 & 18 & 260 & 830 & 1450 & 3500 \\
\hline $3-4$ & 27 & 64 & 36 & 440 & 1110 & 2000 & 1200 \\
\hline $4-5$ & 24 & 76 & 24 & 580 & 1140 & 1820 & 850 \\
\hline $5-6$ & 26 & 74 & 26 & 690 & 1310 & 2250 & 740 \\
\hline $6-7$ & 32 & 82 & 18 & 560 & 1060 & 1650 & 790 \\
\hline $7-8$ & 22 & 84 & 16 & 170 & 850 & 1230 & 480 \\
\hline $8-9$ & 18 & 85 & 15 & 200 & 790 & 1360 & 340 \\
\hline $9-10$ & 22 & 97 & 2.9 & 170 & 870 & 1340 & 380 \\
\hline $10-15$ & 69 & 96 & 4.1 & 61 & 740 & 1230 & 180 \\
\hline $15-20$ & 14 & 98 & 2.0 & - & - & - & 25 \\
\hline$>20$ & 1.67 & 100 & - & - & - & - & - \\
\hline Total & 493 & 74 & 26 & - & - & - & - \\
\hline
\end{tabular}

Table B-6. Energetic-purity-corrected $2 \mathrm{~mm}$ sieve masses, mass proportions, and $<2 \mathrm{~mm}$ particle sizes for $81 \mathrm{~mm}$ IMX-104 test 19FRA L03.

\begin{tabular}{|c|c|c|c|c|c|c|c|}
\hline \multirow[b]{2}{*}{$\begin{array}{l}\text { Distance } \\
\quad(\mathrm{m})\end{array}$} & \multirow[b]{2}{*}{$\begin{array}{l}\text { Total Mass } \\
\text { (g) }\end{array}$} & \multirow[b]{2}{*}{$\begin{array}{c}>2 \mathrm{~mm} \\
(\%)\end{array}$} & \multirow[b]{2}{*}{$\begin{array}{c}<2 \mathrm{~mm} \\
(\%)\end{array}$} & \multicolumn{3}{|c|}{$<2 \mathrm{~mm}$ Fraction } & \multirow[b]{2}{*}{$\begin{array}{l}\text { Total Deposition Rate } \\
\qquad\left(\mathrm{mg} / \mathrm{m}^{2}\right)\end{array}$} \\
\hline & & & & $\begin{array}{l}\text { D10 } \\
(\mu \mathrm{m})\end{array}$ & $\begin{array}{l}\text { D50 } \\
(\mu \mathrm{m})\end{array}$ & $\begin{array}{l}\text { D90 } \\
(\mu \mathrm{m})\end{array}$ & \\
\hline $0-1$ & 29 & 30 & 70 & 91 & 5890 & 1130 & 9100 \\
\hline $1-2$ & 38 & 68 & 32 & 480 & 1150 & 2050 & 4000 \\
\hline $2-3$ & 41 & 69 & 31 & 380 & 1030 & 1790 & 2600 \\
\hline $3-4$ & 37 & 67 & 33 & 470 & 960 & 1620 & 1700 \\
\hline $4-5$ & 42 & 80 & 20 & 510 & 1120 & 1900 & 1500 \\
\hline $5-6$ & 51 & 84 & 16 & 320 & 900 & 1350 & 1500 \\
\hline $6-7$ & 25 & 84 & 16 & 370 & 1000 & 1550 & 620 \\
\hline $7-8$ & 25 & 93 & 7.0 & \multirow{2}{*}{230} & \multirow{2}{*}{850} & \multirow{2}{*}{1550} & 520 \\
\hline $8-9$ & 57 & 95 & 4.8 & & & & 1100 \\
\hline $9-10$ & 10 & 90 & 10 & 100 & 480 & 1480 & 170 \\
\hline $10-15$ & 26 & 93 & 7.2 & 64 & 690 & 1100 & 67 \\
\hline $15-20$ & 15 & 98 & 1.9 & - & - & - & 28 \\
\hline$>20$ & 7.88 & 7.88 & - & - & - & - & - \\
\hline Total & 404 & 79 & 21 & - & - & - & - \\
\hline
\end{tabular}




\section{Appendix C: Particles >20 m from Detonation}

Table C-1. Particles identified $>20 \mathrm{~m}$ from the detonation site for 19DTA samples.

\begin{tabular}{|l|c|c|c|c|}
\hline Detonation & $\begin{array}{c}\text { Mass } \\
(\mathrm{g})\end{array}$ & $\begin{array}{c}\text { Length } \\
(\mathrm{mm})\end{array}$ & $\begin{array}{c}\text { Width } \\
(\mathrm{mm})\end{array}$ & Notes \\
\hline L01 & 15.037 & 30.4 & 30.4 & In tailfin/base \\
\hline L03 & 0.176 & 14 & 5 & \\
\cline { 2 - 5 } & 0.166 & 8 & 7 & \\
\cline { 2 - 5 } & 0.018 & 4 & 3 & \\
\cline { 2 - 5 } & 0.043 & 6 & 5 & \\
\cline { 2 - 5 } & 0.372 & 6 & 3 & \\
\cline { 2 - 5 } & 0.029 & 4 & 3 & \\
\cline { 2 - 5 } & 0.17 & 5 & 4 & \\
\cline { 2 - 5 } & 0.078 & 6 & 5 & \\
\cline { 2 - 5 } & 0.07 & 6 & 4 & \\
\cline { 2 - 5 } & 0.184 & 7 & 4 & \\
\cline { 2 - 5 } & 0.971 & 10 & 8 & \\
\cline { 2 - 5 } & 0.139 & 8 & 5 & \\
\cline { 2 - 5 } & 25.894 & 60 & 37 & In tailfin/base \\
\hline
\end{tabular}

Table C-2. Particles identified $>20 \mathrm{~m}$ from the detonation site for 19FRA samples.

\begin{tabular}{|l|c|c|}
\hline Detonation & $\begin{array}{c}\text { Distance } \\
(\mathrm{m})\end{array}$ & $\begin{array}{c}\text { Mass } \\
(\mathrm{g})\end{array}$ \\
\hline LO1 & 27.75 & 1.58 \\
\hline LO2 & 22.6 & 0.10 \\
\cline { 2 - 3 } & 23.7 & 0.17 \\
\cline { 2 - 3 } & 22.0 & 0.26 \\
\cline { 2 - 3 } & 21.2 & 0.06 \\
\cline { 2 - 3 } & 21.8 & 1.08 \\
\hline L03 & 21.3 & 0.42 \\
\cline { 2 - 3 } & 23.8 & 0.21 \\
\cline { 2 - 3 } & 26.7 & 5.891 \\
\cline { 2 - 3 } & 26.9 & 0.71 \\
\cline { 2 - 3 } & 21.6 & 0.29 \\
\cline { 2 - 3 } & 21.0 & 0.36 \\
\hline
\end{tabular}




\section{Appendix D: PSD Plots from Individual Detonations and Annuli}

Figure D-1. PSDs from $60 \mathrm{~mm}$ IMX-104 LO detonations. Select annuli needed to be combined to have the mass necessary to process by LD-PSA.
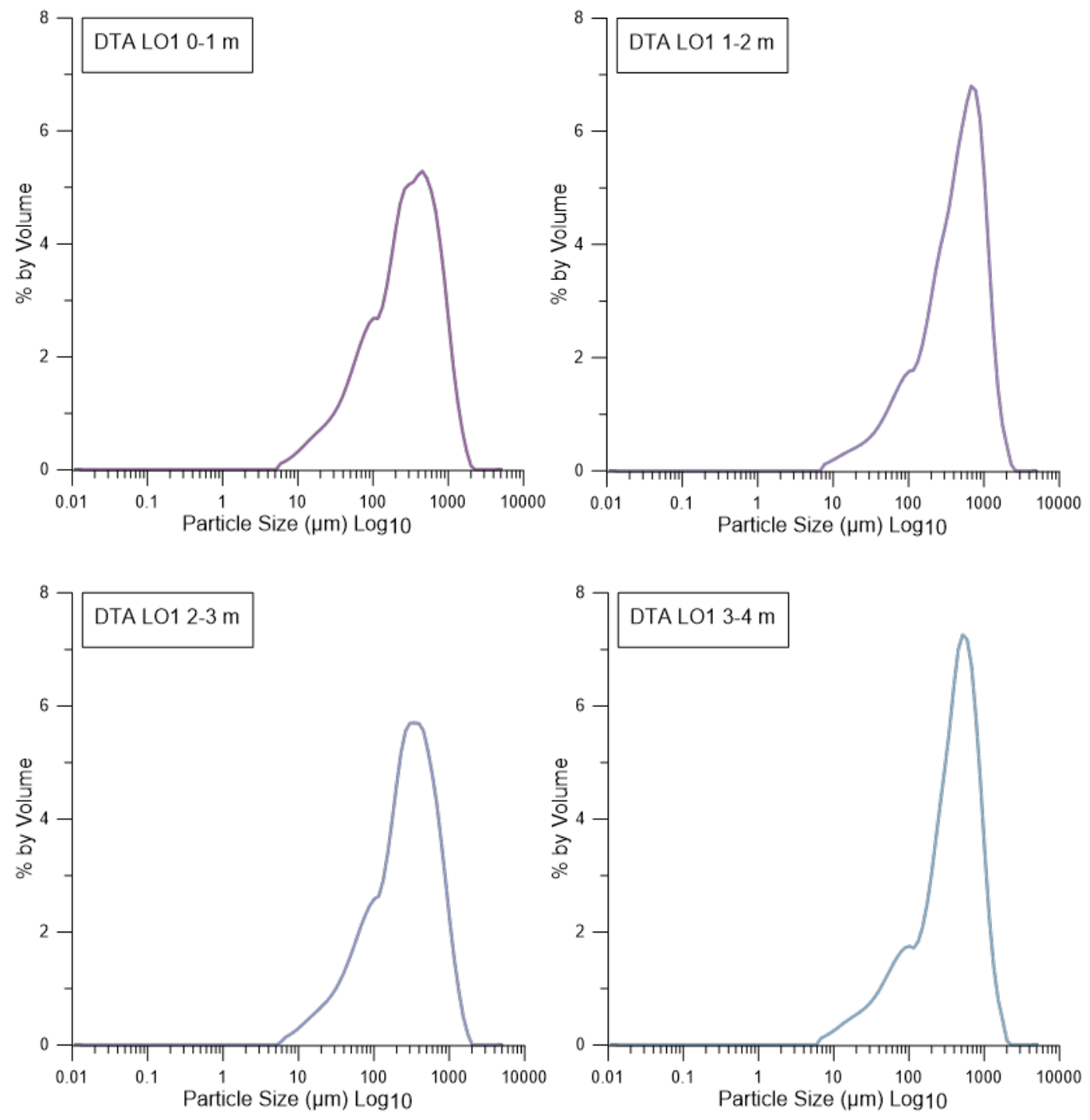
Figure D-1 (cont.). PSDs from $60 \mathrm{~mm}$ IMX-104 LO detonations. Select annuli needed to be combined to have the mass necessary to process by LD-PSA.
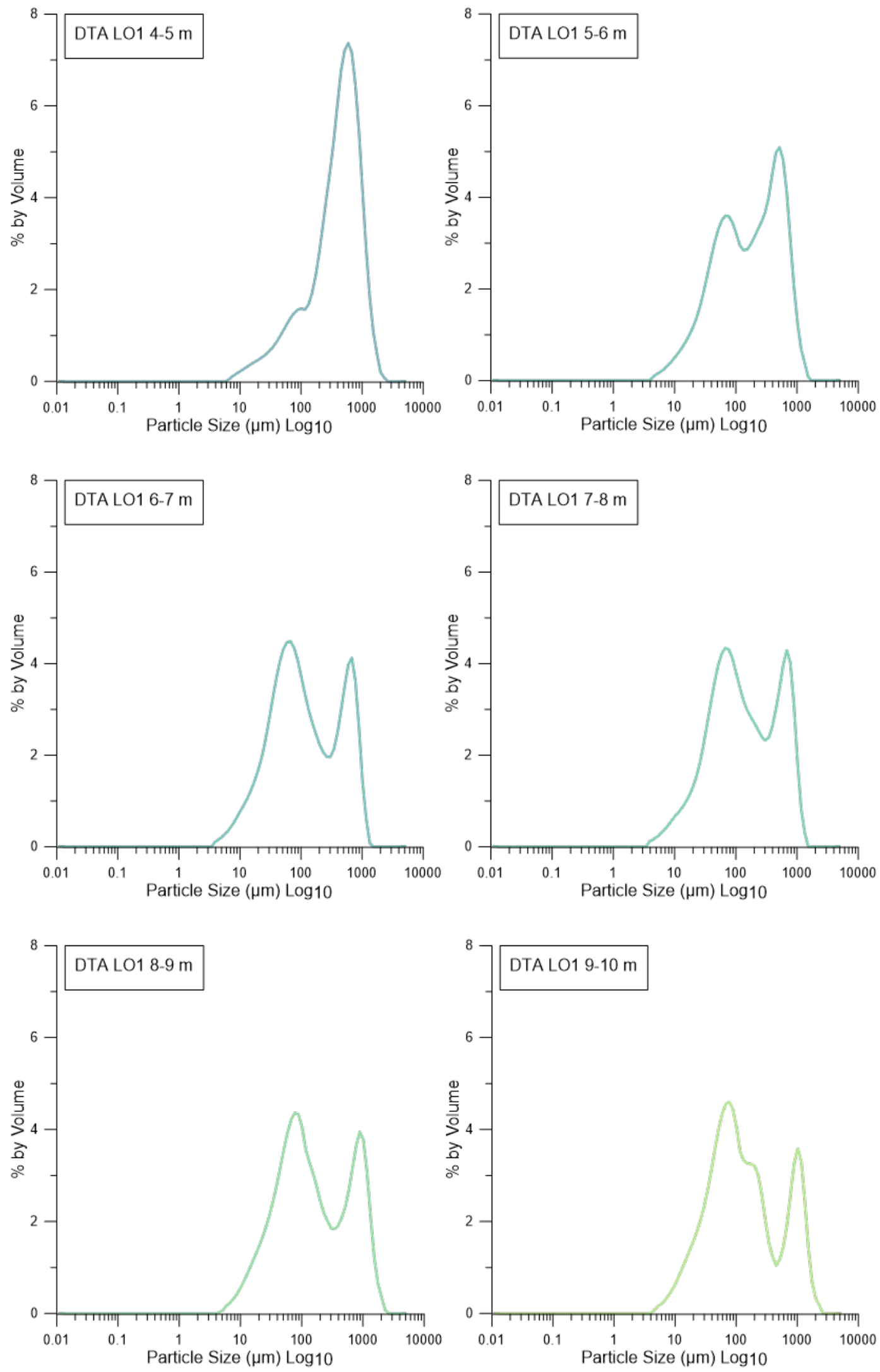
Figure D-1 (cont.). PSDs from $60 \mathrm{~mm}$ IMX-104 LO detonations. Select annuli needed to be combined to have the mass necessary to process by LD-PSA.
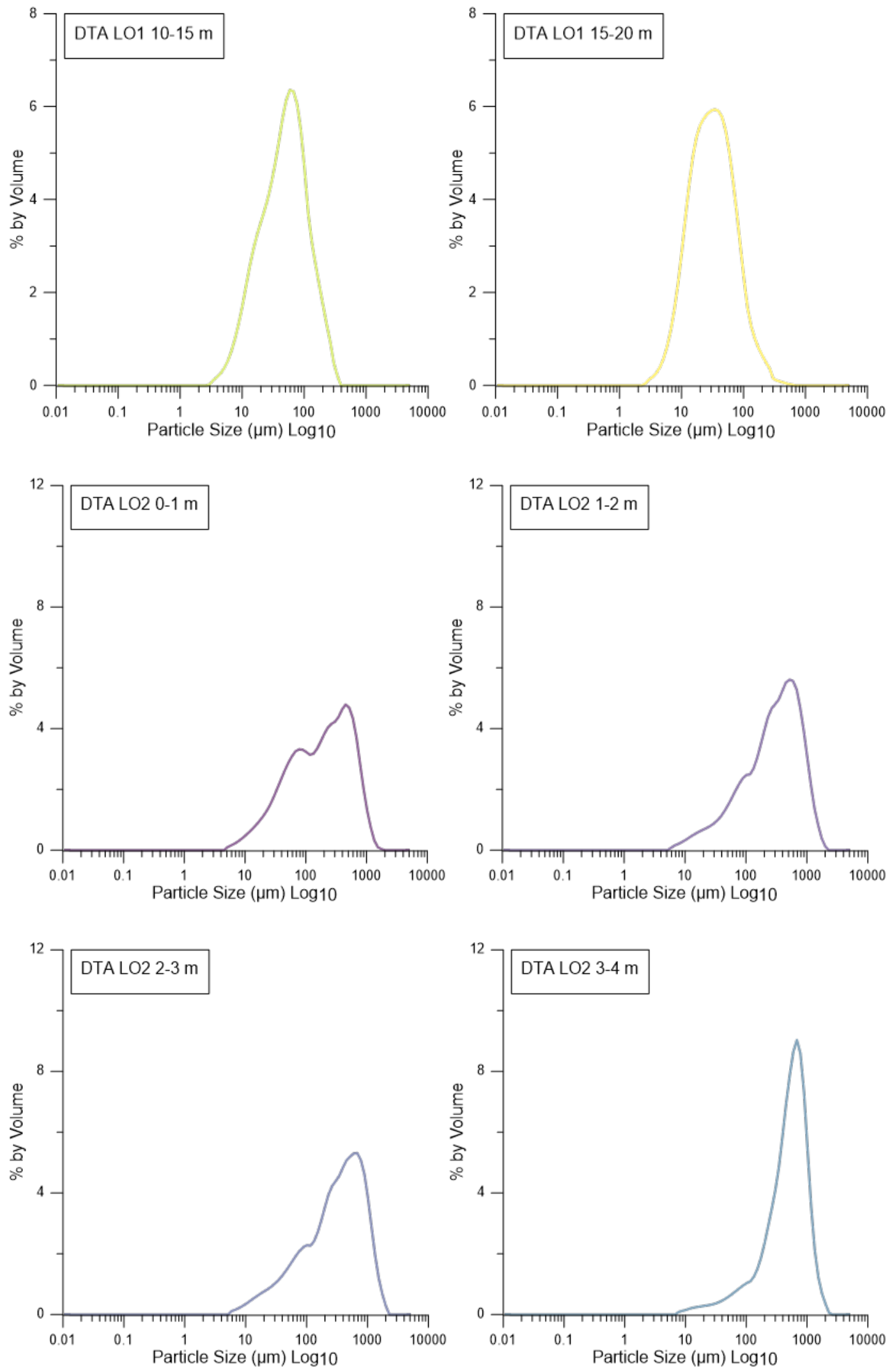
Figure D-1 (cont.). PSDs from $60 \mathrm{~mm}$ IMX-104 LO detonations. Select annuli needed to be combined to have the mass necessary to process by LD-PSA.
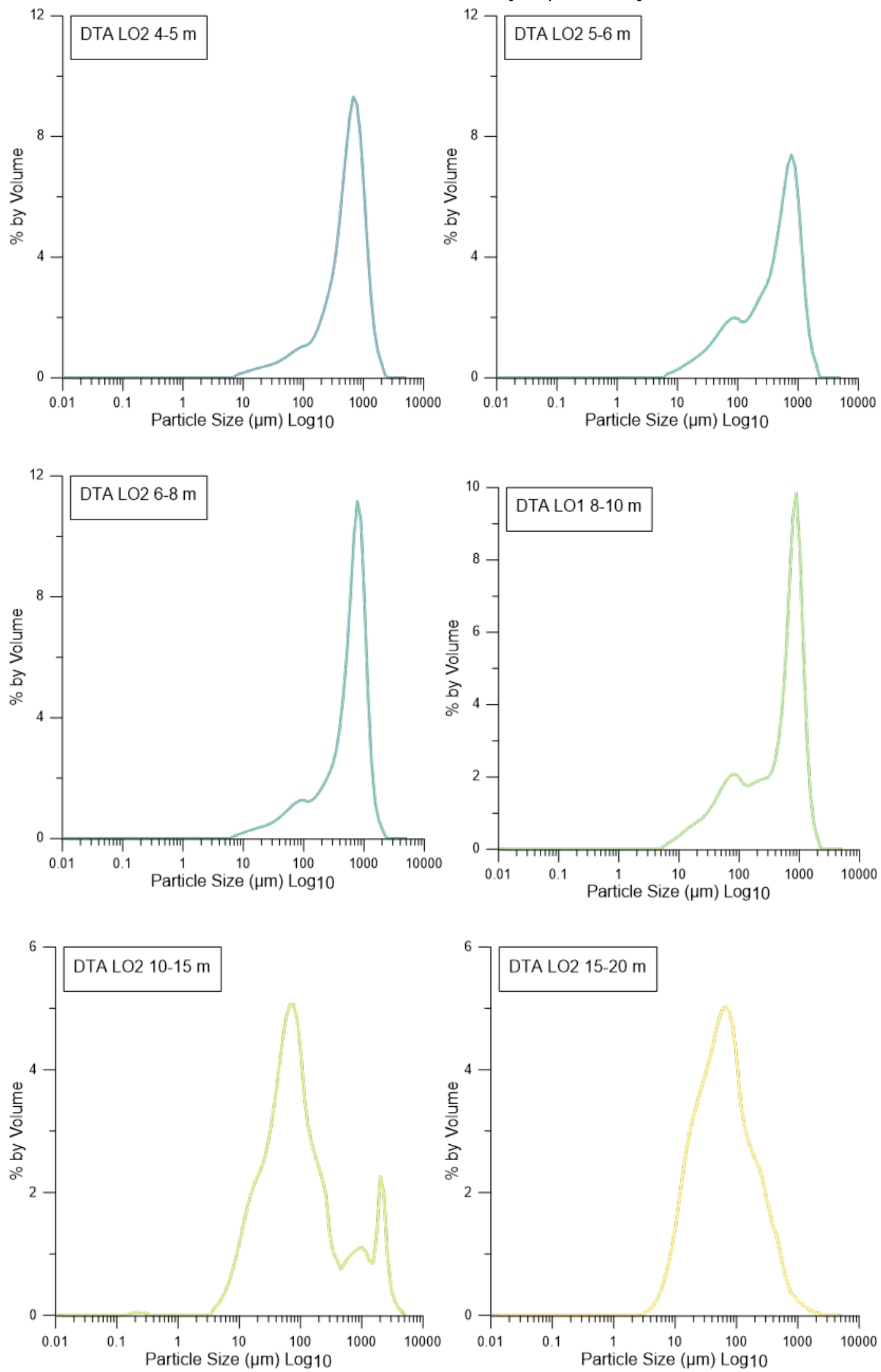
Figure D-1 (cont.). PSDs from $60 \mathrm{~mm}$ IMX-104 LO detonations. Select annuli needed to be combined to have the mass necessary to process by LD-PSA.
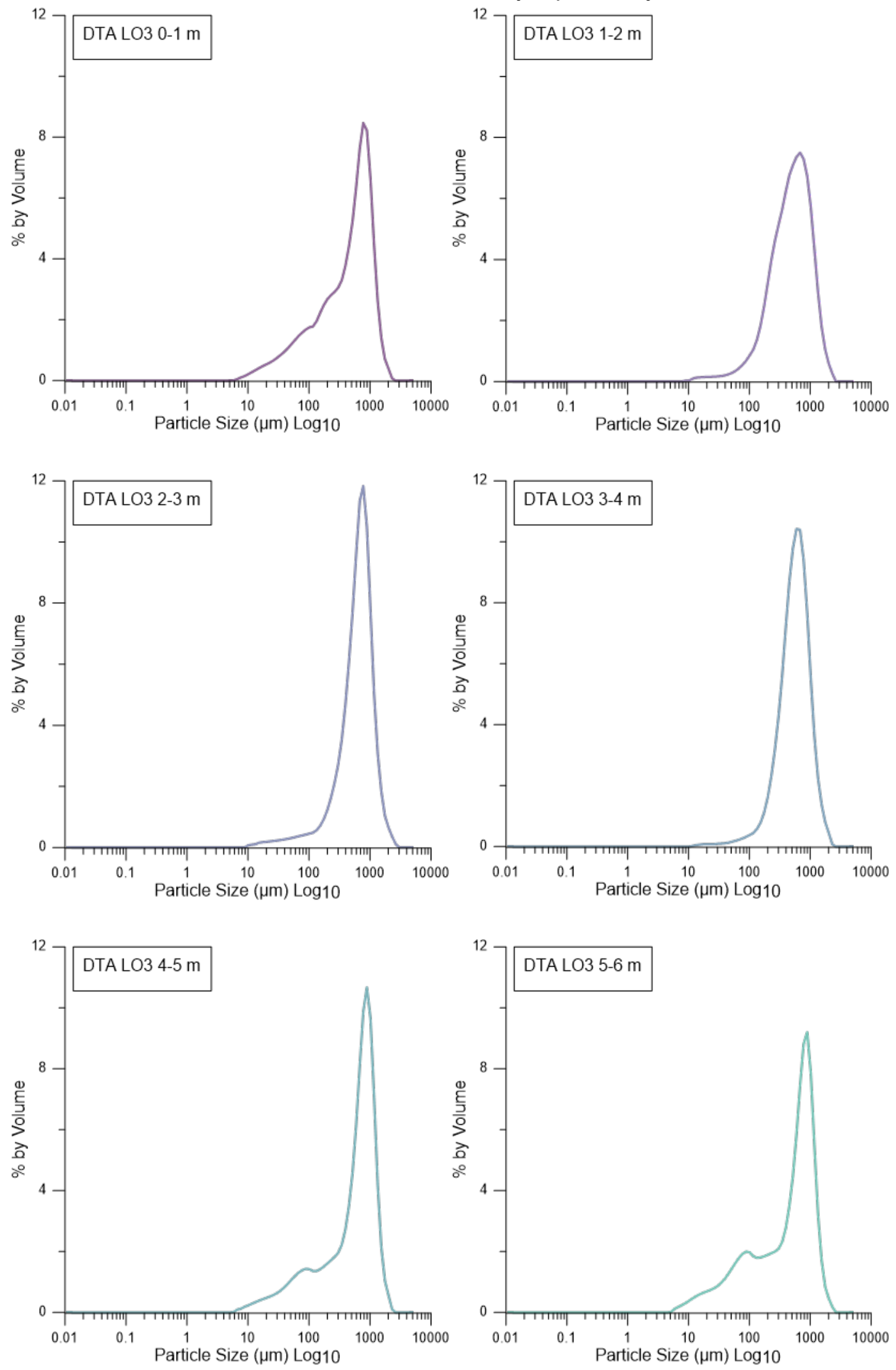
Figure D-1 (cont.). PSDs from $60 \mathrm{~mm}$ IMX-104 LO detonations. Select annuli needed to be combined to have the mass necessary to process by LD-PSA.
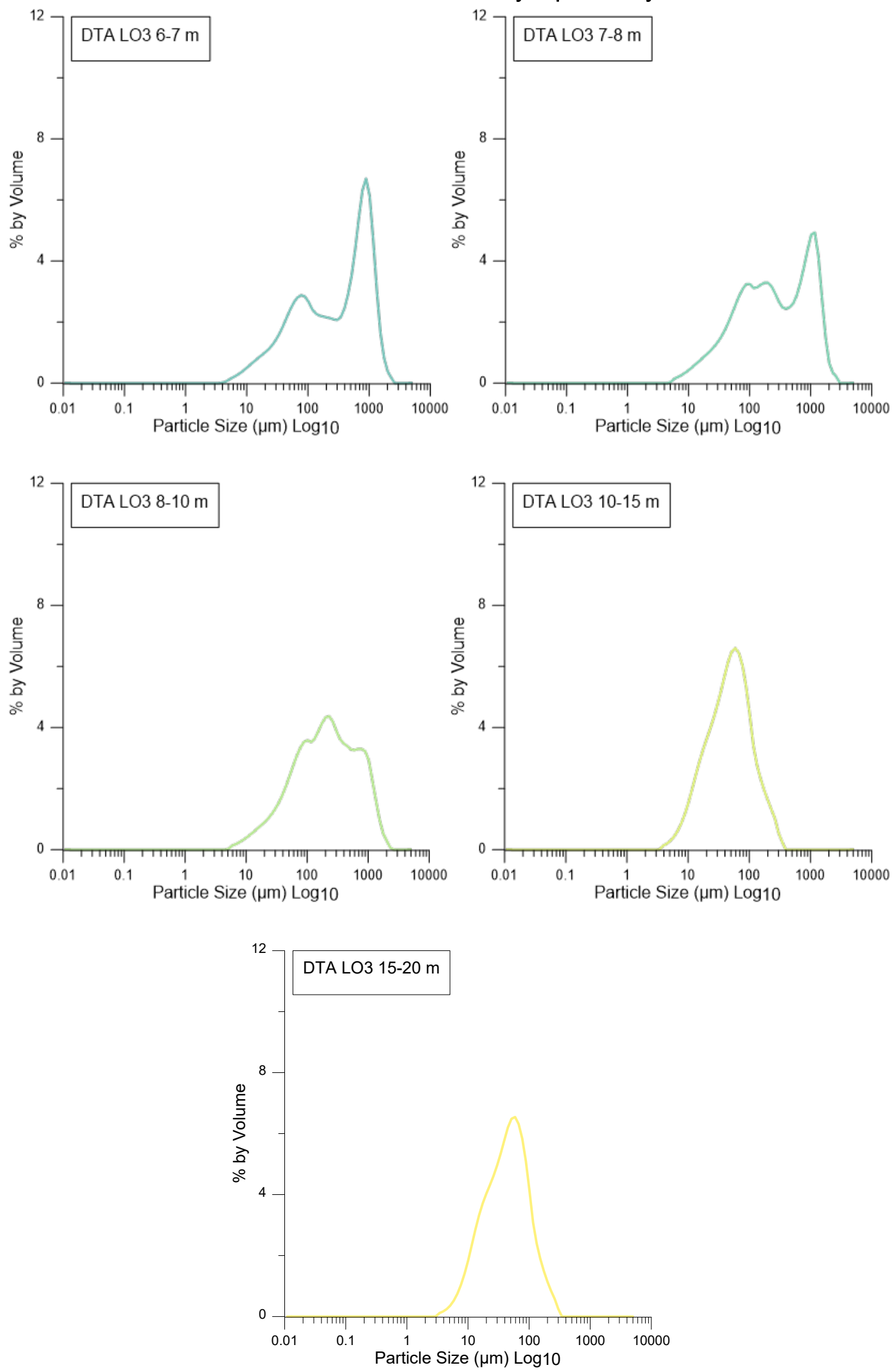
Figure D-2. PSDs from $81 \mathrm{~mm}$ IMX-104 LO detonations. Select annuli needed to be combined to have the mass necessary to process by LD-PSA.
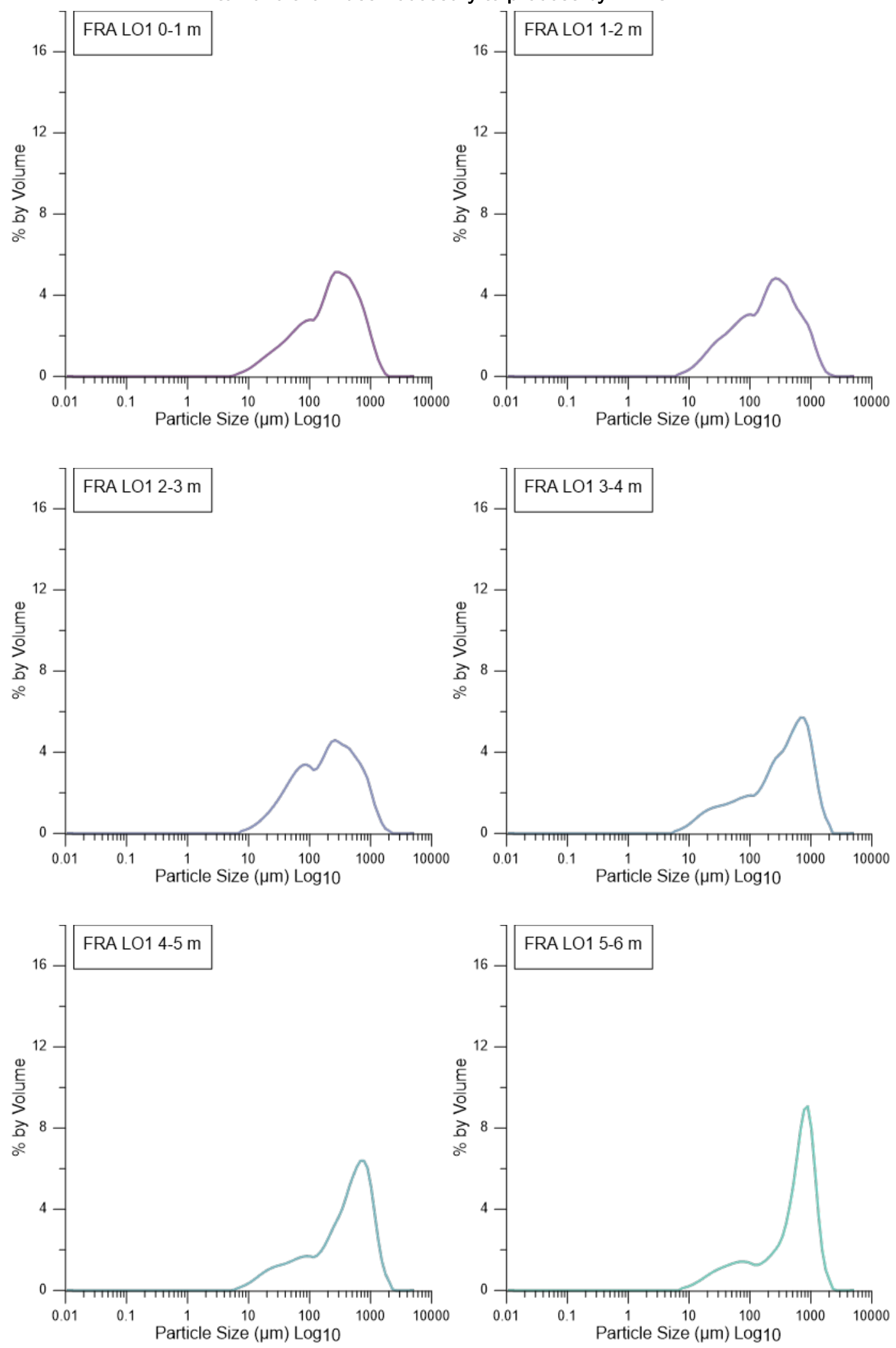
Figure D-2 (cont.). PSDs from $81 \mathrm{~mm}$ IMX-104 LO detonations. Select annuli needed to be combined to have the mass necessary to process by LD-PSA.
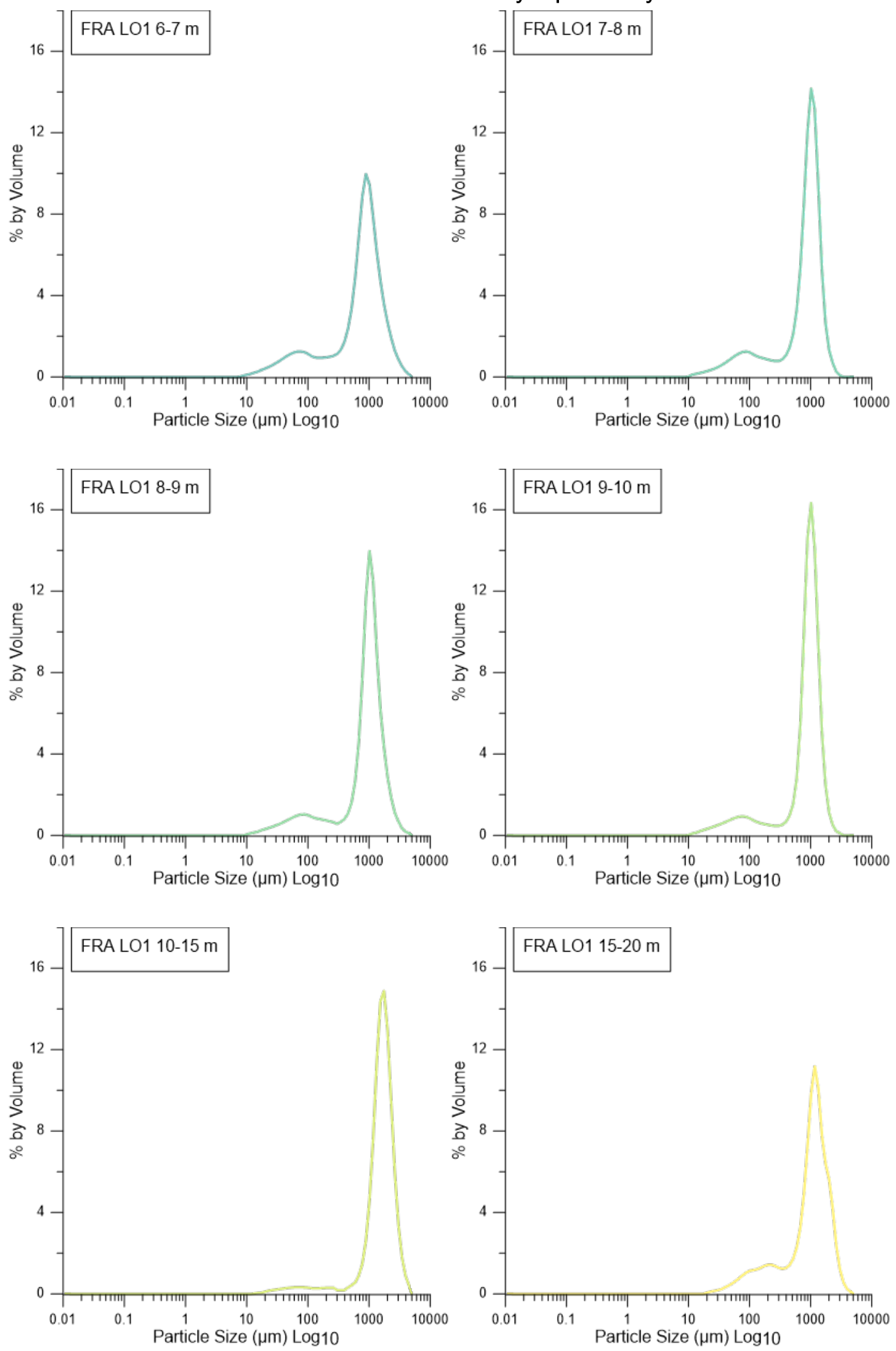
Figure D-2 (cont.). PSDs from $81 \mathrm{~mm}$ IMX-104 LO detonations. Select annuli needed to be combined to have the mass necessary to process by LD-PSA.
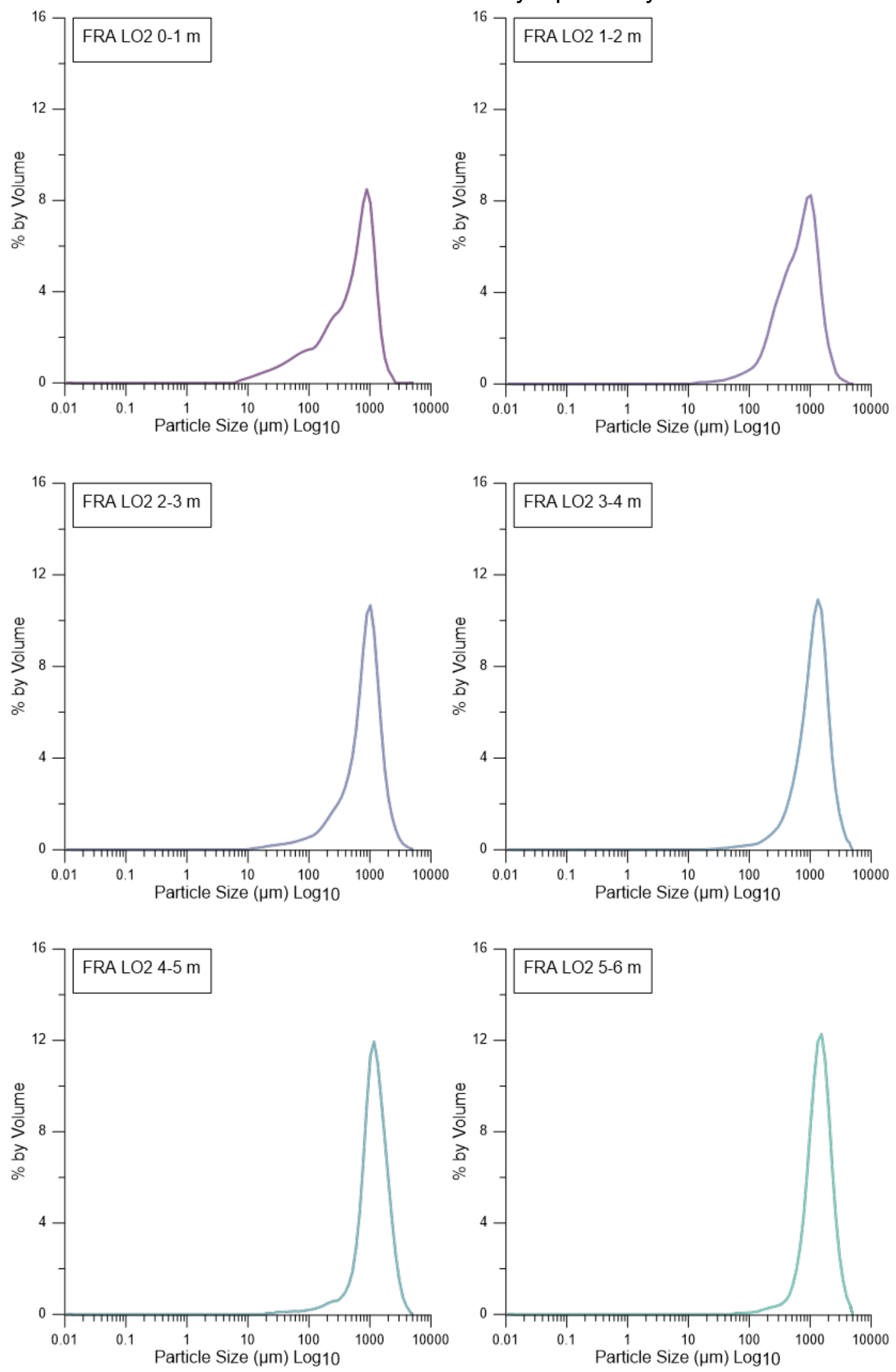
Figure D-2 (cont.). PSDs from $81 \mathrm{~mm}$ IMX-104 LO detonations. Select annuli needed to be combined to have the mass necessary to process by LD-PSA.
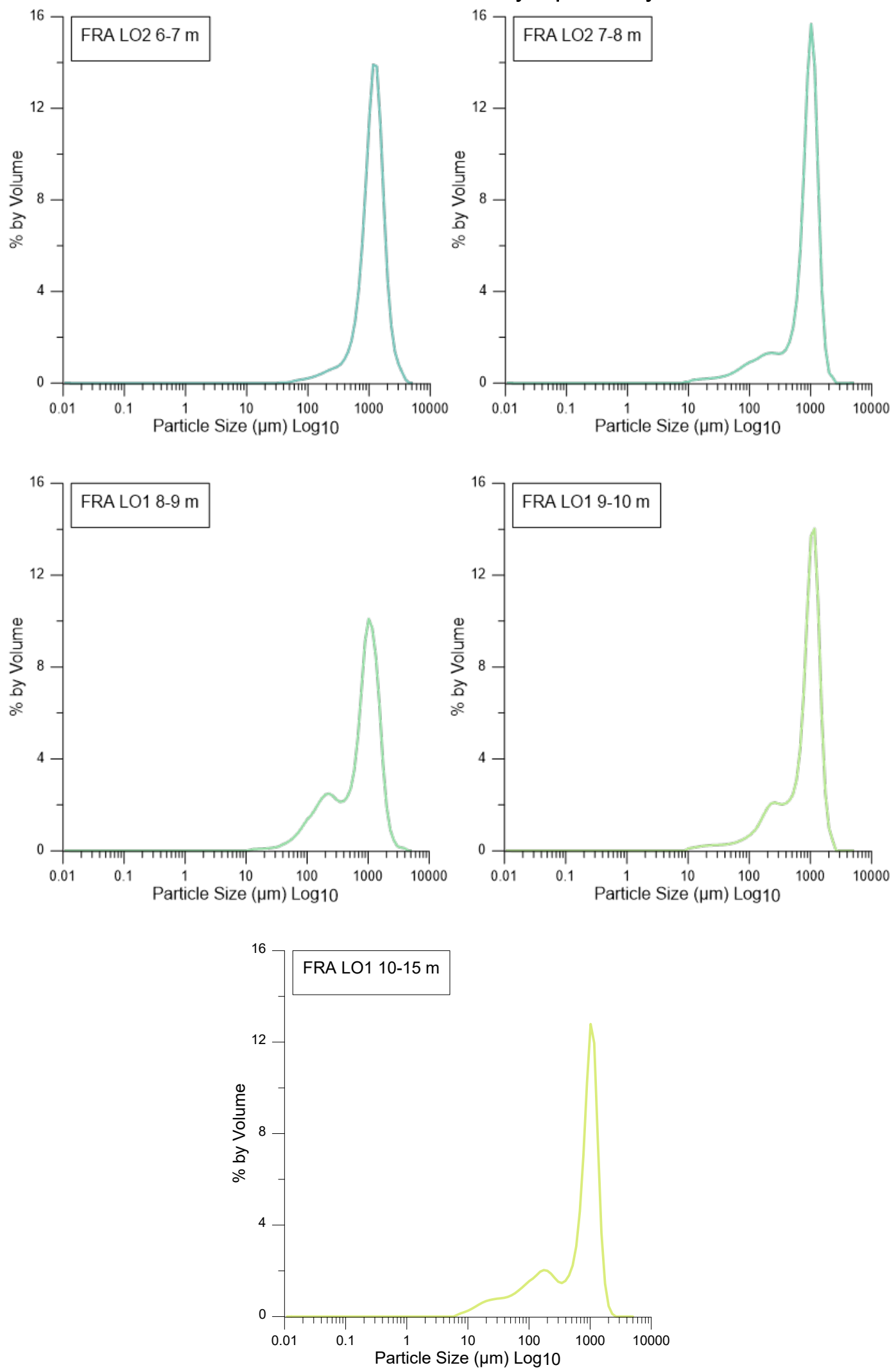
Figure D-2 (cont.). PSDs from $81 \mathrm{~mm}$ IMX-104 LO detonations. Select annuli needed to be combined to have the mass necessary to process by LD-PSA.
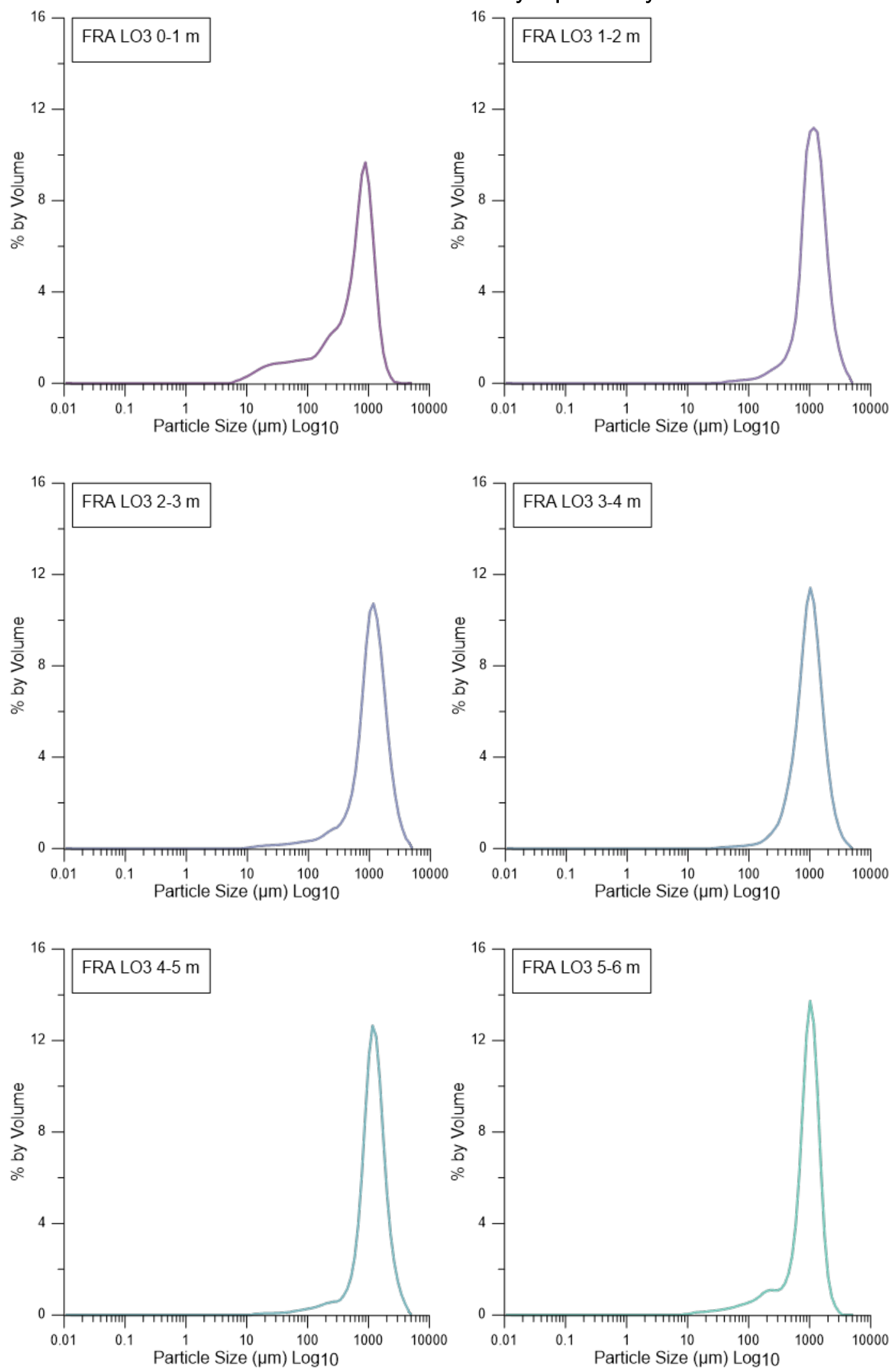
Figure D-2 (cont.). PSDs from $81 \mathrm{~mm}$ IMX-104 LO detonations. Select annuli needed to be combined to have the mass necessary to process by LD-PSA.
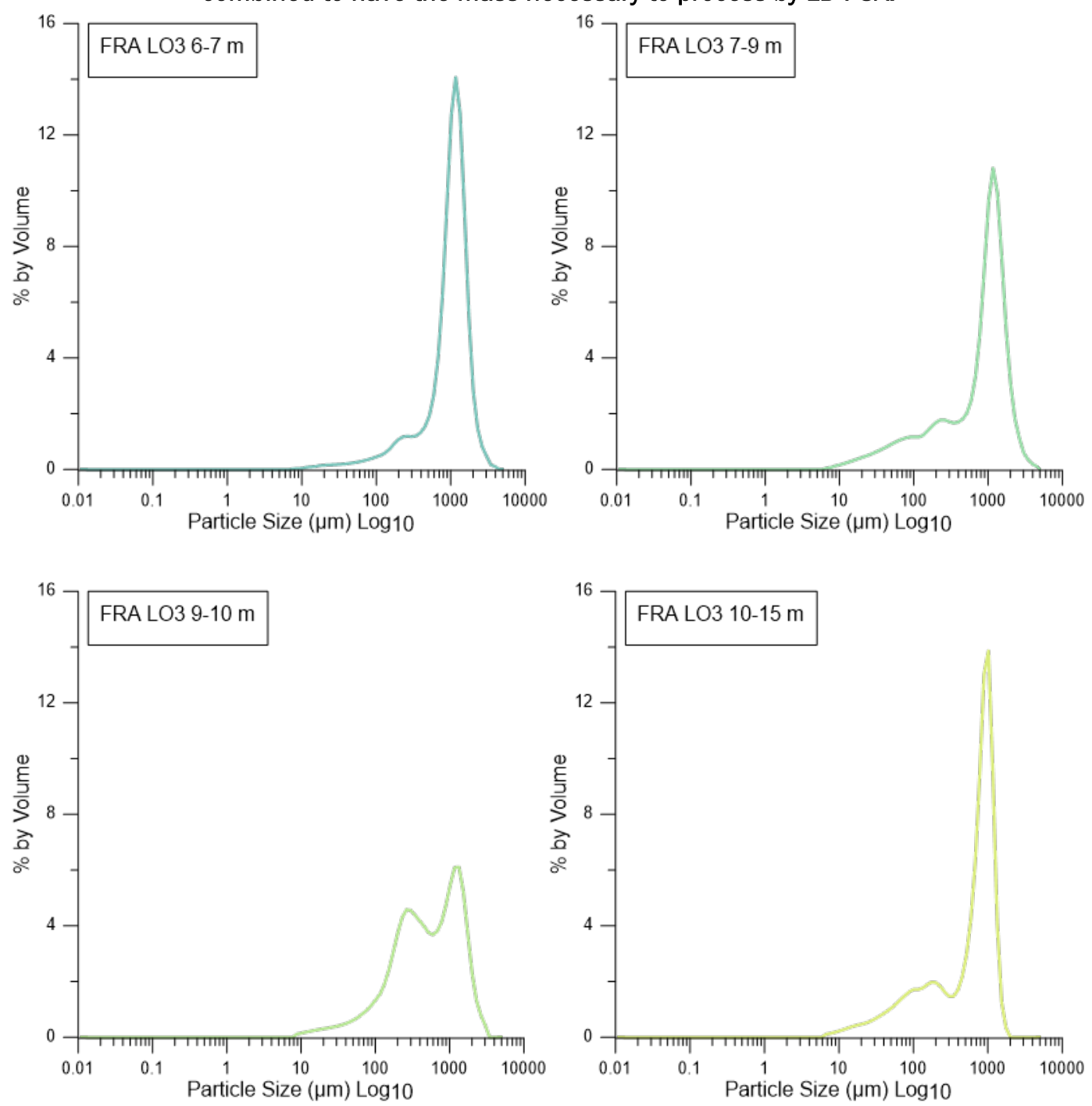


\section{Appendix E: Energetic-Purity Data}

Table E-1. Formulation-normalized energetic purity of whole-sample dissolved samples from the LD-PSA chamber, fines from shaking the LD-PSA filter, and total weighted masses of both the sample and fines.

\begin{tabular}{|c|c|c|c|c|c|c|c|}
\hline \multirow[b]{2}{*}{ Sample Name } & \multicolumn{3}{|c|}{ Sample } & \multicolumn{3}{|c|}{ Fines } & \multirow[b]{2}{*}{ Weighted Tota } \\
\hline & NTO & DNAN & RDX+HMX & NTO & DNAN & RDX+HMX & \\
\hline 19FRA-L01-1-2 m & 0.934 & 0.753 & 0.845 & 0.694 & 0.683 & 0.774 & 0.838 \\
\hline 19FRA-L01-4-5 m & 0.935 & 0.755 & 0.842 & 0.620 & 0.599 & 0.672 & 0.831 \\
\hline 19FRA-L01-7-8 m & 1.018 & 0.953 & 1.049 & - & - & - & 1.002 \\
\hline 19FRA-L01-9-10 m & 0.953 & 0.907 & 0.978 & - & - & - & 0.942 \\
\hline 19FRA-L01-15-20 m & 0.878 & 0.859 & 0.913 & - & - & - & 0.877 \\
\hline 19FRA-LO2-1-2 m & 0.985 & 0.808 & 0.867 & 0.900 & 0.847 & 0.926 & 0.909 \\
\hline 19FRA-LO2-4-5 m & 0.851 & 0.822 & 1.038 & 0.822 & 0.883 & 0.988 & 0.870 \\
\hline 19FRA-LO2-7-8 m & 0.893 & 0.898 & 0.959 & 0.800 & 0.850 & 0.938 & 0.902 \\
\hline 19FRA-LO2-10-15 m & 0.860 & 0.820 & 0.987 & 0.700 & 0.896 & 1.048 & 0.853 \\
\hline 19FRA-L03-1-2 m & 0.967 & 0.882 & 0.969 & 0.776 & 0.856 & 0.969 & 0.935 \\
\hline 19FRA-LO3-4-5 m & 0.905 & 0.870 & 0.948 & 0.700 & 0.762 & 0.866 & 0.889 \\
\hline 19FRA-L03-6-7 m & 0.912 & 0.830 & 0.910 & 0.789 & 0.848 & 0.959 & 0.880 \\
\hline 19FRA-L03-9-10 m & 0.953 & 0.774 & 0.841 & 0.785 & 0.726 & 0.830 & 0.867 \\
\hline 19FRA-LO3-10-15 m & 0.907 & 0.809 & 0.860 & 0.723 & 0.887 & 1.010 & 0.858 \\
\hline 19DTA L01-1-2 m & 1.024 & 0.591 & 0.655 & 0.525 & 0.499 & 0.570 & 0.728 \\
\hline 19DTA L01-5-6 m & 0.966 & 0.694 & 0.756 & 0.565 & 0.498 & 0.555 & 0.800 \\
\hline 19DTA L01-7-8 m & 0.662 & 0.645 & 0.697 & 0.500 & 0.641 & 0.697 & 0.618 \\
\hline 19DTA L01-9-10 m & 0.725 & 0.793 & 0.841 & 0.575 & 0.729 & 0.851 & 0.743 \\
\hline 19DTA L01-15-20 m & 0.091 & 0.101 & 0.109 & 0.107 & 0.170 & 0.168 & 0.114 \\
\hline 19DTA LO2-0-1 m & 0.980 & 0.739 & 0.812 & 0.764 & 0.789 & 0.888 & 0.859 \\
\hline 19DTA L02-1-2 m & 0.981 & 0.657 & 0.709 & 0.691 & 0.525 & 0.591 & 0.814 \\
\hline 19DTA L02-3-4 m & 0.524 & 0.340 & 0.370 & 0.599 & 0.543 & 0.626 & 0.456 \\
\hline 19DTA-LO2-5-6 m & 0.728 & 0.621 & 0.660 & 0.616 & 0.593 & 0.659 & 0.677 \\
\hline 19DTA-LO2-10-15 m & 0.313 & 0.288 & 0.308 & 0.203 & 0.224 & 0.254 & 0.282 \\
\hline 19DTA-LO2-15-20 m & 0.234 & 0.203 & 0.237 & 0.264 & 0.337 & 0.370 & 0.245 \\
\hline 19DTA-LO3-1-2 m & 0.994 & 0.667 & 0.723 & 0.570 & 0.560 & 0.619 & 0.803 \\
\hline 19DTA-LO3-4-5 m & 0.756 & 0.700 & 0.743 & 0.397 & 0.508 & 0.558 & 0.669 \\
\hline 19DTA-LO3-7-8 m & 0.690 & 0.701 & 0.747 & 0.457 & 0.564 & 0.626 & 0.630 \\
\hline 19DTA-LO3-10-15 m & 0.322 & 0.332 & 0.347 & 0.249 & 0.380 & 0.427 & 0.325 \\
\hline
\end{tabular}


Table E-2. Linear regressions statistics of the pooled total weighted purity $(y)$ by median distance $(x)$.

\begin{tabular}{|c|c|c|c|c|c|c|c|}
\hline \multirow{2}{*}{ Munition } & Parameter & Estimate & $\begin{array}{c}\text { Standard } \\
\text { Error }\end{array}$ & $t$-Value & $p$-Value & $R^{2}$ & DFa $^{2}$ \\
\hline \multirow{2}{*}{$60 \mathrm{~mm}$ IMX-104 } & Slope & -0.0371 & 0.0057 & -6.452 & $2.16 \times 10^{-5}$ & 0.762 & 13 \\
\cline { 2 - 7 } & Y-intercept & 0.852 & 0.052 & 16.397 & $4.58 \times 10^{-10}$ & & \\
\hline \multirow{2}{*}{$81 \mathrm{~mm}$ IMX-104 } & Slope & -0.0008 & 0.0028 & -0.289 & 0.777 & 0.007 & 12 \\
\cline { 2 - 8 } & Y-intercept & 0.895 & 0.024 & 37.523 & $8.25 \times 10^{-14}$ & & \\
\hline
\end{tabular}

a Degrees of freedom 


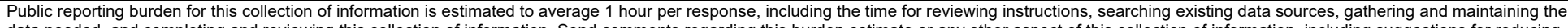

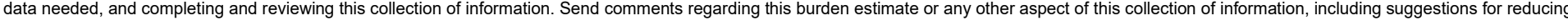

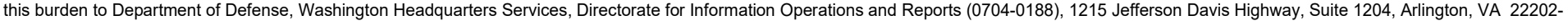

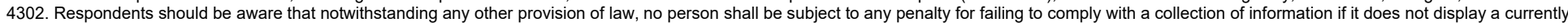
valid OMB control number. PLEASE DO NOT RETURN YOUR FORM TO THE ABOVE ADDRESS.

\begin{tabular}{l|l} 
valid OMB control number. PLEASE DO NOT RETURN YOUR FORM TO THE ABOVE ADDRESS. \\
\hline 1. REPORT DATE (DD-MM-YYYY) & $\mathbf{2}$. REPORT
\end{tabular}

\begin{tabular}{c|c} 
August 2021 & Technical Report / Final \\
\hline
\end{tabular}

\section{TITLE AND SUBTITLE}

Determination of Residual Low-Order Detonation Particle Characteristics from IMX-104 Mortar Rounds

\section{AUTHOR(S)}

Matthew F. Bigl, Samuel A. Beal, and Charles A. Ramsey

3. DATES COVERED (From - To)

FY18-FY21

5a. CONTRACT NUMBER

\section{5b. GRANT NUMBER}

5c. PROGRAM ELEMENT

5d. PROJECT NUMBER

5e. TASK NUMBER

5f. WORK UNIT NUMBER

8. PERFORMING ORGANIZATION REPORT NUMBER

ERDC/CRREL TR-21-12

Envirostat, Inc.

PO Box 339

Vail, AZ 85641

72 Lyme Road

Hanover, NH o3755-1290

\section{SPONSORING / MONITORING AGENCY NAME(S) AND ADDRESS(ES)}

Strategic Environmental Research and Development Program

Environmental Security Technology Certification Program

Environmental Restoration Program Area

4800 Mark Center Drive, Suite $16 \mathrm{~F} 16$

Alexandria, VA 22350-3605

10. SPONSOR/MONITOR'S ACRONYM(S)

SERDP

11. SPONSOR/MONITOR'S REPORT NUMBER(S)

\section{DISTRIBUTION / AVAILABILITY STATEMENT}

Approved for public release; distribution is unlimited.

\section{SUPPLEMENTARY NOTES}

Funded by Environmental Restoration Program project number ER18-5105, "Determination of Residual Low-Order Detonation Particle Characteristics," through MIPRs W74RDV80715663, W74RDV80715688, W74RDV90156248, and W74RDV90497295

\section{ABSTRACT}

The environmental fate and transport of energetic compounds on military training ranges are largely controlled by the particle characteristics of low-order detonations. This study demonstrated a method of command detonation, field sampling, laboratory processing, and analysis techniques for characterizing low-order detonation particles from $60 \mathrm{~mm}$ and $81 \mathrm{~mm}$ mortar rounds containing the insensitive munition formulation IMX-104. Particles deposited from three rounds of each caliber were comprehensively sampled and characterized for particle size, energetic purity, and morphology. The $60 \mathrm{~mm}$ rounds were command-detonated low order consistently (seven low-order detonations of seven tested rounds), with consumption efficiencies of $62 \%-80 \%(n=3)$. The $81 \mathrm{~mm}$ rounds detonated low order inconsistently (three loworder detonations of ten tested rounds), possibly because the rounds were sourced from manufacturing test runs. These rounds had lower consumption efficiencies of $39 \%-64 \%(n=3)$. Particle-size distributions showed significant variability between munition calibers, between rounds of the same caliber, and with distance from the detonation point. The study reviewed command-detonation configurations, particle transfer losses during sampling and particle-size analysis, and variations in the energetic purity of recovered particles. Overall, this study demonstrated the successful characterization of IMX-104 low-order detonation particles from command detonation to analysis.

\section{SUBJECT TERMS}

Bombing and gunnery ranges, Command detonation, Detonations, Dissolution (Chemistry), Explosives, Military, Fate and transport, Insensitive munitions, Laser diffraction, Particle analysis, Soil absorption and adsorption, Training range management

\begin{tabular}{|c|c|c|c|c|c|}
\hline \multicolumn{3}{|c|}{ 16. SECURITY CLASSIFICATION OF: } & \multirow{2}{*}{$\begin{array}{l}\text { 17. LIMITATION } \\
\text { OF ABSTRACT } \\
\text { SAR }\end{array}$} & \multirow{2}{*}{$\begin{array}{l}\text { 18. NUMBER } \\
\text { OF PAGES } \\
72\end{array}$} & 19a. NAME OF RESPONSIBLE PERSON \\
\hline $\begin{array}{l}\text { a. REPORT } \\
\text { Unclassified }\end{array}$ & $\begin{array}{r}\text { b. ABSTRACT } \\
\text { Unclassified }\end{array}$ & $\begin{array}{l}\text { c. THIS PAGE } \\
\text { Unclassified }\end{array}$ & & & $\begin{array}{l}\text { 19b. TELEPHONE NUMBER } \\
\text { (include area code) }\end{array}$ \\
\hline
\end{tabular}

